\title{
Chapter 4 \\ Decision Support for Local Water Authorities in Guantao
}

Policy selection and implementation rely on monitoring data and technical decision support tools. Monitoring data of Guantao County include groundwater levels at 55 observation wells, pumping rates of 7600 wells, surface water flows, precipitation, and land use in monthly time steps. The most difficult task is to monitor pumping of thousands of primitive irrigation wells. As all wells are powered by electricity in Guantao, monitoring via electricity consumption was chosen and shown to be effective. The electricity-to-water conversion factor is established via pumping tests. Four different groundwater models were developed serving different purposes: A box model computing the groundwater balance and the water gap of Guantao County; A distributed model of the shallow aquifer visualizing the spatial variation of groundwater levels and priority areas for pumping control; A real-time model updating and improving the distributed model by assimilating monthly observation data; And an upscalable data driven model using machine learning algorithms to forecast groundwater levels. All these tools together with monitoring data and current pumping control options are integrated in a web-based decision support system with a userfriendly interface. It allows local water managers without specialized knowledge to use complex technical tools in their groundwater management practice.

Electronic supplementary material The online version of this chapter (https://doi.org/10.1007/978-981-16-5843-3_4) contains supplementary material, which is available to authorized users. 


\subsection{Hydrogeological Basis: Shallow Versus Deep Groundwater}

Commissioned by the local project partners, a hydrogeological survey of Guantao has been carried out by China National Administration of Coal Geology (CNCG) in 2015. The contents of the report, which is directly relevant to our project is summarized in this section. It is augmented by some results from the hydrogeological mapping conducted by the China Geological Survey (CGS).

\subsubsection{Borehole Locations}

20 boreholes in total were drilled for this work to investigate the hydrogeological conditions in Guantao including 11 boreholes in the shallow aquifer and 9 boreholes in the deep aquifer (Fig. 4.1). The depths of the boreholes in the shallow aquifer vary from 60 to $100 \mathrm{~m}$ while the depths of the deep boreholes vary from 300 to $400 \mathrm{~m}$.

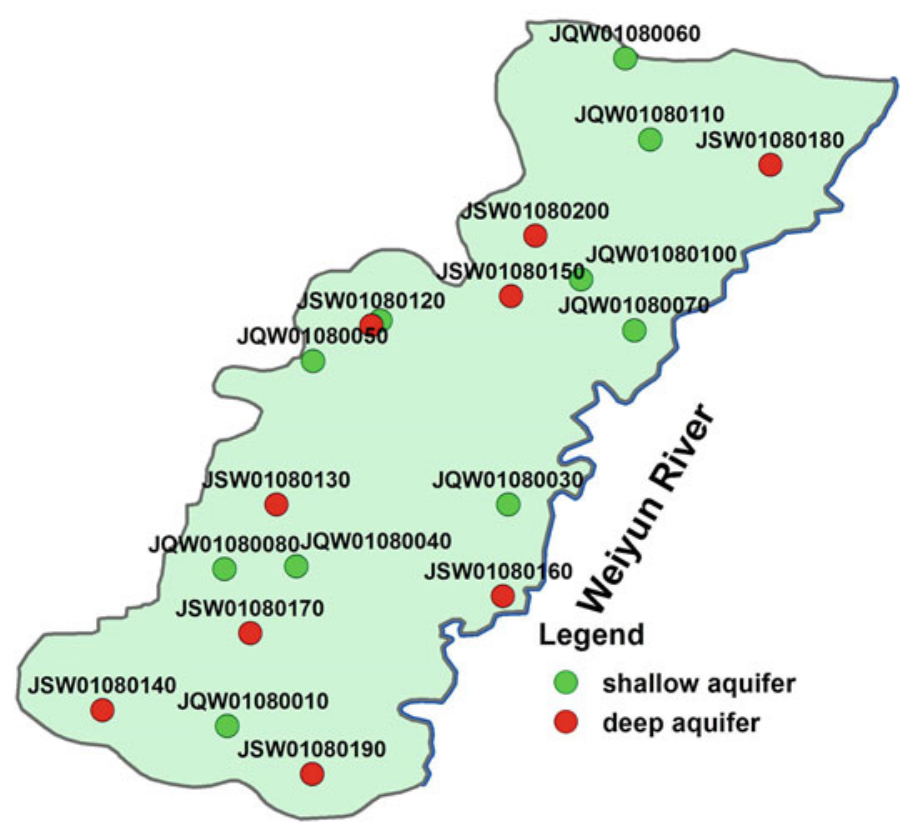

Fig. 4.1 Borehole locations of the hydrogeological survey 


\subsubsection{Borehole Logs and Pumping Tests}

Guantao is located in the Yellow River alluvial plain mainly composed of porous Quaternary deposits. In vertical direction, the deposits in Guantao can be divided into four aquifer layers interbedded with clay and silt aquitard layers. All aquifers are composed of permeable fine sand layers. The upper two aquifer layers are called "shallow aquifer", while the lower two are referred to as "deep aquifer" (Fig. 4.2). The average bottom level of the shallow aquifer is around $90 \mathrm{~m}$ below ground surface. The deep aquifer has a large thickness of around $200 \mathrm{~m}$. The aquitard layer separating the shallow and deep aquifers has an average thickness of around $100 \mathrm{~m}$. The piezometric heads in the shallow and deep aquifers differ by as much as $50 \mathrm{~m}$. Furthermore, the hydrochemistry of groundwater is very different in both aquifers, with the deep aquifer being considerably less mineralized than the shallow aquifer. Hence, one can conclude that there is no direct hydraulic connection between the shallow and deep aquifers in the region of Guantao. The deep layer receives only little recharge from upstream at the piedmont, so groundwater levels have been decreasing continuously since pumping for domestic, industrial and irrigation uses started. The only way to stop the decline and start a recovery of the deep aquifer's piezometric levels is to abandon all pumping from the deep aquifer. The shallow aquifer is exclusively used for irrigation. It is recharged by precipitation, irrigation backflow and canal and river seepage. We focus mainly on modelling the shallow aquifer in the project.

Pumping tests were conducted at each borehole to investigate aquifer properties such as hydraulic conductivity (HK), and specific yield (SY) of the shallow aquifer. The HK-value of the shallow aquifer is around $10 \mathrm{~m} /$ day in the South of Guantao and decreases to around $1 \mathrm{~m} /$ day in the north. Similar results were found by the CGS in their mapping work. The SY values show a similar trend and decrease from South to North. Their absolute values could not be determined as the pumping tests were too short. Values from the literature were used.
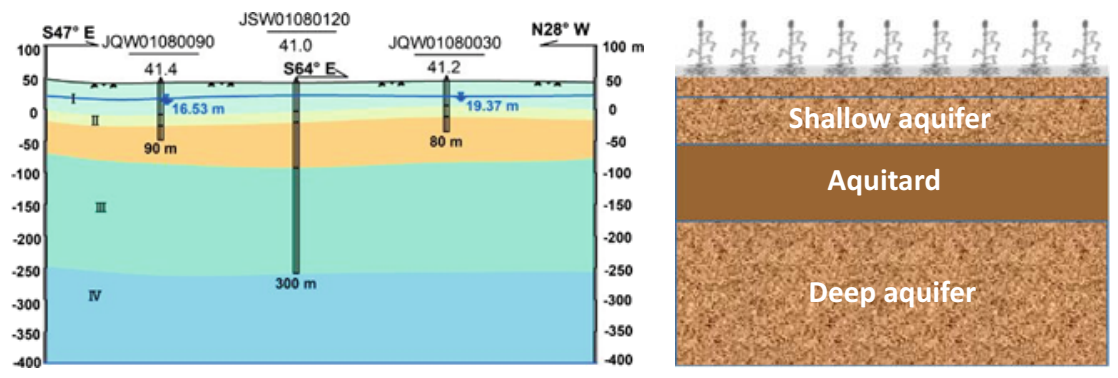

Fig. 4.2 Left: Hydrogeological cross-section of Guantao from west to east according to 3 borehole logs (Elevations in m asl. Brown: Aquitard, Green to Blues: Aquifers, I + II Shallow aquifer, III + IV deep aquifer) Right:Schematic view of aquifer structure generalized from borehole logs 


\subsubsection{The Distribution of Total Dissolved Solids (TDS)}

The TDS distribution in the shallow aquifer is shown in Fig. 4.3 (left). The groundwater with TDS larger than $3 \mathrm{~g} / \mathrm{L}$ cannot be used for irrigation. In these areas, groundwater from the deep aquifer is needed to irrigate crops. Therefore, the irrigation wells installed in the deep aquifer are mainly distributed in the areas with high salinity in the shallow aquifer (Fig. 4.3, right). The deep aquifer water is of drinking water quality with TDS-values clearly less than $1 \mathrm{~g} / \mathrm{L}$. Except for irrigation, the deep aquifer provides water supply for domestic and industrial use (Zone 2, the small area in purple color on the east boundary in Fig. 4.3 right). In recent years over 30 Mio. $\mathrm{m}^{3} /$ year of surface water were diverted into Guantao to replace groundwater used for irrigation, domestic and industrial purposes.

\subsection{Monitoring Options}

Monitored items include groundwater levels, pumping rates, land use and meteorological quantities. The monitoring data are transferred to a server, where they are used as input time series for model simulations and decision support.
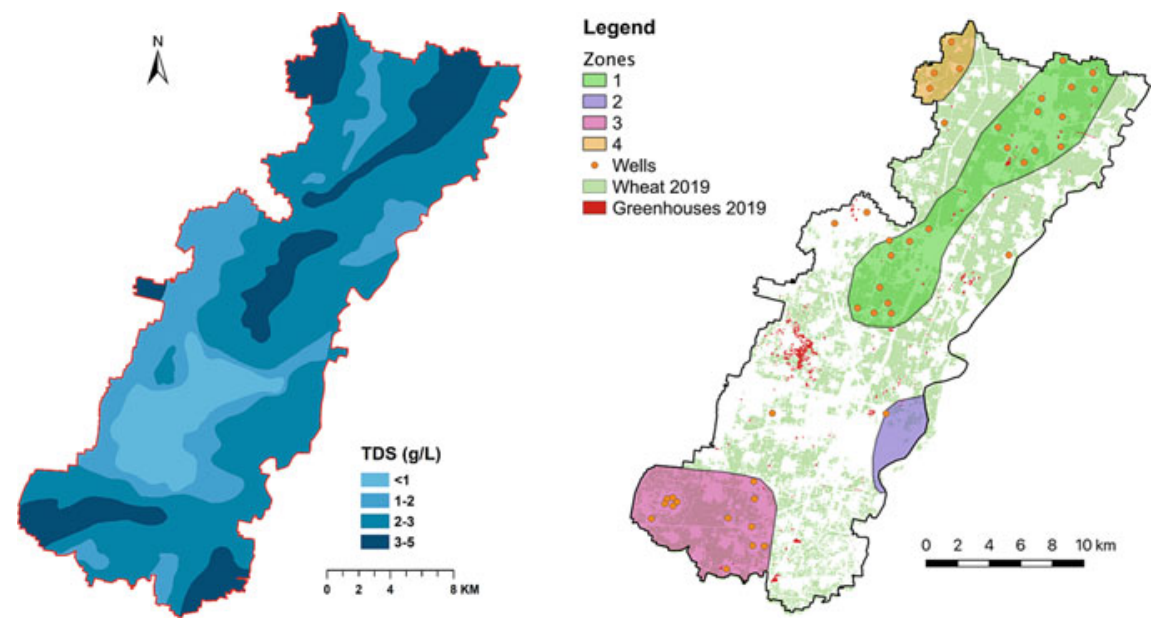

Fig. 4.3 TDS distribution in the shallow aquifer (left) and locations of surveyed pumping wells in the deep aquifer on the background of a satellite remote sensing map of wheat growing area and greenhouses (right). Wells in Zone 2 are urban drinking water wells. Zones 1, 3 and 4 have recently been connected to surface water canals 


\subsubsection{Groundwater Level Monitoring (Contributed by CIGEM and GIWP)}

The groundwater level observation wells of the shallow and deep aquifers in Guantao are shown in (Fig. 4.4). The observation network was installed jointly by Hebei Department of Water Resources and the China Geological Survey, with most of the wells being recorded automatically on a daily basis. It comprises 55 observation points, 38 in the shallow aquifer and 17 in the deep aquifer. The modelling focus of the project is on the shallow aquifer (up to $100 \mathrm{~m}$ depth). Therefore, more observation wells are installed in the shallow aquifer. Since there is practically no recharge to the deep aquifer, head observations directly reflect pumping as the only item balanced by the long-term storage decrease. In 2017, it has been decided to close down all deep aquifer pumping wells. This has however only happened partially. The data obtained from the observation wells are discussed in detail below.

\section{GW levels close to the river}

The shallow observation wells ZK01-1, ZK02-1, ZK03, ZK04, ZK05, ZK06, ZK07, ZK08 and ZK09-1 of CIGEM (Fig. 4.5), lie on the eastern boundary of the county, on the two banks of the Weiyun River. The peak of observed heads in July/August 2016 is due to heavy rains and flooding, which means that the infiltration of water from the river is fast and leads to a groundwater level rise with practically no delay. After August, the "water mountain" under the river diffuses and the groundwater levels drop again. After 2016, groundwater levels fluctuate little as they are still mainly
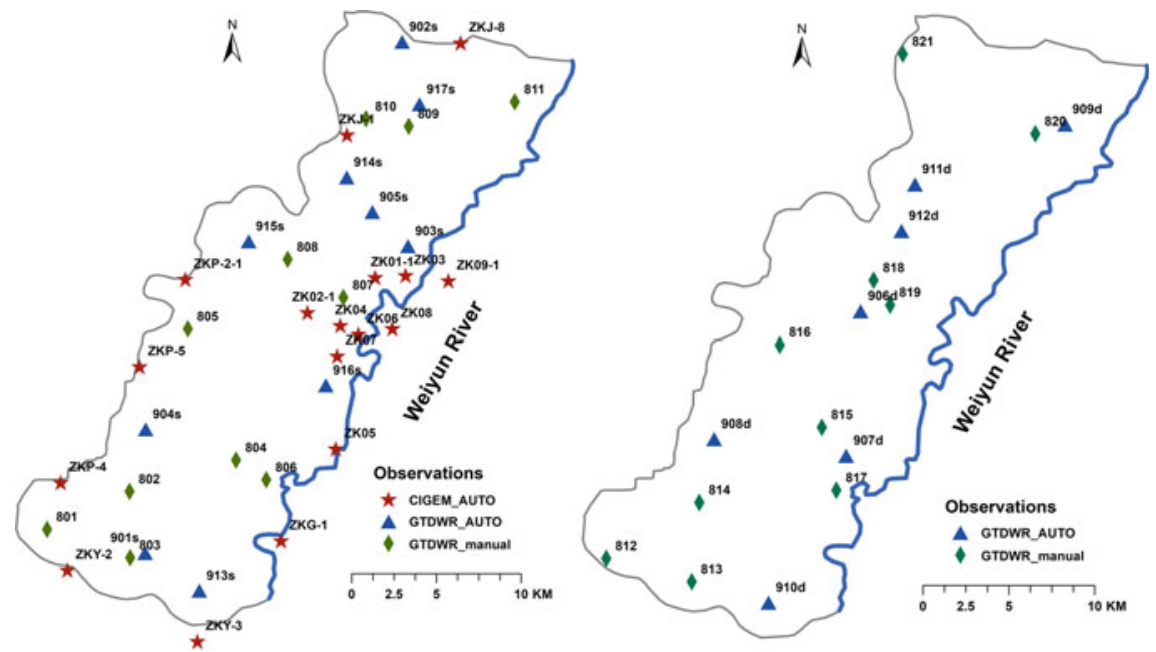

Fig. 4.4 Piezometers installed and monitored since 2015 within the project. Left shows the shallow aquifer observation wells, right shows the deep aquifer observation wells. Red stars: automatic wells monitored by CIGEM, blue triangles: automatic wells monitored by Hebei Province, Green diamonds: wells monitored manually by Hebei Province 


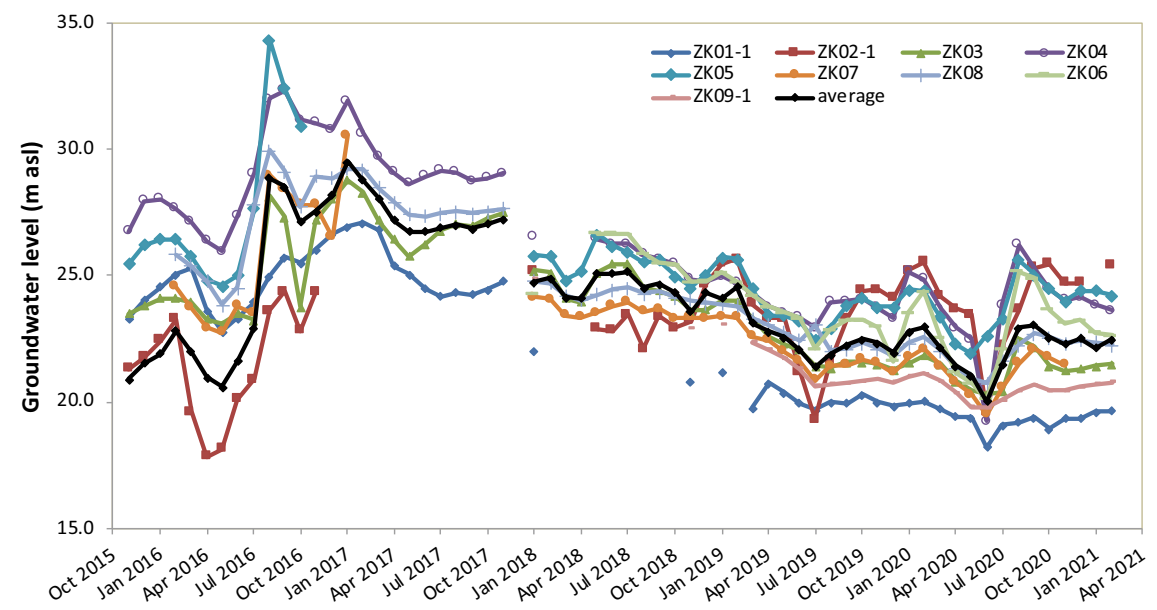

Fig. 4.5 Observed groundwater levels in the shallow aquifer recorded since 2015 by observation wells of CIGEM close to the eastern boundary of Guantao County

controlled by river infiltration. Since 2019, the groundwater levels again show large fluctuations as pumping for irrigation becomes the dominant driver, which is typical for normal and dry years. Due to little precipitation in 2019, the groundwater level shows a declining trend in that year.

\section{GW levels on Guantao boundary away from the river}

The heads recorded in the newly drilled observation wells of CIGEM in the shallow aquifer are shown in Fig. 4.6. These wells have been operating since 2017. The observed groundwater levels in wells ZKP-2-1, ZKJ-1, ZKP-5 and ZKY-2 are almost constant, which means that they are sufficiently far away from any individual pumping well and represent the outcome of the collective pumping in the surrounding area. The other wells show a decrease in groundwater level in the irrigation season and a recovery when pumping stops. The groundwater level in well ZKY-3 shows an increasing trend in 2020, probably caused by reduced groundwater pumping in that area. Generally, the groundwater levels on the boundary of Guantao represented by these observation wells have not shown any obvious decline since 2018.

\section{GW levels inside Guantao boundary}

The temporal pattern seen in the automatic observation wells of Hebei Province in the shallow aquifer (Fig. 4.7) shows the usual decline after the start of irrigation in March and recovery after September. In some locations, pumping activity in September/November is observed. Well 915s shows a constant groundwater level, comparable to what is seen in wells close to the western boundary in Fig. 4.6.

The deep observation wells of Hebei Province show a very similar pattern to the ones in the shallow aquifer (Fig. 4.8). Obviously, they supply irrigation water 


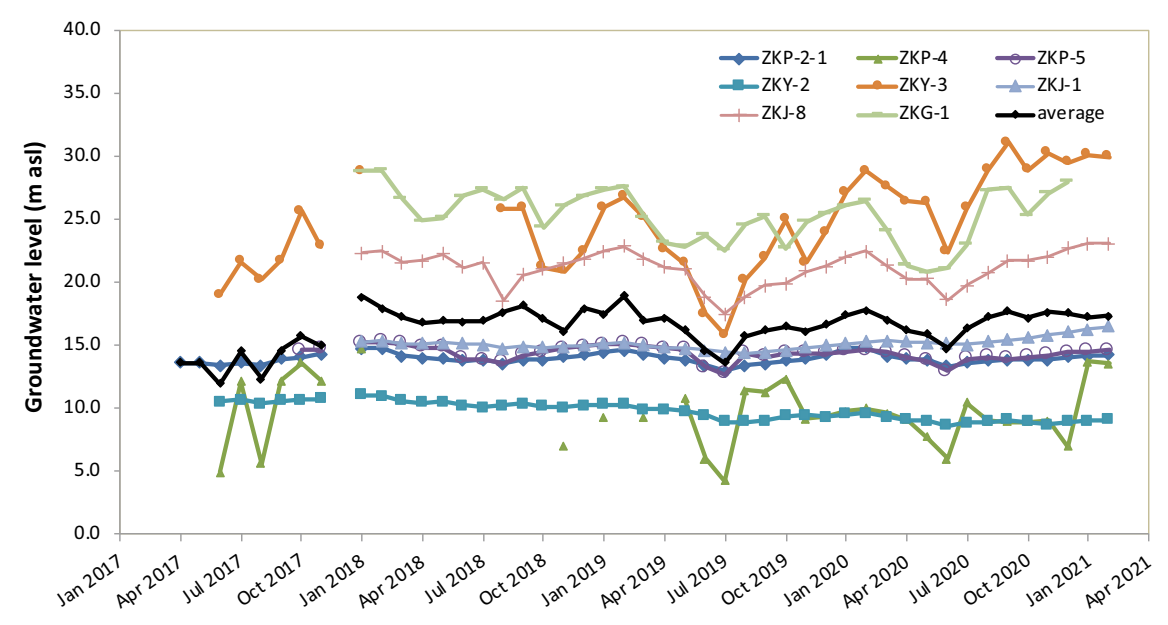

Fig. 4.6 Observed groundwater levels of the shallow aquifer recorded in new observation wells of CIGEM since 2017

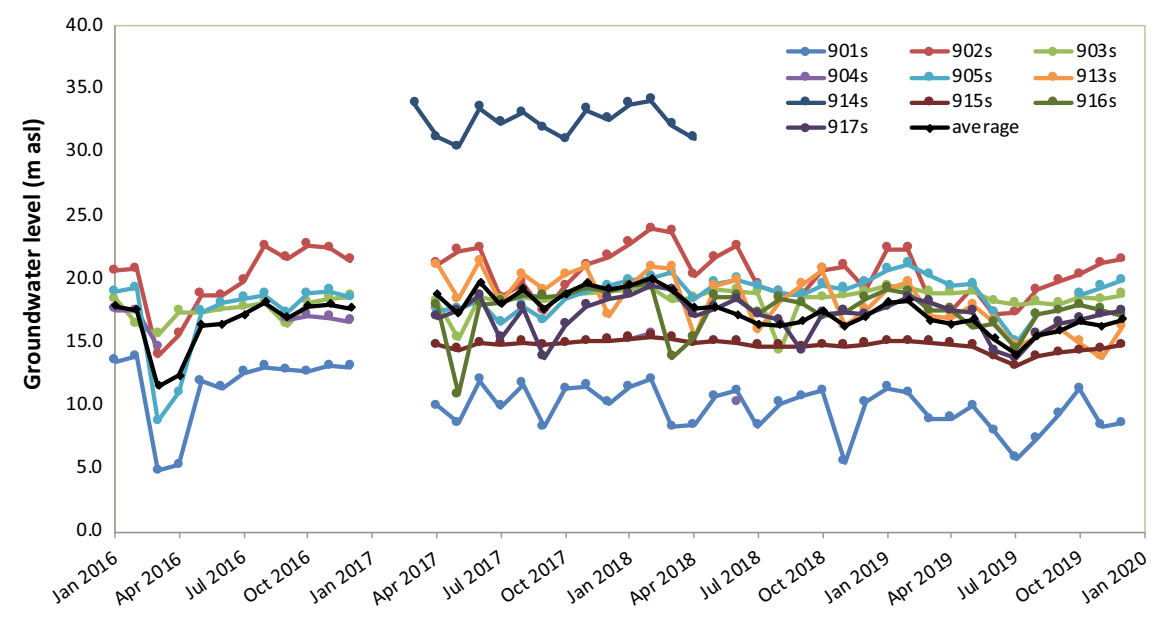

Fig. 4.7 Observed groundwater levels of the shallow aquifer recorded in automatic observation wells of Hebei Province since 2016

at the same time as wells in the shallow aquifer. The levels are generally lower and the amplitudes larger than in the shallow aquifer. As the deep aquifer is not recharged locally in Guantao, an increase in piezometric heads is either due to a decrease in pumping or due to pressure increase caused by the increased weight of the overburden in the course of large input of water at the surface (e.g. by extreme precipitation events as in 2016). Any decrease of a piezometric level is caused by pumping. The groundwater level decreased dramatically in 2019, due to intensified groundwater abstraction for irrigation in the drought year of 2019. Pumping in the 


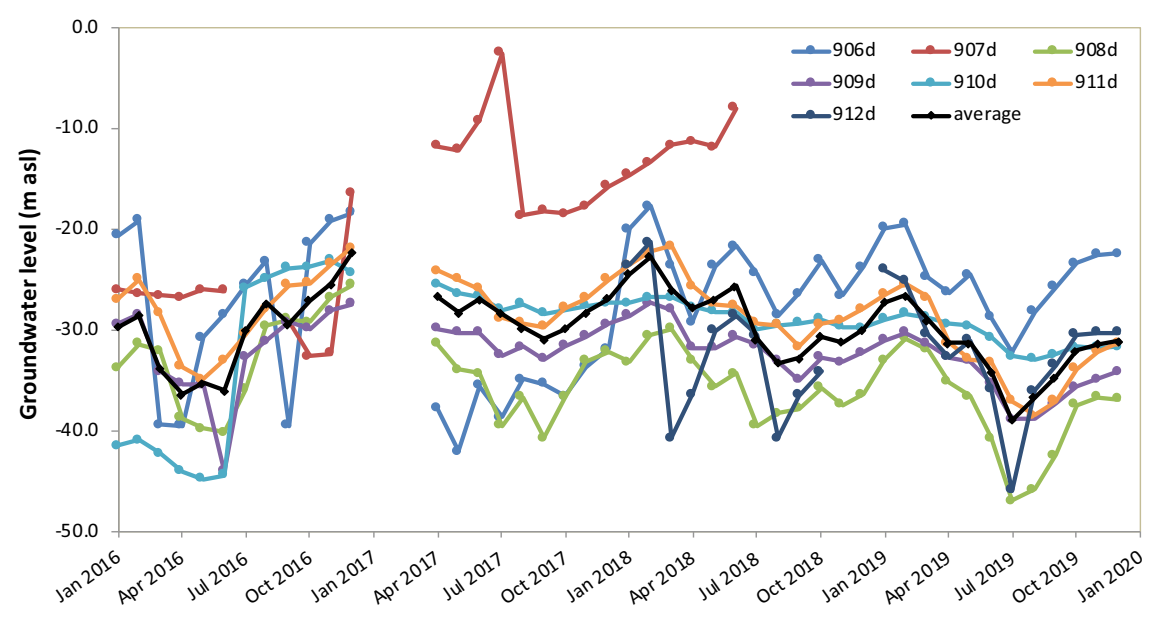

Fig. 4.8 Observed piezometric heads of the deep aquifer recorded in automatic observation wells of Hebei Province since 2016

deep aquifer has to be reduced to zero and the monitoring data can directly be used to verify, whether this goal has been reached.

The data of the observation wells of Hebei Province have been read manually, twice a year before 2015, three times a year in 2015, and four times a year after that. One can see that the levels of shallow boreholes gradually decreased from 2002 , reached the lowest value in 2011, then started to recover and stayed practically constant between 2016 and 2018. After that they started to decline again (Fig. 4.9)

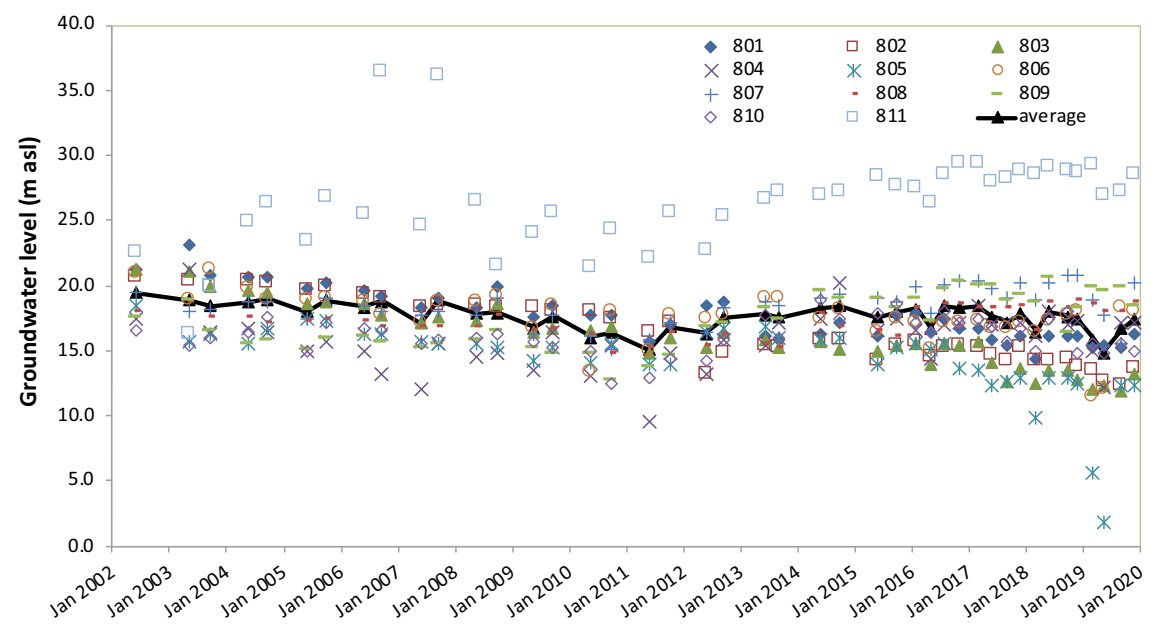

Fig. 4.9 Observed groundwater levels of the shallow aquifer recorded manually in observation wells of Hebei Province 


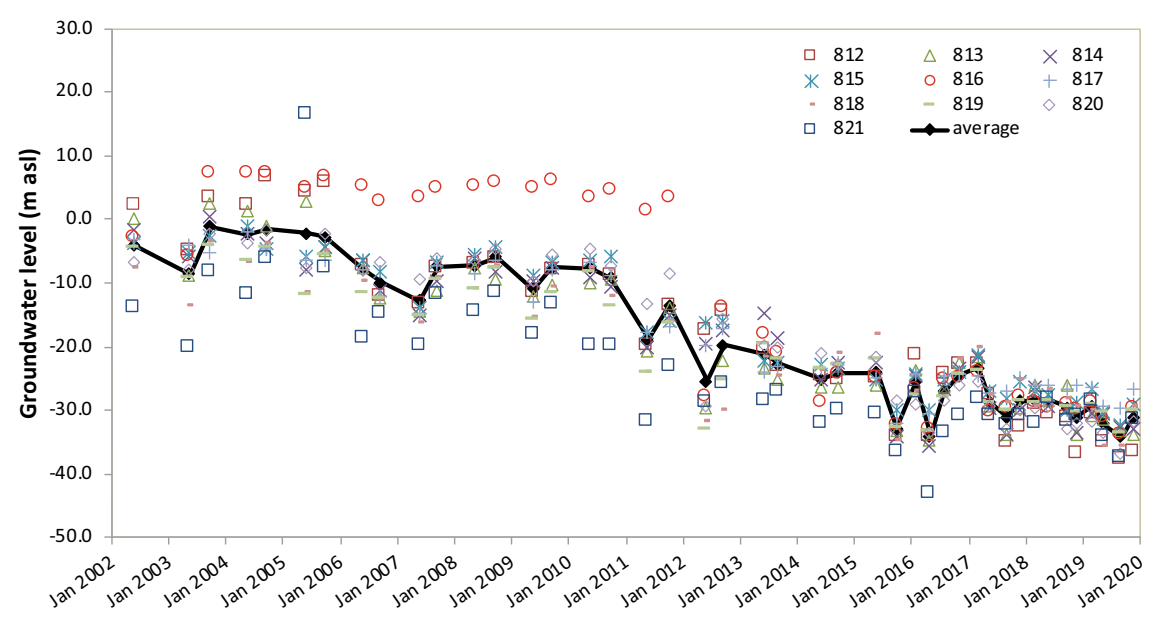

Fig. 4.10 Observed piezometric heads of the deep aquifer recorded manually in observation wells of Hebei Province

in the dry year of 2019.

The decline in observed heads of the deep aquifer is caused by both drinking water wells and irrigation wells. Before 2011 the levels showed a slow decline. From 2011 on, they declined considerably faster until 2017. Then the decline slowed down again (Fig. 4.10). The accelerated decline of some piezometers after 2011 is surprising. Possibly, there is an inhomogeneity in the data end of 2011. After 2017, the rate of decline in groundwater heads decreased due to the partial replacement of groundwater pumped for households and industry by surface water from the SNWT scheme.

\section{Groundwater level contour map}

In July 2020, a simultaneous measurement of groundwater levels of the shallow aquifer in Guantao and its surrounding areas was carried out by CIGEM to better characterize the regional groundwater flow direction. The groundwater level was determined in more than 200 wells (including some pumping wells). The groundwater level contour map of the shallow aquifer is shown in Fig. 4.11 (left), indicating that groundwater flows from east to west. The reasons are twofold: There is less overpumping in the neighboring Shandong Province and the Weiyun River, which forms the eastern border of Guantao, supplies some recharge through river seepage. Two cones of depression are visible, one close to the western boundary in central Guantao, the other on the southern boundary, where the lowest groundwater level is located.

Similarly dense, simultaneous measurements of the groundwater levels of the deep aquifer are not available. The groundwater level contour map of the deep aquifer shown in Fig. 4.11 (right) is interpolated from the observed data of May, 2019 in the observations wells marked in Fig. 4.4 (right). It shows that groundwater in the deep 

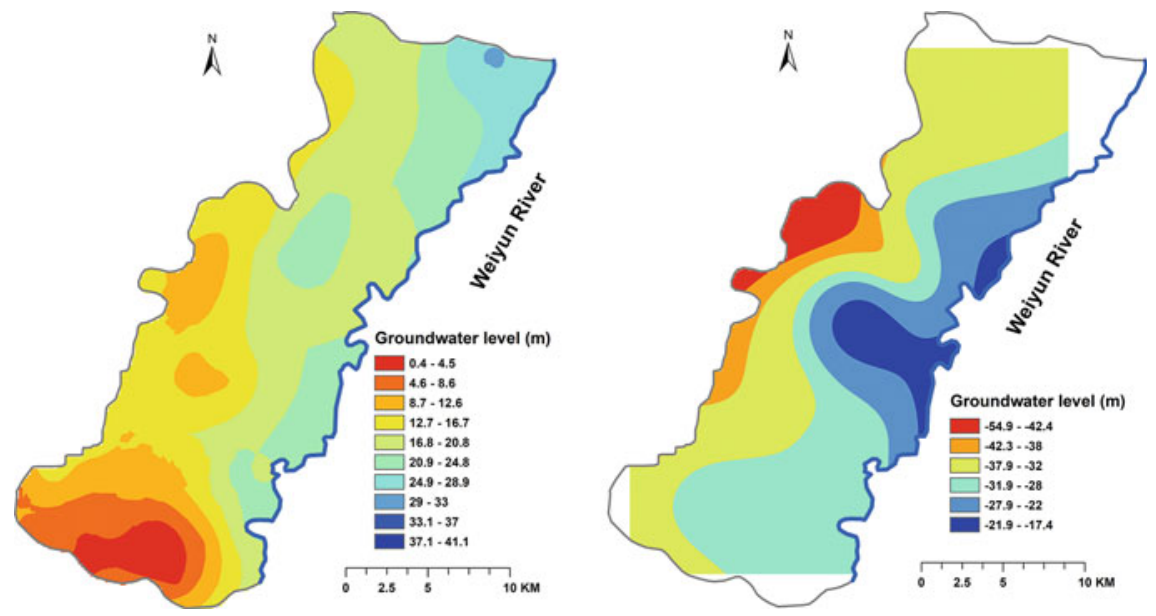

Fig. 4.11 Groundwater level contour map, left: shallow aquifer; right: deep aquifer

aquifer also flows from east to west. This can also be seen from the regional head distribution provided in Fig. 1.15. Piezometric heads are higher in the east.

It should be noted that the head distributions in Fig. 4.11 are momentary "snapshots". The general flow direction, however, does not change significantly over the year.

\section{Conclusions}

In recent years groundwater levels in the shallow aquifer stayed constant or decreased only slightly indicating reduced pumping compared to the time before 2014. This is due to two reasons: a large import of surface water after 2014 (Table 2.4), which amounted to about one third of the usual irrigation amount, and the fallowing measures implemented for winter wheat in Guantao since 2014 (Table 2.2).

The situation in the deep aquifer is different. While about half of the wells for drinking water and industrial water were decommissioned after their substitution with surface water from the SNWT scheme, agricultural pumping continued and even increased. It is essential for areas, where the salinity of the shallow aquifer is high and less-mineralized water from the deep aquifer is needed for dilution of shallow aquifer water or for sensitive greenhouse cultures. Consequently, groundwater heads in the deep aquifer layer are still declining. While the recharge-discharge gap in the shallow aquifer has practically been closed, the remaining gap is caused by the deep aquifer pumping. Paradoxically the increased pumping in the deep aquifer supports the groundwater levels in the shallow aquifer by irrigation backflow.

The equilibrium or even increase in heads in the shallow aquifer is very welcome. However, one should not become complacent as there are cycles of wet and drought years as seen in the past (Fig. 1.12). The next drought will certainly come, and it will be easier to manage if water levels in the shallow aquifer are allowed to increase now. Another important consideration is that with decreasing heads in the deep aquifer 
and with stagnant or increasing heads in the shallow aquifer the head difference between the two aquifers is further increasing. This implies an increased possibility of contamination of the high-quality water of the deep aquifer by leakage from the saline aquifer and aquitard above (Fig. 1.13). Finally, the continued recycling of irrigation water in a closed system such as a regional cone of depression in the shallow aquifer will inevitably lead to salt accumulation and thus deterioration of water quality. A sustainable system must provide an outlet for dissolved salts via drainage. Such outlets arise naturally if the drainage function of rivers and streams is revitalized by a sufficiently high water table.

\subsubsection{Groundwater Pumping Monitoring}

A water meter is the most straightforward method to monitor groundwater pumping. However, direct water metering at irrigation wells is still absent in most of the NCP despite huge investments by the local water authority. In comparison to the monitoring of groundwater levels, monitoring of abstraction is much more difficult, given the large number of wells. There are 7300 shallow pumping wells and 300 deep pumping wells. A low-cost metering solution would use cheap mechanical meters on each well, which are read off once a year. However, this solution is not deemed feasible by the water authorities. Previous experience shows that mechanical meters are unreliable and commonly tampered with. They often break under freezing conditions. They are not inseparably connected to pumps. They are removed when pumps are repaired, moved to another well, or completely taken out of the wells in winter.

A modern high-end solution is the smart water meter, which is offered for irrigation wells by several suppliers in China. A smart water meter is operated with a swipe card, which carries a prepaid amount of water. The volume pumped is abstracted from the amount stored on the card. The protection against tampering comes with the wireless connection of the smart meter to a server, receiving in real time all relevant data from the well usually at an interval of one hour. The transmission makes sure that the meter is working properly. If this is not the case, service personnel have to be sent to the field immediately to repair the meter. In China, such a system was first introduced in Minqin County, Gansu Province, in 2007 (Liu 2016). In the Sino-Swiss groundwater project's Heihe pilot site in Luotuocheng, Gansu Province, a smart metering system has been installed on 700 wells of the irrigation district in 2015, which is functioning very well up to today ( $\mathrm{Li}$ et al. 2021b). The reasons for its functioning are fourfold: Wells have large capacities pumping around 150,000 $\mathrm{m}^{3} /$ year. They provide full irrigation under arid climate leading to a non-negligible water bill for the single user. The collection of a high water fee of $0.1 \mathrm{CNY}$ for every cubic meter pumped provides sufficient funds for the maintenance of the system. Finally, smart meters have been classified as electrical equipment, making vandalism against them a crime punishable by existing law. None of these conditions is fulfilled in the NCP.

Equipment of more than 1000 wells in Guantao with smart water meters has been tried by Hebei Department of Water Resources with disappointing results. Of 

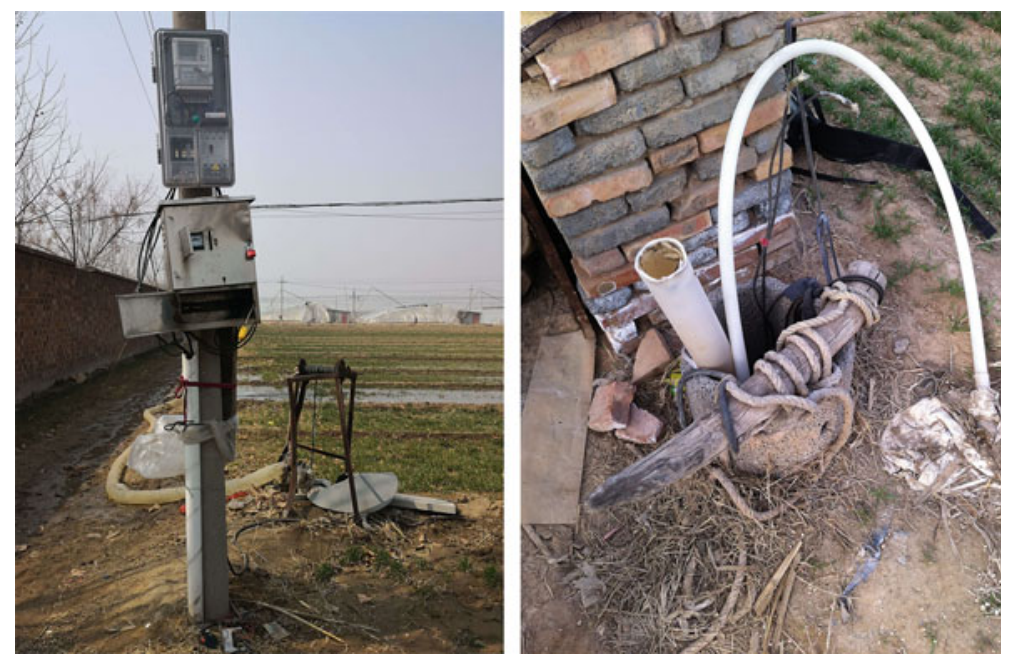

Fig. 4.12 Typical irrigation wells and electricity meters installed in Guantao County

700 smart meters installed in 2016 only 6 were still working in 2018 . While the initial installation was paid for by the water administration, funds for maintenance and repair were insufficient. Moreover, many wells are so primitive that they are not suited for the equipment with smart meters (Fig. 4.12). The main reason for failure was the farmers' lack of cooperation or even opposition resulting from unwillingness to pay water fees.

10 experimental smart water meters installed in this project provided the chance to assess the performances of different types of meters and to explore the feasibility of monitoring groundwater pumping by smart water meters on single wells. The measurements of the water meters allowed us to understand farmers' irrigation habits and the effectiveness of watersaving equipment.

\section{Comparison of water meters}

Five pairs of smart water meters from different producers were installed in Shoushansi District of Guantao. These meters differ in cost, meter type and data transmission method, which allows a comparison concerning the implementation of the different meters and measurement principles in practice. All the producers of water meters can provide the service of data management including data transmission and provision of a web-based data platform. A uniform communication protocol makes the data collection easier when several producers participate. An overview of the meter information is summarized in Table 4.1.

Mechanical water meters (Fig. 4.13) have the advantages of low cost, long service life and simple technology. When used for measuring groundwater, sand in the water can clog up and damage the propeller, causing a deterioration of measurement accuracy. Farmers generally resist the installation of sand filters as they entail an increase in energy consumption. Freezing can destroy meters immersed in water. 
Table 4.1 Comparison of meters installed in Guantao for testing

\begin{tabular}{l|l|l|l}
\hline Meter producer & Metering principle & Measurements & Price per unit $^{\mathrm{a}}$ \\
\hline Haisen (Tangshan, China) & $\begin{array}{l}\text { Mechanical water } \\
\text { meter (Nylon) }\end{array}$ & $\begin{array}{l}\text { Water abstraction, } \\
\text { electricity consumption, } \\
\text { water level }\end{array}$ & $4400 \mathrm{CNY}$ \\
\hline $\begin{array}{l}\text { Hengyuan (Shijiazhuang, } \\
\text { China) }\end{array}$ & Ultrasonic water meter & $\begin{array}{l}\text { Water abstraction, } \\
\text { electricity consumption, } \\
\text { water level }\end{array}$ & $12,000 \mathrm{CNY}$ \\
\hline Hengze (Qingdao, China) & Mechanical water meter & $\begin{array}{l}\text { Water abstraction, } \\
\text { electricity consumption }\end{array}$ & $3000 \mathrm{CNY}$ \\
\hline RSA (Iran) & $\begin{array}{l}\text { Electricity consumption } \\
\text { calibrated for flow }\end{array}$ & $10,000 \mathrm{CNY}$ \\
\hline $\begin{array}{l}\text { Itron (France/Suzhou) } \\
\text { Mechanical meter with } \\
\text { high accuracy }\end{array}$ & $\begin{array}{l}\text { Water abstraction } \\
7600 \mathrm{CNY}\end{array}$ \\
\hline
\end{tabular}

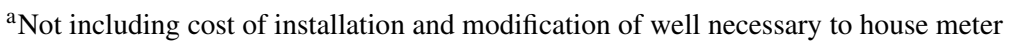
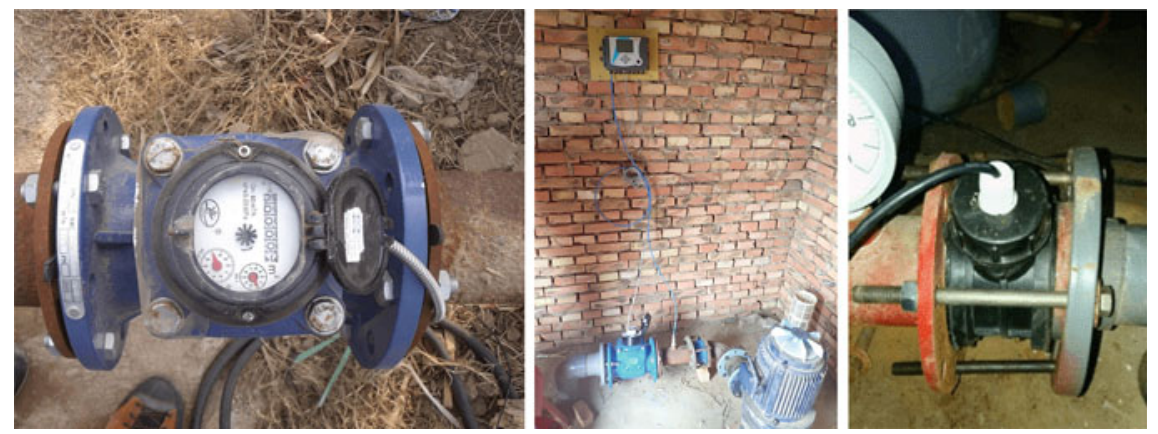

Fig. 4.13 The Hengze meter (left), the Itron meter with transmission unit Watermind on the wall (middle) and the Haisen meter (right)

These are practical problems faced by mechanical water meters. The mechanical meters installed in the project differed in material, technology, and accuracy.

Meters based on ultrasound and electricity are shown in Fig. 4.14. Clamped-on ultrasonic water meters do not have the problem of clogging as mechanical water meters do, but the accuracy of the measurements can be impaired by air bubbles in the conveying pipe. Well houses or plastic huts are necessary accessories to protect the probes of the meters. The price of the meter and accessory equipment make ultrasonic water meters more expensive than mechanical water meters.

The electricity-based water meters only monitor electric energy consumption, which is then converted to water abstraction within the meter. An initial pumping test is required for its calibration. The test provides a conversion factor as a function of the pump's lift. Among the experimental monitoring systems, the electricitybased meter has the simplest hardware setup, containing only an electricity meter. However, the price of the meter from Iran is high due to the patented technology 

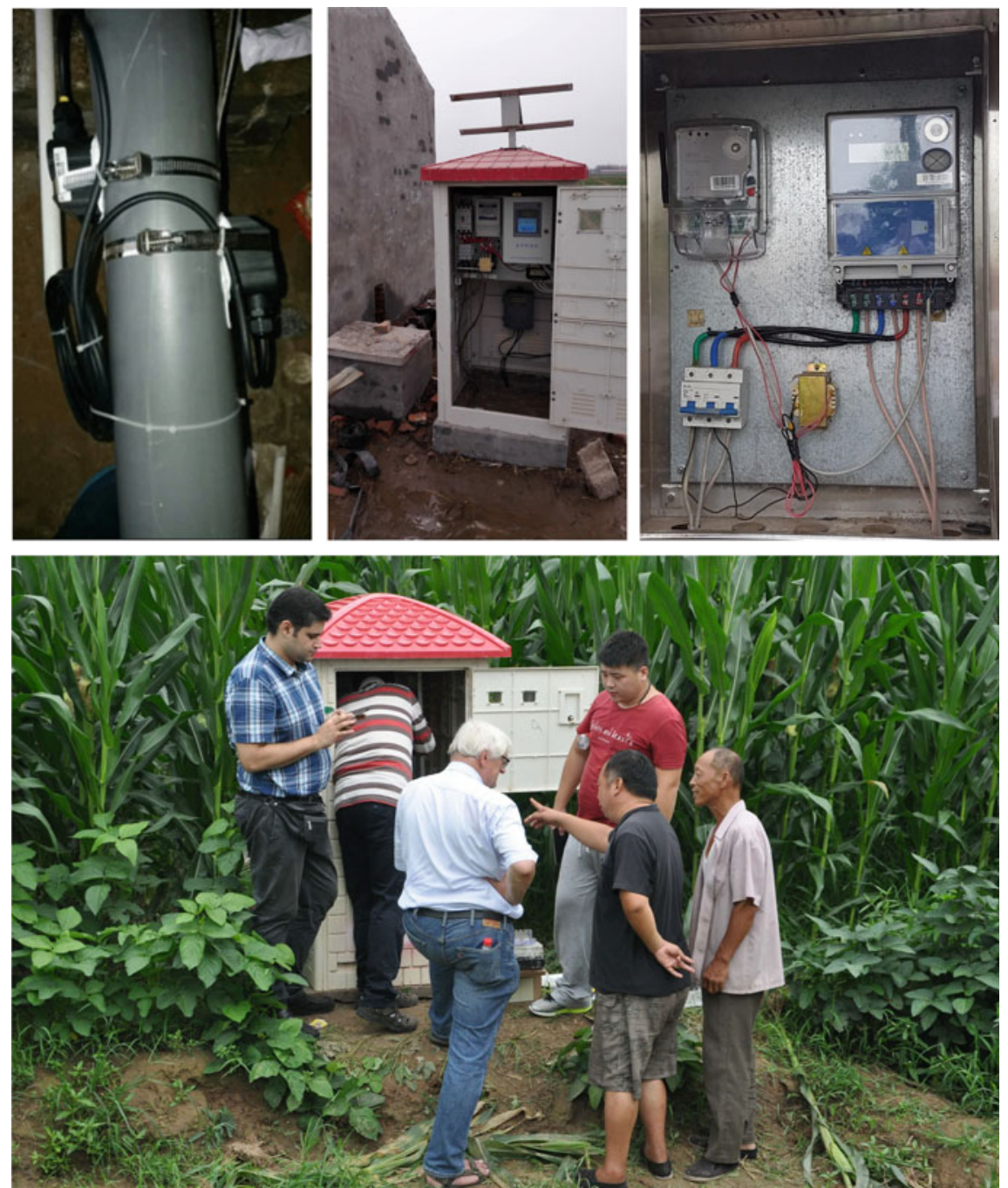

Fig. 4.14 Hengyuan meter and RSA meter. Upper left: The Hengyuan ultrasonic water meter;Upper middle: The meter is protected by a concrete box. The control box and data transmission unit are protected by a plastic hut; Upper right: RSA meter box; Bottom: Swiss expert answering questions from the local farmers during the installation of RSA meters by technicians from RSA and local DWR

of data processing, which provides corrections of the conversion factor in time. A similar meter is available on the Chinese market for a considerably lower price from Huafeng Electronics Company, Jiuquan.

The experience of installing and operating these meters was very valuable, as it showed what could go wrong in the implementation of metering solutions regarding 
the issues of hardware installation, maintenance, data transmission and user-induced problems. Eight out of the ten smart water meters were not functional by the end of 2018 due to various reasons, listed below:

- Malfunctioning of the water meters.

- Farmers' unwillingness to cooperate and subsequent vandalism destroying the meters.

- Failures of data transmission units due to unforeseen update of the data transmission network or due to the malfunctioning of the transmission unit.

- Meters were bypassed manually due to circuit malfunction.

- Theft (One meter was stolen during the change of the well users.)

The meters that are still functional, are a clamped-on ultrasonic water meter and a high-resolution mechanical water meter. Although the operation of the ultrasonic water meter had been interrupted due to hardware malfunction and vandalism, its longer service time compared to other meters is attributed to the presence of an efficient local maintenance team. The high-resolution mechanical water meter is still functional at present. This type of meter is usually used by water utilities. It provides robust hardware and an independent battery-based data transmission unit, which makes it less vulnerable to vandalism. However, the cost of this type of meter is twice that of the common mechanical water meters.

The experience with the experimental water meters shows that a sustainable monitoring system must satisfy two requirements: (1) the hardware must be robust (for both meters and data transmission units) and (2) a prompt and efficient maintenance service must be provided. Guantao DWR had the same experience with their installation of smart meters on a larger scale.

\section{Water usage and farmers' irrigation habits}

From 2014 to 2016 in total 1037 water metering devices for pumping well monitoring have been installed in Guantao County through the locally funded projects. All these devices have been installed in wells with water saving equipment. In contrast, the 10 experimental water meters installed in this project have been installed in pairs on wells with and without water saving equipment (sprinkler) in the same region, to allow for an assessment of water saving, by comparison between the two, as well as farmers' irrigation habits. Annual water application per mu at five locations with pipe irrigation (flood irrigation in small field units) and five locations with sprinkler irrigation is shown in Fig. 4.15.

For each pair of measurements from the same meter brand, sprinkler irrigation utilized more water than pipe irrigation, except for the Hengyuan meter, which underestimated the water use by sprinklers due to missing measurements. The average annual amount of water applied in sprinkler irrigation is $277 \mathrm{~m}^{3} / \mathrm{mu}$, while the average annual water application with pipe irrigation is $263 \mathrm{~m}^{3} / \mathrm{mu}$. The values are close to the water quota of $296 \mathrm{~m}^{3} / \mathrm{mu}$, exceeding which farmers need to pay a water tax.

The surprising fact that sprinklers use more water than pipe irrigation is due to improper use of the sprinklers by the farmers. Flood irrigation in small field units requires application of at least $70 \mathrm{~mm}$ each irrigation time to flood the whole plot 


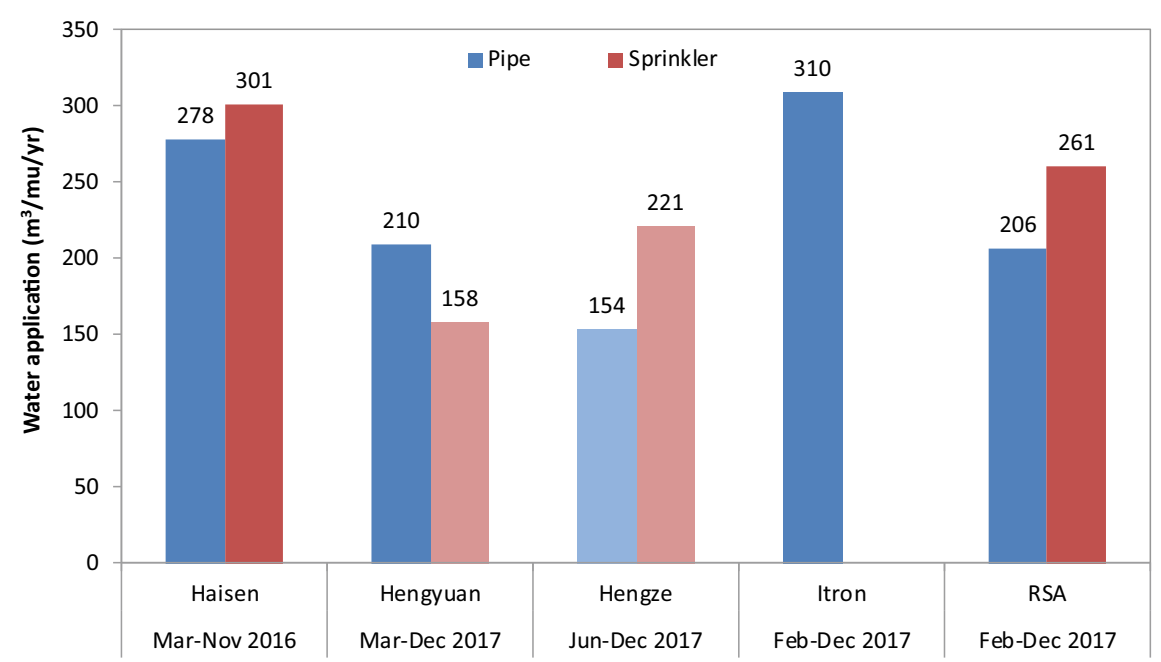

Fig. 4.15 Water application monitored by 5 experimental water meters (Bars in light colour indicate that meters covered less than one irrigation year)(Measurements of Itron sprinkler irrigation are missing due to malfunctioning of the pump.)(in $\mathrm{m}^{3} / \mathrm{mu} /$ year)

and water saving can only be achieved by reducing the frequency of irrigation. The water application by a sprinkler system is much more flexible. A sprinkler system in principle saves water due to its more even spreading. The application times can be adapted to plant need and water can be given more often in smaller amounts. As can be seen from Fig. 4.16, the irrigation days and the daily water application

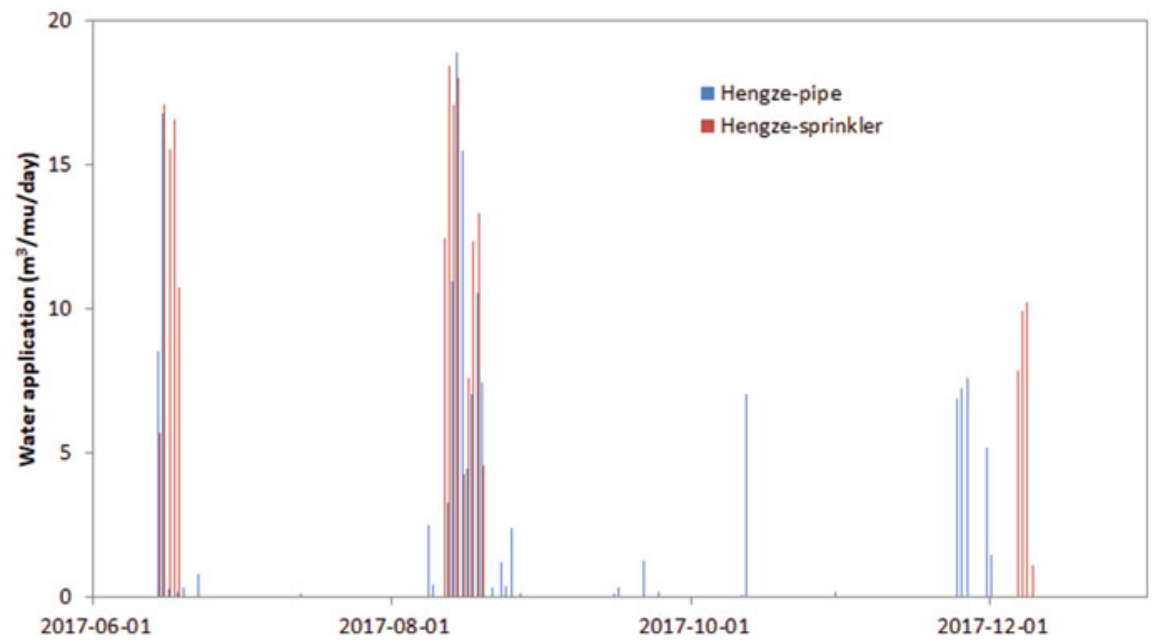

Fig. 4.16 Comparison of daily water application between pipe irrigation and sprinkler (in $\mathrm{m}^{3} / \mathrm{mu} /$ day) 
of sprinklers are similar to those of pipe irrigation, which means that farmers apply sprinkler irrigation in the same way as they apply pipe irrigation, according to a fixed irrigation calendar. Therefore, no water was saved by using sprinklers. Efficient use of a sprinkler system means making full use of its flexibility in applying less water per time, spreading out irrigation times and targeting plant needs in critical crop growth stages instead of simply following the calendar days of flood irrigation. Possibly labor cost prevented a more efficient use.

It can also be observed that pumping lasts for one week (or less) in each irrigation season. Pumping observed in June and August was for irrigation of maize. Pumping in early October is usually expected to irrigate the winter crop fields before seeding. However, there was little pumping in October in 2017 due to sufficient precipitation in the previous months. Therefore, pumping is only observed by the end of November and in early December due to the dry winter.

Analysis without taking into account the particular situation in the field will produce biased results. Various factors can lead to a wrong determination of the amount of water pumped. For example, the Haisen meters did not work properly one year after installation. Still, the meter automatically transmits virtual data instead of real measurements when there is a hardware malfunctioning. For the user, this is difficult to detect as it can only be revealed when looking into the time series of flow rate in the data base. Additionally, when calculating water use per mu, errors can be introduced by inaccurate estimation of the irrigation area. This happens in two situations: (1) usually several households share one well, and the farmers or the electricians can only give a rough number of the total irrigation area of a well; (2) the irrigation area of one well varies as fields located between two wells A and B can be irrigated by either well A or well $\mathrm{B}$. The error in the irrigation area is estimated to be around $20 \%$ according to farmers. The aforementioned factors prevent us from getting reliable results. These problems raise doubts in collecting water fees/taxes based on the monitored water use per mu.

\section{Lessons learned}

The smart metering experiment provided valuable experience in monitoring groundwater pumping at single wells. There is no evidence of obvious differences in the accuracy of the measurements using different types of water meters. The meters that monitor and convert electricity consumption to water abstraction have the advantage of being convenient and robust, but the accuracy depends on the initial calibration at each single well. All water meters require protection against tampering and theft.

The experiment raises questions about the feasibility of pumping monitoring based on smart water meters on single wells in well-intensive regions such as the NCP. First, the infrastructural investment of monitoring pumping on single wells will be enormous. Investment is not only needed for water meters and data management but also for upgrading and adapting the pipe systems at the primitive wells. Secondly, the monitoring system will not work functionally without efficient maintenance, which proved to be both costly and laborious. On-site inspection and data examination are two indispensable parts of maintenance work. The meter producers must offer to take on this task and cooperate closely with the local water department. Thirdly, farmers' 
unwillingness to cooperate had serious negative impacts on the operation of the monitoring system. Efforts are needed to educate farmers to accept the use of water meters and to properly use and protect them. The second and third requirements are hard to fulfil in the NCP, where there is little experience with public-private partnership in meter installation and maintenance yet, and where farmers are used to abstract groundwater without paying additional water fees.

The conditions are quite different from the situation in Europe, the US, Mexico and even Northwest China where agricultural wells are fewer in number, larger in capacity, and owned and controlled by a small fraction of the population. Monitoring and quantification of groundwater abstraction in these regions is feasible through direct monitoring of pumping activity. In contrast, any monitoring or control action on the small wells in the NCP involves millions of individual users, which greatly complicates an effective abstraction management.

\subsubsection{Pumping Electricity Monitoring}

A large number of pumping tests were performed from 2016 through 2018 to determine the conversion factor between electricity consumption and pumped volume. It was shown that for a single well with a single pumping test the annual pumped volume can be estimated from the annual electricity consumed within an error of less than 20\% (Wang et al. 2020). The variation of the conversion factor from well to well is large with values varying between $1 \mathrm{~m}^{3} / \mathrm{kWh}$ and $4 \mathrm{~m}^{3} / \mathrm{kWh}$ for shallow wells. This implies that for equitability in fee collection a test has to be performed on each well. Technical background and procedures are provided in Appendix A-1.

To obtain an estimate of the total annual abstraction in a village at the same accuracy, it is sufficient to apply an average conversion factor, obtained from about 20 pumping tests distributed over the village, to the aggregated annual electricity consumption of all wells involved (Wang et al. 2020). In Guantao, the average conversion factors from electricity consumed to water pumped are $2.62 \mathrm{~m}^{3} / \mathrm{kWh}$ for shallow wells, $1.32 \mathrm{~m}^{3} / \mathrm{kWh}$ for deep wells and $13 \mathrm{~m}^{3} / \mathrm{kWh}$ for pumping of surface water from the main irrigation canal to the fields.

\section{Monitoring at single wells}

All irrigation wells in Guantao County are equipped with electricity meters, which were mostly traditional mechanical electricity meters without data transmission before 2018, recorded once per month by the village electricians. Since 2018 Guantao EPSC has upgraded the metering system by installing smart electricity meters with data transmission at the frequency of once a day, which makes real-time pumping monitoring possible and allows to observe and identify the irrigation patterns of different crops (Fig. 4.17).

Due to the variability in the hydro-geological conditions, the types and working conditions of the pumps as well as the accuracy of the electricity meters, the spread in electricity-to-water conversion factors among single wells is large. Using a uniform 

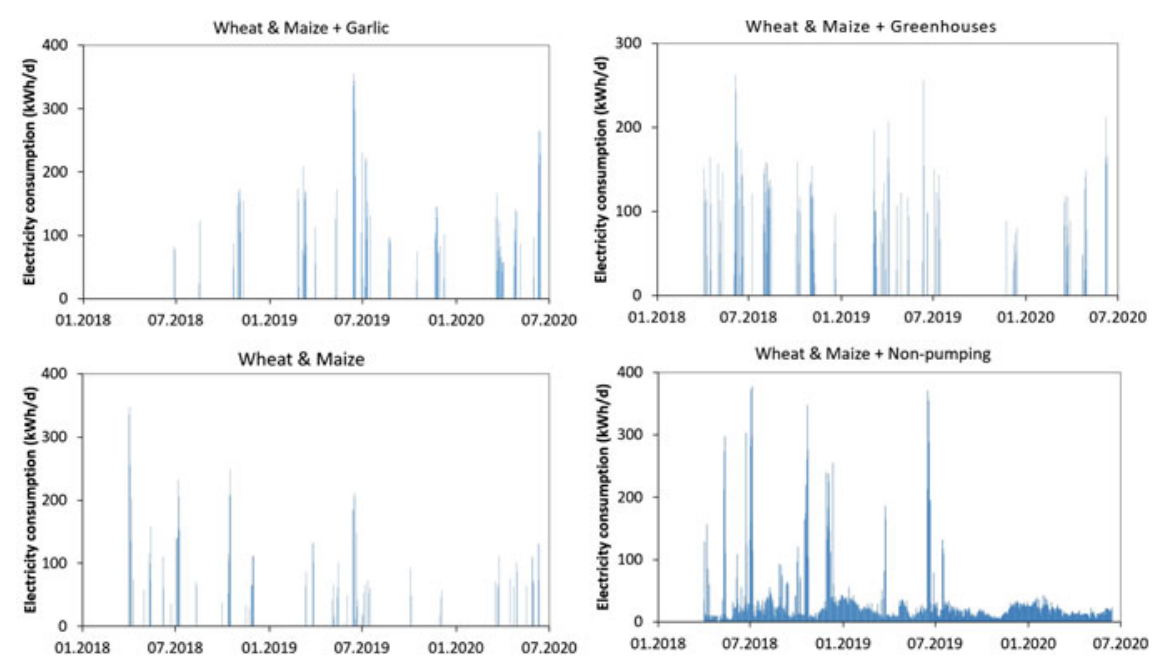

Fig. 4.17 Typical daily electricity consumption of single wells for irrigation of different crops in Guantao County (in kWh/day)

(average) conversion factor at single wells would lead to an error of up to $60 \%$. Thus, for fee collection purposes, the conversion factor should be established for each well to achieve an accuracy of pumped volumes within 10-20\%. Compared to using one uniform conversion factor, classifying the conversion factors by the pumps' rated powers improves the accuracy of water use estimation to a limited extent. It would be a compromise solution to increase fairness in collecting water fees. As pumping tests have not been conducted at every well, the average conversion factor calculated from pumping tests at representative wells has been used to obtain annual water volumes pumped at single wells. Not knowing accurately the irrigated area covered by a single well, it was suggested to collect water resources fees or taxes at village level. For this purpose, the use of an average conversion factor for the village would be justified. Using a uniform conversion factor on single wells is the equivalent of taxing energy use instead of water use, which is another method of taxing groundwater.

Quantification of water volumes pumped at single wells has been achieved by converting the annual electricity consumption of single wells shared by Guantao EPSC since 2017. Pumping electricity data include not only the electricity consumption of shallow wells but also energy consumption of deep wells and surface water pumping stations. By converting the electricity consumption using the corresponding electricity-to-water conversion factors, the spatial distributions of the use of different sources of water as well as the total use of irrigation water were obtained (Figs. 4.18 and 4.19). The use of deep groundwater is concentrated in Fangzhai, Chaibao, Luqiao and Weisengzhai Townships, where the salinity of the shallow groundwater is too high to be used for irrigation. The distribution of surface water consumption is concentrated along the Weixi Main Canal and branch canals in the southern and northern part of the county. 

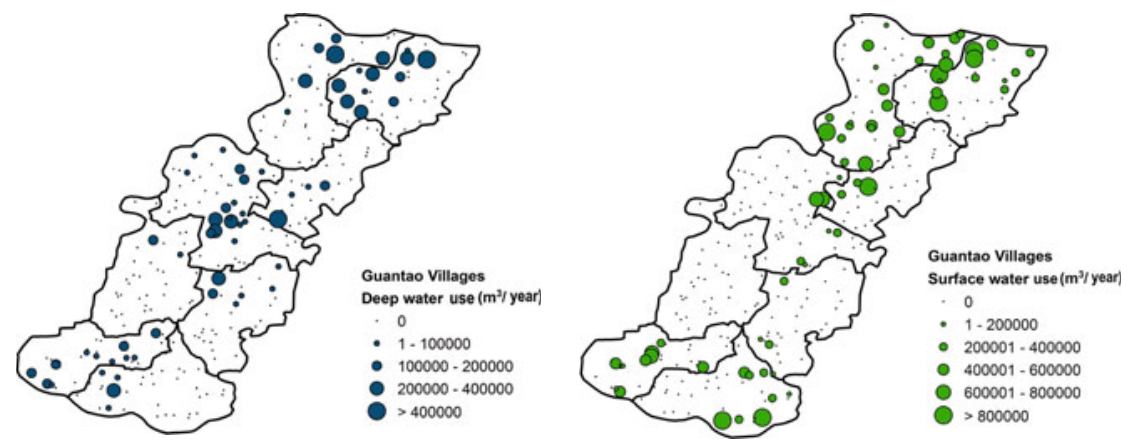

Fig. 4.18 Deep water use (left) and surface water use (right) of villages in Guantao in 2019 (in $\mathrm{m}^{3} /$ year)

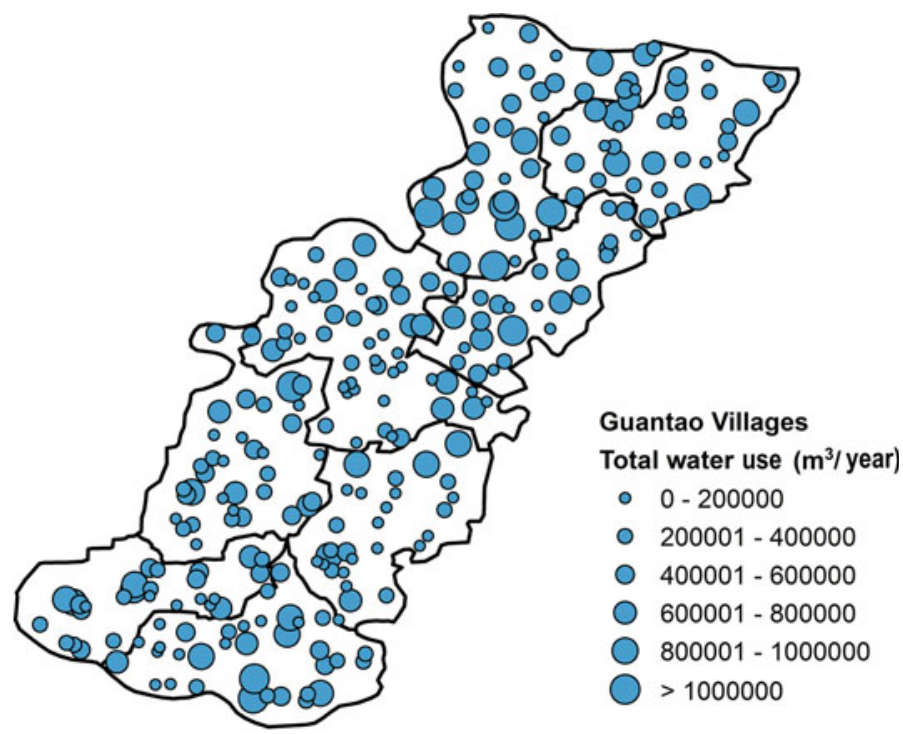

Fig. 4.19 Total water use of all villages in Guantao in 2019 (in $\mathrm{m}^{3} /$ year)

The specific use of the different sources of water in the 8 townships of Guantao County is shown in Fig. 4.20. Shallow groundwater is the main water source for irrigation, while the fraction of deep groundwater is not negligible in most of the townships. On average, no township surpasses the limit of $296 \mathrm{~m}^{3} / \mathrm{mu}$, while only 3 townships surpass the quota of $222 \mathrm{~m}^{3} / \mathrm{mu}$. Although more than 30 Mio. $\mathrm{m}^{3}$ of surface water were imported to Guantao every year since 2014, the actual use of surface water only accounts for a small fraction of the total water use (similar to the situation in BTH described in Sect. 2.3). It is notable that the calculated total water use in some villages was greater than 1,000,000 $\mathrm{m}^{3} / \mathrm{year}$, which is questionable and 


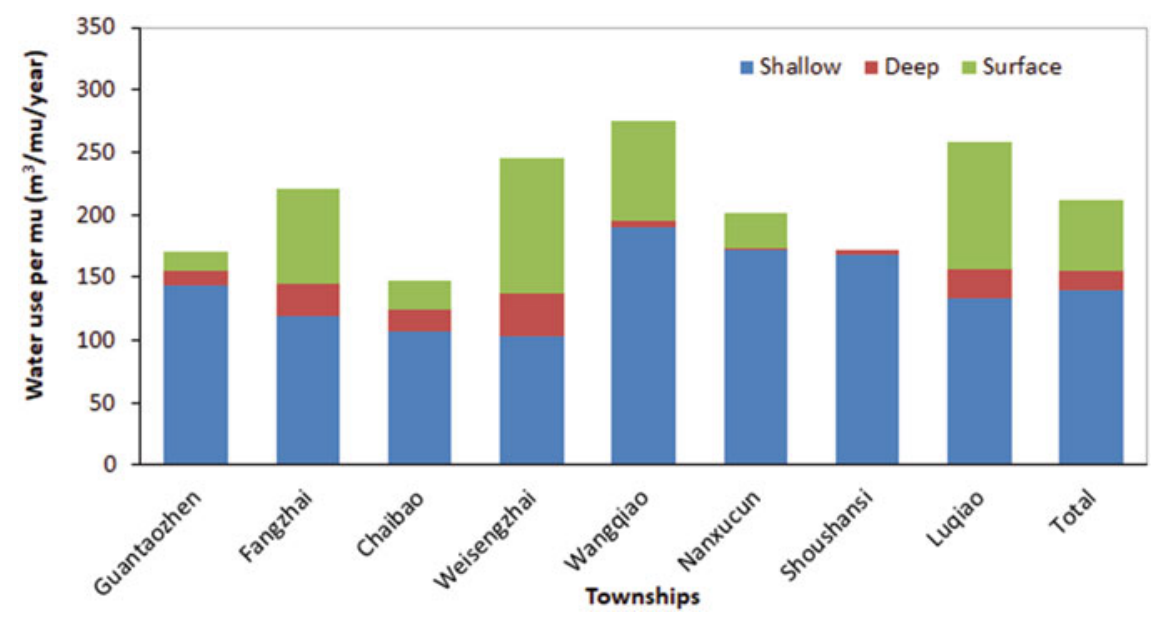

Fig. 4.20 Annual water use per mu of different townships in Guantao County in 2019 (in $\mathrm{m}^{3} / \mathrm{mu} /$ year)

needs to be verified. This can be caused by incorrectly including some non-pumping electricity consumption by rural industry (e.g. chicken farms), connected to the same meter as the pumping well. Verification of the reported data is necessary to avoid overestimation of groundwater extraction.

\section{Monitoring at transformers}

At the final stage of the electric power distribution system, transformers step down the transmission voltage to the level required by the end users, which is $380 \mathrm{~V}$ (line voltage) for pumping wells. Power supply for agricultural use is separated from that of other sectors, i.e., residential and industrial uses, by using separate transformers. Electricity consumption is metered by Guantao EPSC at the transformers by smart electricity meters with remote data transmission once a day. There are 2 to 10 transformers for agricultural use per village. Each transformer supplies electric power for 3 to 10 irrigation wells. Monitoring at transformer level can certainly reduce the monitoring effort for a village by a factor of up to 10, from dozens of wells to a few transformers.

To test the monitoring method, 100 smart electricity meters were installed by the project on electrical transformers that supply power to irrigation pumps. The frequency of data transmission of these meters is once per $2.5 \mathrm{~min}$, much higher than that of EPSC's meters. Since one transformer usually supplies power to several pumps, the meter on one transformer measures the total input power for the pumps connected to this transformer. The data collected, provide an opportunity to explore the possibility of monitoring several single wells' electricity consumption by one meter on their common transformer (Fig. 4.21). Machine learning techniques can be used to solve the data disaggregation problem involved. The method of Non-Intrusive Load Monitoring (NILM), which originated from household appliance monitoring 


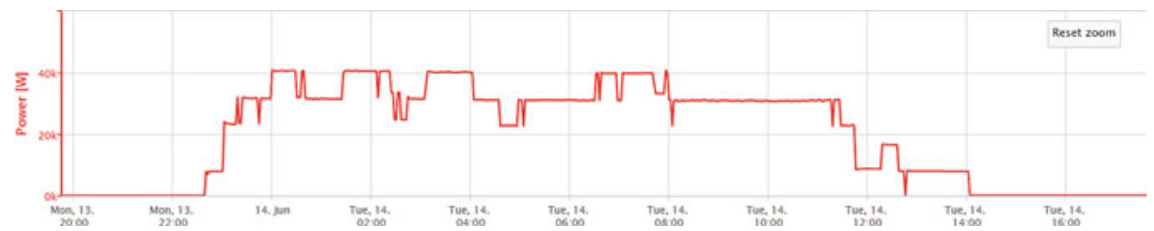

Fig. 4.21 Time series of the working power showing status of pumps connected to one transformer (In this example 4 pumps are connected to the transformer)

(Zoha et al. 2012), was applied to separate the electricity consumption of single wells from the total electricity consumption on transformers. Attempts were made to distinguish between types of pumps connected to one transformer, along with pumping duration. Analyzing events, where only one pump was operating at a time, led to successful separation of single pumps' contributions to the selected transformer's power output when no more than 4 pumps were involved. More sophisticated analysis is ongoing.

\section{Monitoring at regional level}

Historical electricity consumption records show that average pumping electricity for every month of the year is generally in line with the irrigation demand (Fig. 4.22). (Averages were taken over the time period from 2007 to 2016). One must note that the pumping electricity is not reported according to the calendar month, e.g., Shoushansi EPSA reads the electricity meter every $18^{\text {th }}$ of a month. Thus, the peak of pumping electricity in April represents a peak of water consumption in late March and early April, which is the time of spring irrigation for winter wheat. Spring irrigation

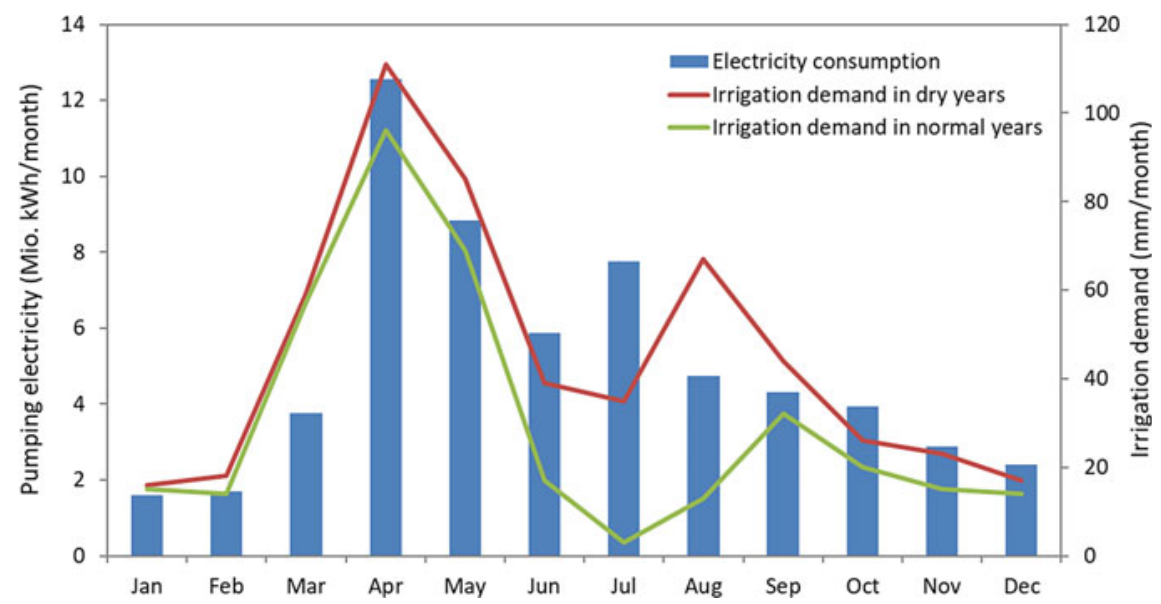

Fig. 4.22 Multi-year averaged monthly pumping electricity consumption of Guantao and irrigation demand for winter wheat-summer maize in dry and normal years (Averages of electricity consumption from 2007 to 2016 in Mio. kWh/month) 
requires more water than the other irrigation seasons due to lack of precipitation in spring. It is interesting to observe that there is quite an amount of pumping in May and June, supposedly for irrigating winter wheat and vegetables. The third high value appearing in July represents the pumping for seeding summer maize in late June. There is no peak in October as one would expect during seeding of winter wheat. This can be explained by the abundant antecedent precipitation.

The inter-annual variability of pumping electricity of single districts agrees well with that of the county (Fig. 4.23). Only anomalies against multi-year average of pumping electricity are shown in the figure to avoid the influence of the magnitude of absolute values. The relative differences between the anomalies of single districts and that of the county are less than $20 \%$, while the inter-annual variability of pumping electricity is much larger, with anomalies up to $50 \%$, caused by the randomness of rainfall. It was also observed that the ratio between the pumping electricity of a district and that of the whole county is relatively stable from year to year. This implies that the pumping electricity of one region is also a good representative index of the pumping electricity, and consequently the irrigation water use, of a larger region. This indicates that it is feasible to estimate groundwater pumping of a larger area through monitoring of a smaller area.

As mentioned before, electricity-to-water pumping tests should be carried out for each individual well to reach an acceptable accuracy for taxing, while the required number of pumping tests can be much less, when estimating the groundwater abstraction of a larger area (village or county). Its accuracy depends on the accuracy of the areal conversion factor calculated as the average of tested conversion factors at individual wells. The results show that at a confidence level of $95 \%$, at least 13 wells should be tested in Guantao if the error of the areal mean conversion factor of shallow wells is expected to be less than $20 \%$. The number increases to 45 wells if the error is expected to be less than 10\% (Wang et al. 2020). Compared to the total of about 7300 shallow wells in the whole county, the required number of pumping tests is very

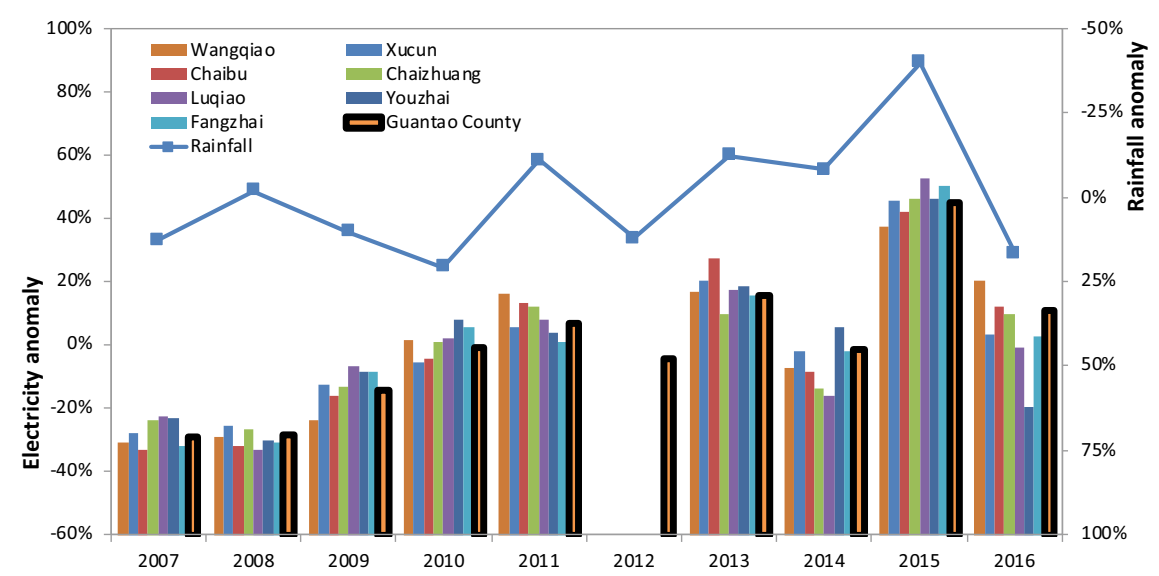

Fig. 4.23 Inter-annual variability of pumping electricity of the county and main districts 
small. It implies that reliable areal estimates of aggregated groundwater abstraction can be obtained by testing only a small proportion of wells in the region. This conclusion provides the basis for reconstructing historical groundwater abstraction of the county for groundwater balance analysis (see details in the box model Sect. 4.3.1).

\section{Recommendations}

In Guantao, the depth to static groundwater table is large, on average more than $20 \mathrm{~m}$. The cyclical fluctuation of the groundwater level within a year (on average $\pm 5 \mathrm{~m}$ ) is small compared to the depth to groundwater table, which means that a pump's total lift does not vary much within a year, e.g., within $20 \%$ according to the measurements of conversion factors at a representative well. This situation is typical for over-pumped aquifers, where groundwater management is necessary. Under other circumstances, more tests may be needed to obtain a temporal distribution of the conversion factor over the year. The influence of a long-term groundwater decline is negligible within a year but becomes more significant over time. It has to be taken into account by repeating pumping tests every few years. Additional tests are also needed in extreme drought events when groundwater levels decline drastically beyond the normal range of pump lift or when a new pump is installed in a well.

Besides the errors introduced by energy-to-water conversion, there are also uncertainties in energy data collection. Although less critical compared to water meters, tampering is still a risk with traditional electro-mechanical meters. The introduction of new smart electricity meters with remote data transmission has eliminated this risk through efficient on-line detection. In China, power for irrigation wells is supplied by transformers for agricultural use, which are separate from those for industry and residential use. However, besides providing pumping energy, transformers for agricultural use also supply power for other agricultural activities, which are eligible for the subsidized electricity price of $0.5115 \mathrm{CNY} / \mathrm{kWh}$, e.g., animal husbandry and preliminary processing of agricultural products. The regular price for households is tiered between 0.52 and $0.82 \mathrm{CNY} / \mathrm{kWh}$. Additional efforts are needed to separate pumping electricity from non-pumping electricity in areas, where energy records of wells are not easily identifiable.

Cooperation between water and energy departments (DWR and EPSC) is crucial to achieve a successful system of groundwater abstraction monitoring using electric energy as proxy. EPSC has been sharing annual energy data at single wells with DWR since 2017 for water resources tax collection in all counties of Hebei Province. This is the first step of cooperation between electricity and water departments. Policy support and legislation are needed to achieve further multi-departmental cooperation to ease the procedures of data collection, data sharing, quantification of groundwater abstractions and implementation of control methods. 


\subsubsection{Land Use Monitoring}

The planting area of the most irrigation intensive crops, winter wheat and greenhouse vegetables, can be monitored through satellite remote sensing. The relevant methods were developed or adapted in the project (Ragettli et al. 2018) (see also Appendix A-2). Figure 4.24 shows the winter wheat area of Guantao in the 5 consecutive years of 2016 to 2020 at a resolution of $10 \mathrm{~m}$ by $10 \mathrm{~m}$. Some changes are visible, which are related to the policy of encouraging farmers through subsidies to fallow winter wheat. Winter wheat is easy to monitor as in January and February it is the only green crop in the fields. Except for haze days good images can be obtained in this season. The use of radar remote sensing products enhances the data base as it can "look through" the haze. The control of a cropping system by remote sensing alone has been practiced successfully in the Eastern La Mancha of Spain, where each irrigation unit assigns crops to each of its plots within its water right. The execution of the plan is verified by weekly satellite images (Sanz et al. 2016). The crop-specific temporal variation of the vegetation index week by week allows identification of the different crops and comparison to the crops declared. Only in cases of doubt an inspector has to do a check on the ground. Similarly, subsidized fallowing can be reliably verified in Guantao by remote sensing (Fig. 4.25).

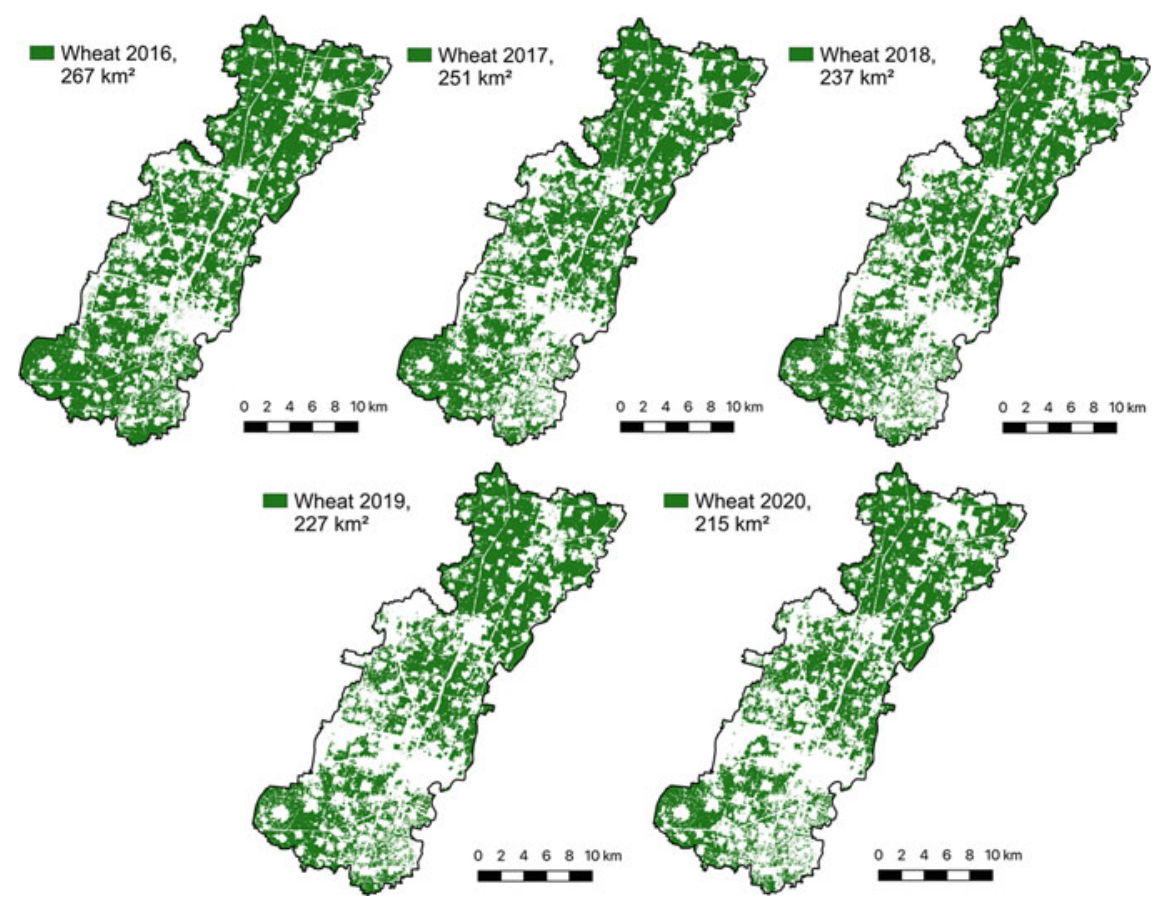

Fig. 4.24 Winter wheat area in Guantao County in five consecutive years 2016-2020 


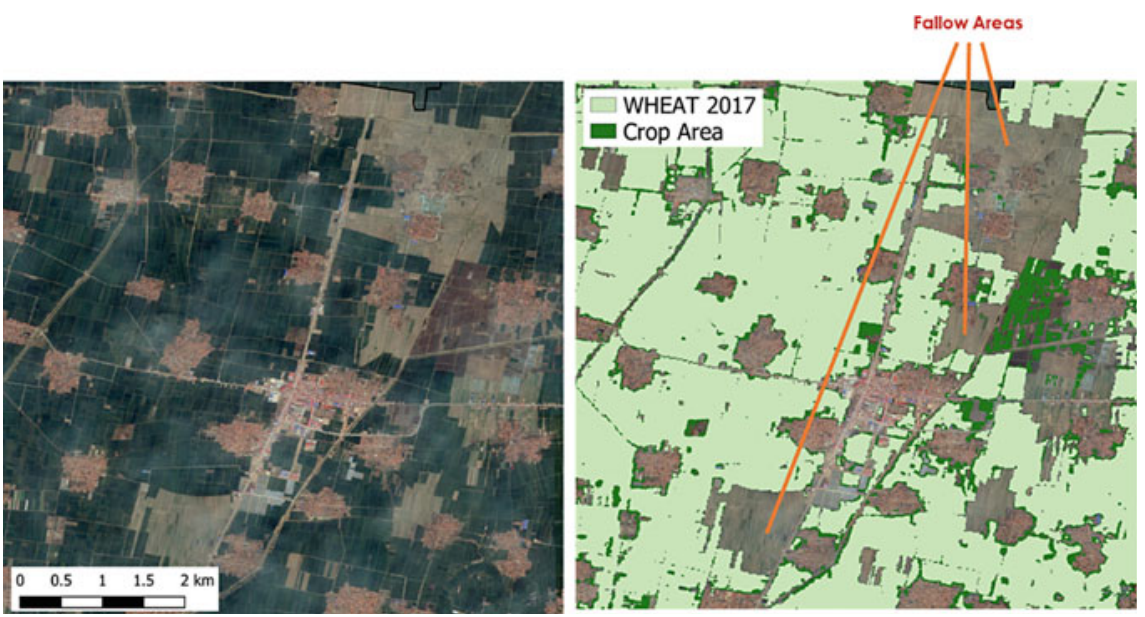

Fig. 4.25 Identification of fallowed wheat areas by comparison of images from two consecutive years

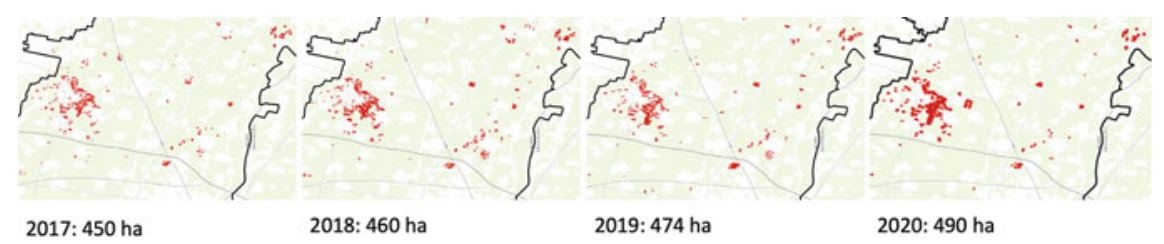

Fig. 4.26 Development of greenhouse area in Guantao (Image focuses on concentration in Shoushansi district) from 2017 to 2020

A relatively new development in Guantao is the fast increase in greenhouses, which are used for growing vegetables such as cucumbers and tomatoes. Although greenhouses save water for a single crop, greenhouse vegetables harvested multiple times per year are using more water per hectare than wheat-maize double cropping. Greenhouses can be detected by the spectral fingerprint of the plastic covers used (Yang et al. 2017). Figure 4.26 shows the development of the greenhouse area in Shoushansi irrigation district from 2017 to 2020.

\subsection{Modeling for Decision Support}

Four different groundwater models have been developed for interpreting the monitoring data gathered and to draw conclusions for groundwater management. Each of them has a different task. The first is a box model (0-D model), calculating a groundwater balance for the whole of the county (including shallow and deep groundwater). 
This lumped model allows to determine the water gap for the whole county and the size of interventions necessary to close it. The second model is a 2D model of the shallow aquifer. It describes the spatial distribution of groundwater levels and allows to locate interventions (e.g. construction of infiltration basins, allocation of surface water supply) in an efficient way to fill up deep cones of depression. The third model is a real time version of the $2 \mathrm{D}$ model. It updates the 2D model continuously by assimilating monthly incoming observation data. From this model one can at any time get the best possible groundwater contour map of the county as a starting point for the calculation of scenarios. Not everywhere data are available in the same density as in Guantao. Therefore, the last model uses Guantao data to develop a machine learning procedure to predict groundwater levels at an observation well, which can be transferred to other locations. It is based on long-term records of past groundwater levels at the same well and all related time series data from its surroundings such as rainfall, irrigated area, pumping electricity use, etc. Guantao's deep aquifer is not modelled, as pumping has to be reduced to zero for sustainability and the monitoring data are sufficient to verify whether this goal is reached.

\subsubsection{Box Model}

A box model was used to analyze the water balance of the shallow aquifer in Guantao County, including abstractions from the deep aquifer. It can be used as a simple alternative to a spatially resolving numerical groundwater model to simulate the yearly change of the groundwater level averaged over the county. It is useful for fast scenario analysis in decision support. It can be transferred to other counties even if only standard data are available (see Box 4.1).

\section{Model description}

The box model considers the shallow aquifer of Guantao County as a whole and investigates the yearly inflows, outflows and change of storage. The scheme is illustrated in Fig. 4.27.

The recharge of the shallow aquifer includes infiltration of precipitation and irrigation backflow as well as seepage of surface water from the Weiyun River and the Weixi Canal system. Recharge components were estimated using empirical functions of the Handan Water Resources Assessment (Yang and Gu 2008). Pumping for irrigation is the only net outflow of the shallow aquifer. The lateral flux of the shallow aquifer is negligible compared to vertical fluxes (recharge, pumping), and so is exchange with the deep aquifer. Phreatic evaporation need not be taken into account, as the depth to groundwater has been larger than $10 \mathrm{~m}$ since the $1980 \mathrm{~s}$. This is well below the extinction depth for phreatic evaporation. It is also much lower than the bottom levels of river and canal beds. Therefore, surface water-groundwater interaction is a one-way-street: Surface water can seep in, but groundwater cannot drain to the river or irrigation canals. Pumping from the deep aquifer is accounted 


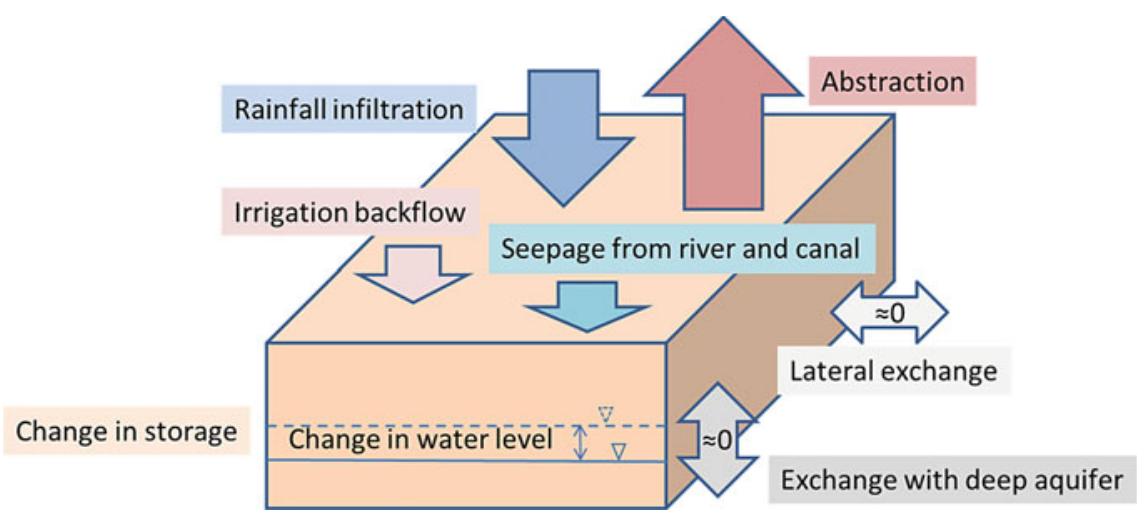

Fig. 4.27 Scheme of the water balance model of Guantao shallow aquifer

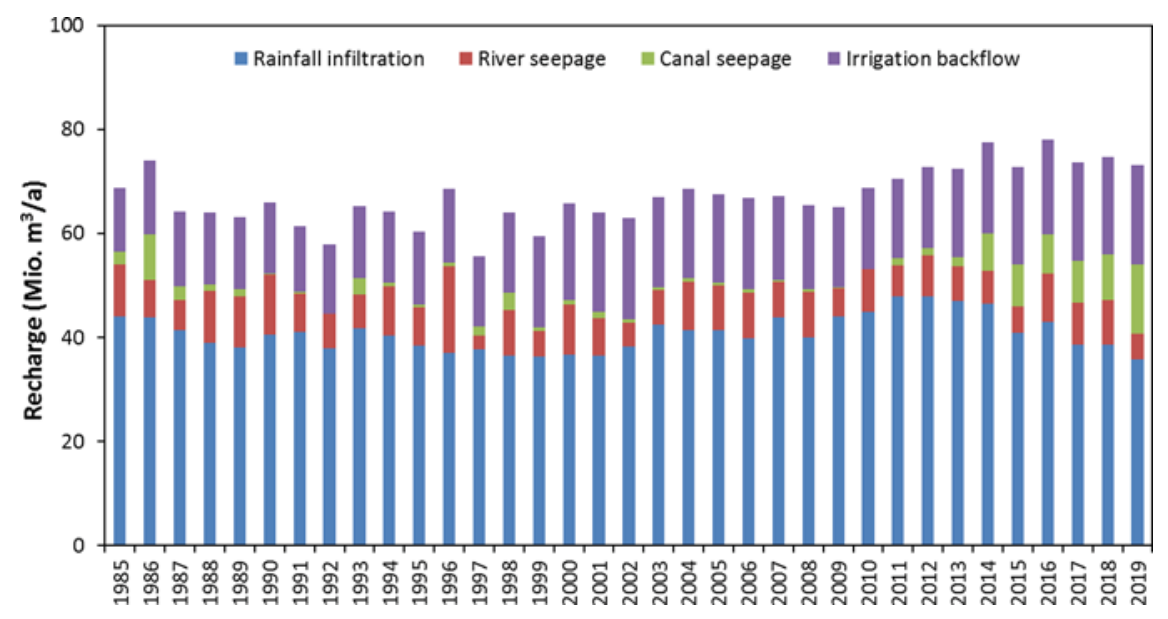

Fig. 4.28 Recharge components of the shallow aquifer in Guantao (in Mio. $\mathrm{m}^{3} /$ year)

for, regarding both domestic and irrigation use. The backflow of irrigation with deep groundwater contributes to the recharge of the shallow aquifer.

Groundwater abstraction for irrigation as the only discharge of the shallow aquifer also influences the recharge to this aquifer by irrigation backflow. Data errors in groundwater abstraction greatly affect the results of the water balance calculation. Therefore, a considerable effort was made to quantify abstraction using pumping electricity as a proxy. Electricity records also allow the reconstruction of groundwater abstractions in the past. The electricity records that were used to reconstruct the total annual groundwater abstraction in Guantao County since 1984 include: 1) Single 
wells' electricity consumption from 2017-2019,2) total electricity consumption for agriculture in Guantao from 2007 to 2016, and 3) rural electricity consumption in Guantao dating back to 1984, extracted from Guantao Statistical Year Books (SYB).

Power supply for agriculture is separated from that for other purposes, such as domestic and industrial use. Therefore, it should represent the electricity consumption for irrigation. However, considerable electricity consumption for other agricultural use, such as livestock and crop processing, was also included in the records of electricity consumption for agriculture. Before any conversion of electricity consumed to water volume pumped, it is important to exclude the non-pumping electricity consumption to avoid overestimation of groundwater abstraction. From total electricity consumption for agriculture, pumping electricity can be extracted by excluding the electricity consumption in non-irrigation months. From rural electricity consumption, pumping electricity can be derived under the assumption that the annual economy-related electricity consumption (for domestic and industrial use) increases smoothly with GDP while the inter-annual variability of rural electricity consumption reflects the inter-annual variability of pumping electricity due to the variation of precipitation from year to year.

Groundwater levels have declined drastically since the 1980s due to pumping for irrigation, which implies that the electric energy used to pump a unit of water has increased accordingly. Thus, the electricity-to-water conversion factor in the past has to take into account the smaller depth to groundwater. Water abstracted from both deep and shallow aquifers is used for irrigation, but the energy used to pump a unit of water from the deep aquifer is about twice the amount needed to pump a unit from the shallow aquifer. Thus, electricity consumption for pumping from the shallow aquifer has to be separated from that of the deep aquifer. However, before 2017 only the sum of both was recorded. To solve this problem, a parameter $c$, which denotes the ratio between the amounts of irrigation water abstracted from the deep aquifer and from the shallow aquifer, is introduced. It can be estimated from the irrigation areas of shallow wells and deep wells, under the assumption that the water use per unit area does not differ between fields supplied by shallow and deep wells respectively. More details concerning the box model can be found in Appendix A-3.

\section{Water balance of Guantao shallow aquifer}

The water balance of the shallow aquifer is determined by recharge and discharge. Rainfall infiltration is the main source of groundwater recharge followed by irrigation backflow (Fig. 4.28). The seepage from the canals was minor compared to other recharge components but has become comparable with the seepage from the river since 2014 due to the increase in imported surface water. 


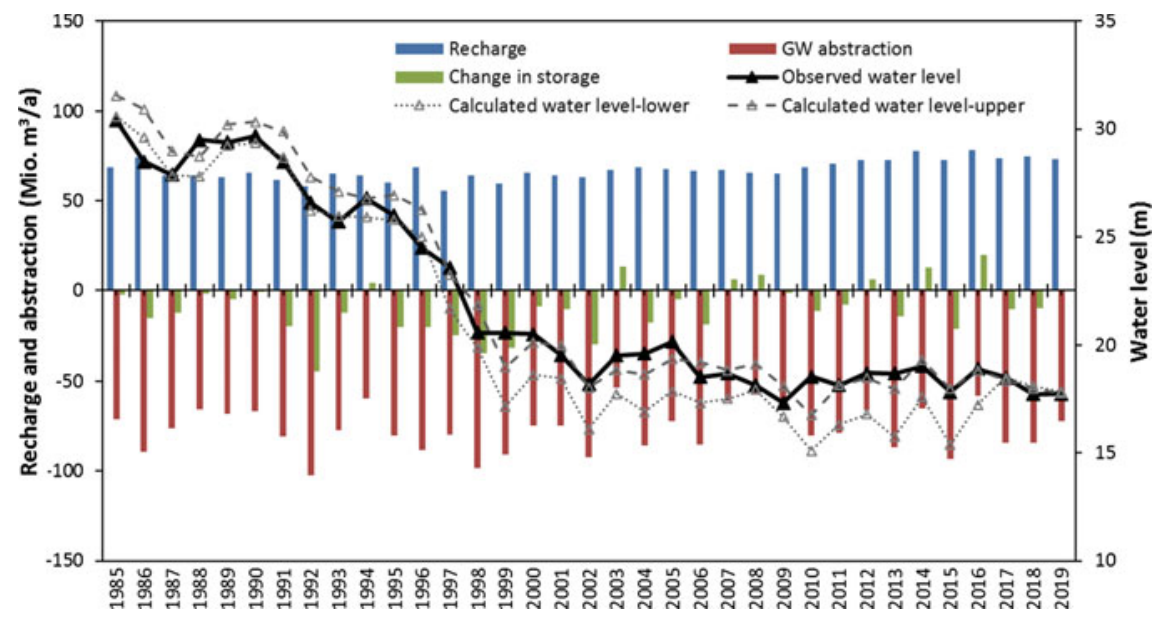

Fig. 4.29 Observed and calculated water levels and annual water balance components in Guantao County (in Mio. $\mathrm{m}^{3} /$ year)

The calculated and observed water levels (averaged over the county) and the corresponding changes of storage in the shallow aquifer from 1985 to 2019 are shown in Fig. 4.29. Since only total pumping electricity was available before 2017, an uncertainty band of calculated water levels is presented to take into account the uncertainty of the parameter $c$. The range of $c$ was set from 0.0 to 0.3 . The annual variability of the calculated water levels generally agrees with the observations. The upper uncertainty band of the calculated water level $(c=0.3)$ basically coincides with the observations since around 2000, while the lower band $(c=0)$ is closer to the observations back in the 1980s and 1990s. This implies an increase in the fraction of deep groundwater use in recent years. It can also be partly attributed to an underestimation in converted pumping energy before the 1990s, when there were still some diesel pumps in use in irrigation. In the water balance calculations presented below $\mathrm{c}=0$ was used from 1985 to $1996, \mathrm{c}=0.3$ was used from 1997 to 2016 and for the last years electricity use in irrigation was provided separately for shallow and deep aquifers. 
Figure 4.29 indicates three periods of depletion of the shallow aquifer, a large water table decline rate between 1984 and 1999, a smaller one in the pre-project period from 2000 to 2013 and a still smaller one between 2014 and 2019. The corresponding depletion rates of the shallow aquifer are $15 \mathrm{Mio} . \mathrm{m}^{3} /$ year, $6 \mathrm{Mio} . \mathrm{m}^{3} /$ year and $1 \mathrm{Mio}$. $\mathrm{m}^{3} /$ year, respectively. The total gap between discharge and recharge including the deep aquifer is shown in more detail for the periods 2000-2013 and 2014-2019 in Fig. 4.30.

The components of recharge and discharge of the shallow aquifer for the two periods are shown in more detail in Fig. 4.31. In contrast to the relatively wet period between 2000 and 2013, three out of six years between 2014 and 2019 were dry years with annual rainfall less than $450 \mathrm{~mm}$. This led to an increase in the abstraction from the shallow aquifer by $3 \%$. However, the use of deep groundwater decreased by $35 \%$, mainly due to replacement by imported surface water and fallowing. The increase in surface water use led to a drastic increase in canal seepage and partly contributed to the increase of irrigation backflow. Thus, the total recharge increased by $11 \%$ despite the decrease in rainfall infiltration.

The development of aquifer depletion in both shallow and deep aquifers for the two periods is shown in Fig. 4.32. The total gap could almost be halved during the project period (2014-2019) compared to the pre-project period (2000-2013). The shallow aquifer's recharge-discharge gap is down to $1.3 \mathrm{Mio} . \mathrm{m}^{3} /$ year from 6.4 Mio. $\mathrm{m}^{3} /$ year. The deep aquifer's gap is still $18.5 \mathrm{Mio}^{3} \mathrm{~m}^{3} /$ year but compared to the pre-project period it has been reduced by about 14 Mio. $\mathrm{m}^{3} /$ year due to project measures. If one takes the balance for the year 2019 only, the improvement is even more impressive. The total gap remaining in the deep aquifer is $11.2 \mathrm{Mio.} \mathrm{m}^{3} /$ year, while the shallow aquifer water level even rose, equivalent to a storage increase of 0.9 Mio. $\mathrm{m}^{3}$. A single year is, however, not as significant for comparison as a period of several years due to the variability of meteorological conditions. 


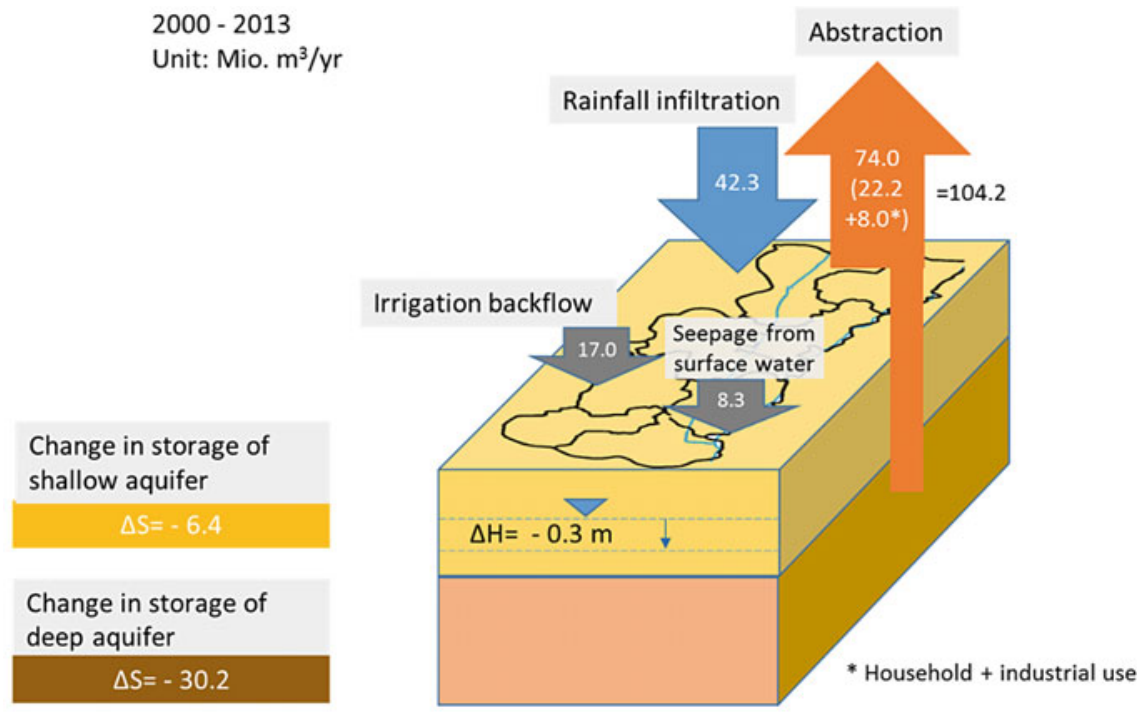

2014 - 2019

Unit: Mio. $\mathrm{m}^{3} / \mathrm{yr}$

Change in storage of shallow aquifer

$\Delta S=-1.3$

\section{Change in storage of} deep aquifer

\section{$\Delta \mathrm{S}=-18.5$}

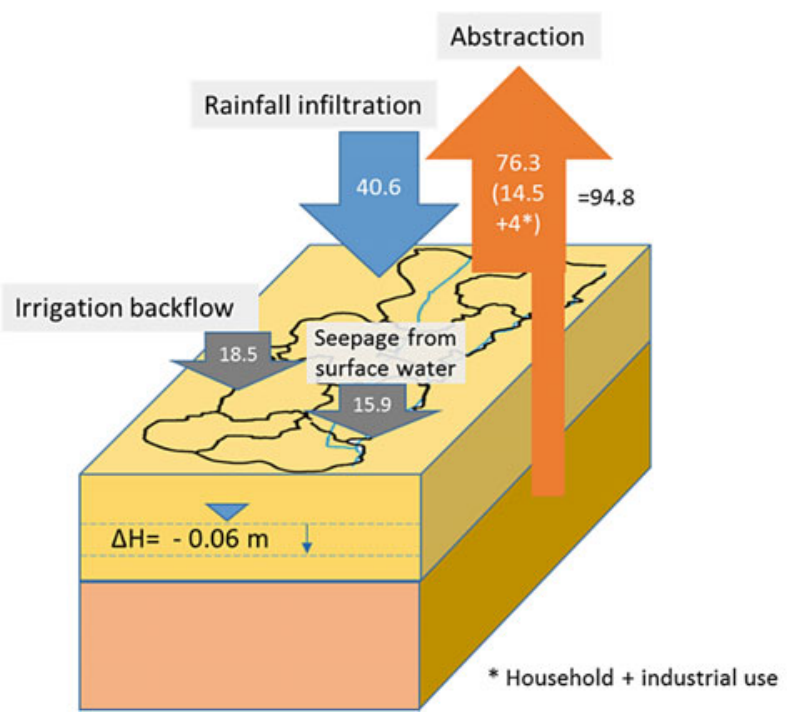

Fig. 4.30 Sketches of water balance of Guantao County 2000-2013 and 2014-2019 (in Mio. $\mathrm{m}^{3} /$ year) 


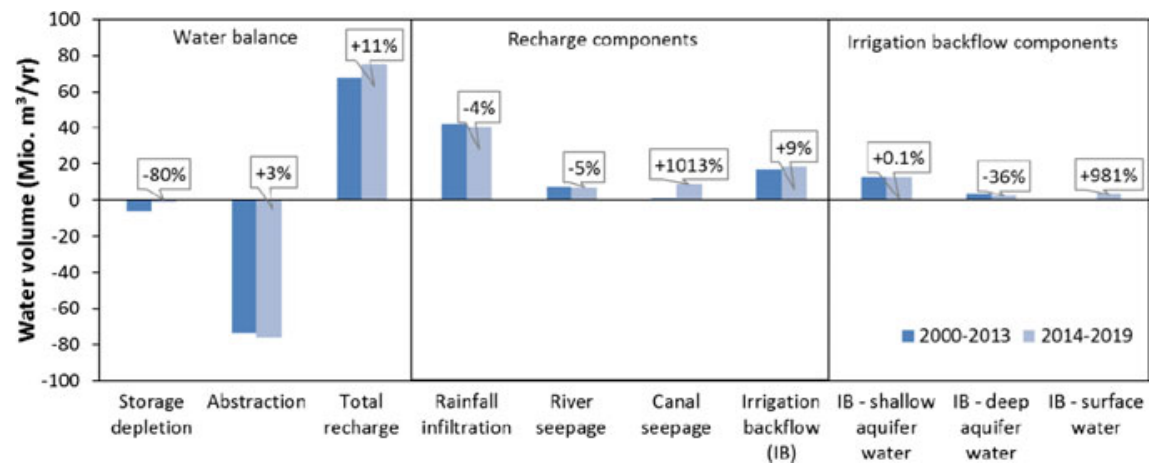

Fig. 4.31 Components of the shallow aquifer's water balance, 2000-2013 (dark blue) and 20142019 (light blue). Positive values for recharge (into the aquifer), negative values for discharge (out of the aquifer) (in Mio. $\mathrm{m}^{3} /$ year)

Fig. 4.32 Guantao's aquifer depletion of different periods with contributions by irrigation and water supply for households and industry (in Mio. $\mathrm{m}^{3} / \mathrm{year}$ )

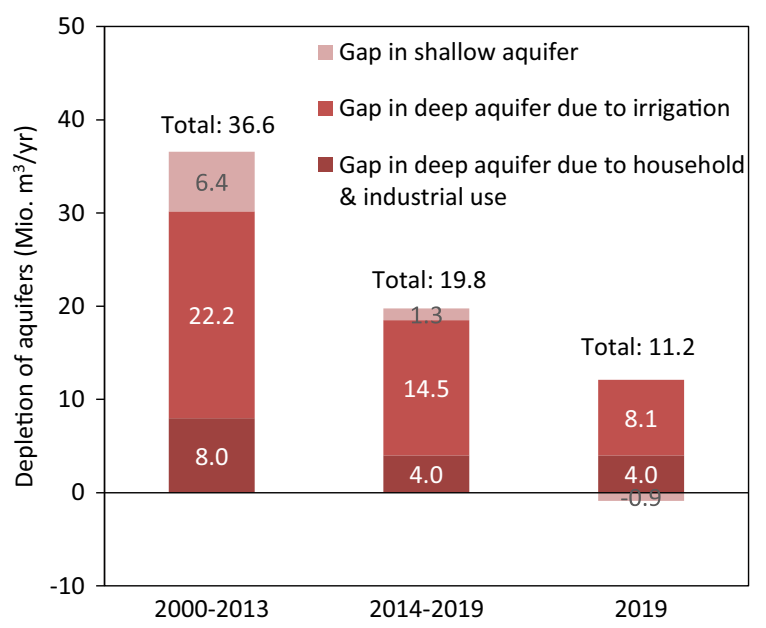




\section{Transfer of the box model approach to other counties in the North China Plain}

The box model can be used not only in Guantao but also in other areas with similar hydrogeological conditions. These conditions are:

- the net lateral flux of the aquifer is negligible compared to vertical fluxes (recharge, pumping).

- Exchange with the deep aquifer is negligible.

- Depth to shallow groundwater table is sufficiently large to exclude phreatic ET and exfiltration to surface water bodies.

- Groundwater is extracted by electric-motored pumps and is the main source of irrigation water.

Basically, the whole of Heilonggang plain shown in the map fulfills these conditions. 8 counties of Handan prefecture served as a test (see insert in figure on the right). Data in Handan Reports of Water Resources were used as well as electricity data from Hebei and Handan statistical yearbooks.

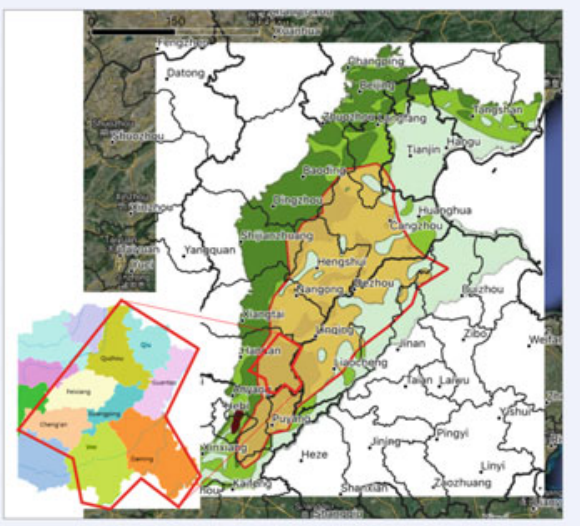
Electricity data had to be corrected to remove non-irrigation use. Performance of the box model is acceptable in five out of eight counties Guantao, Guangping, Feixiang, Daming, and Cheng'an, where the inter-annual variability of water levels was captured most of the years. The poor performance of the box model in other counties is mainly attributable to the use of rural electricity instead of the actual pumping electricity. The reconstruction of pumping electricity for total rural electricity consumption is inaccurate due to the increasing fraction of non-pumping electricity consumption (for domestic and industrial use) in total rural electricity consumption. The performance of the box model will improve when pumping electricity is available for a more accurate estimation of groundwater abstraction, preferably separated into shallow and deep aquifer pumping.
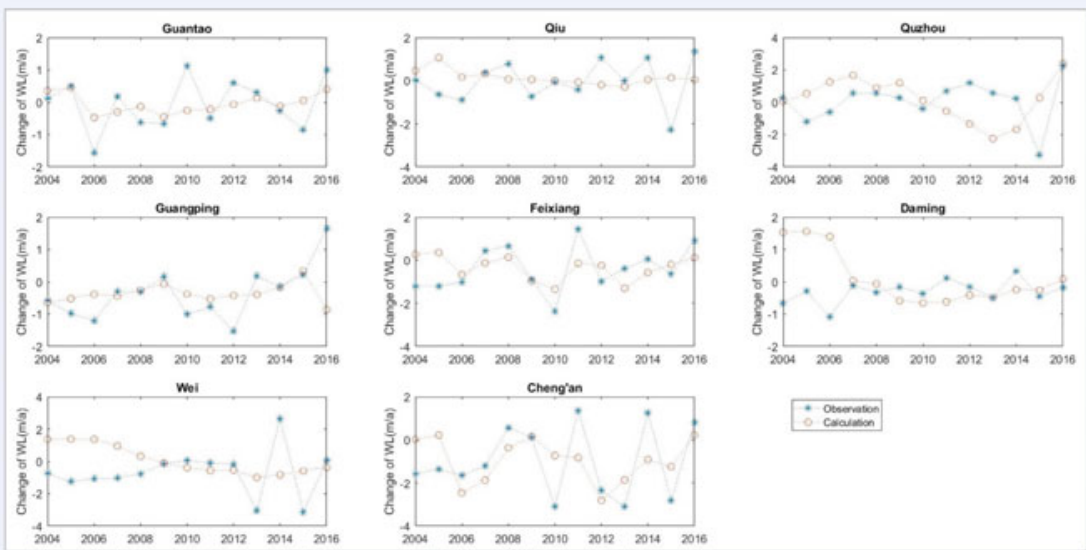

Box 4.1: Upscaling of box model approach to Heilonggang low plain region in the North China Plain

\subsubsection{Distributed Groundwater Model for Guantao}

A numerical groundwater flow model facilitates the understanding a local hydrogeological system. It serves as a basis for decision making by allowing to evaluate 
and compare outcomes of different water allocation scenarios in a spatially resolved manner. As explained in the previous chapter, we focus mainly on the shallow aquifer. Therefore, a 2D groundwater model of the shallow aquifer in Guantao is developed using a structured grid discretization.

\section{Model development}

The groundwater model of Guantao is based on USGS Modflow (Harbaugh et al. 2000) under the GUI Processing Modflow (PMWIN) (Chiang and Kinzelbach 2000). The county area is discretized into 210 rows and 190 columns with a grid size of $200 \mathrm{~m}$ $\times 200 \mathrm{~m}$. The top and bottom of the aquifer are determined by the digital elevation map and interpolated borehole logs, respectively. The model parameters including hydraulic conductivity, specific yield and recharge ratio are determined by data from hydrogeological maps, soil maps, and pumping tests. The model boundary condition is a specified head boundary determined by interpolation of the observed groundwater levels in the observation wells on the boundary. The main sources of groundwater recharge in Guantao are precipitation and irrigation. The recharge is assumed to be a constant fraction of the sum of the two fluxes. Groundwater pumping is the main sink term in the numerical model. It is calculated by converting the pumping electricity consumption of each village by a conversion factor (see Sect. 4.2.2). The Weiyun River on the east boundary infiltrates groundwater as well. Its infiltration is not described explicitly in the numerical model, but implicitly contained in the specified head boundary condition along the river, which is influenced by the river's infiltration.

The numerical model is running in transient mode for the period between March 2018 and December 2019 in monthly time steps. The initial condition of the transient model is interpolated from the measurement data recorded in February 2018, using the Kriging method. After transferring source/sink terms to each model grid, uncertain model parameters are adjusted to minimize the residuals between the observed and computed head values. More details about the model set-up can be found in Appendix A-4.

\section{Model results}

The calibrated hydraulic conductivities are shown in Fig. 4.33. The value decreases in south-north direction. There is a relatively impermeable zone between HK1 and HK3 with a value of $3.3 \mathrm{~m} /$ day. Like the hydraulic conductivity, the calibrated specific yield decreases from south to north (Fig. 4.34). The specific yield influences both the amplitudes of head time series over the year and the general trend over the longer term. The calibrated recharge ratios are shown in Fig. 4.35. The values tend to decrease from east to west, which is consistent with the local hydrological observations.

The correlation coefficients among different calibrated parameters are presented in Table 4.2. Correlation coefficients with a modulus above 0.6 indicate that there is a non-negligible correlation among the respective parameters. The highest correlation coefficient between two zonal parameters is 0.6 (between HK1 and SY1). This implies non-uniqueness of the two parameter values. An increased HK1 with a 
Fig. 4.33 Distribution of hydraulic conductivity (in $\mathrm{m} /$ day)

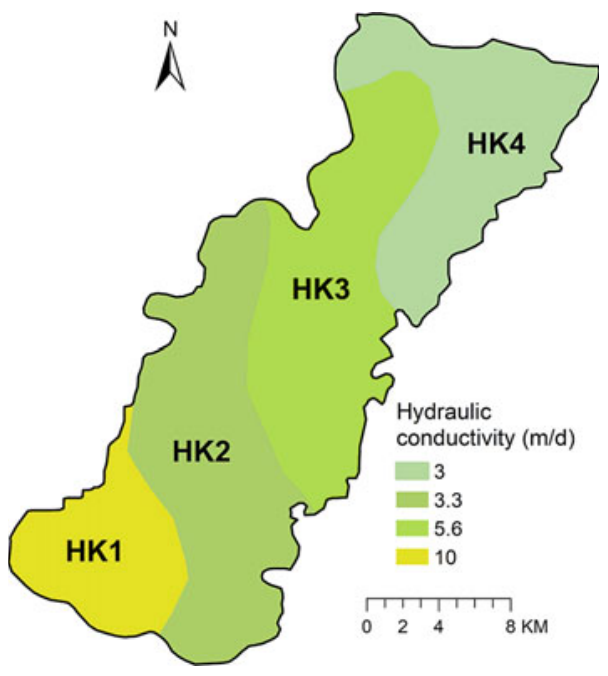

Fig. 4.34 Distribution of specific yield

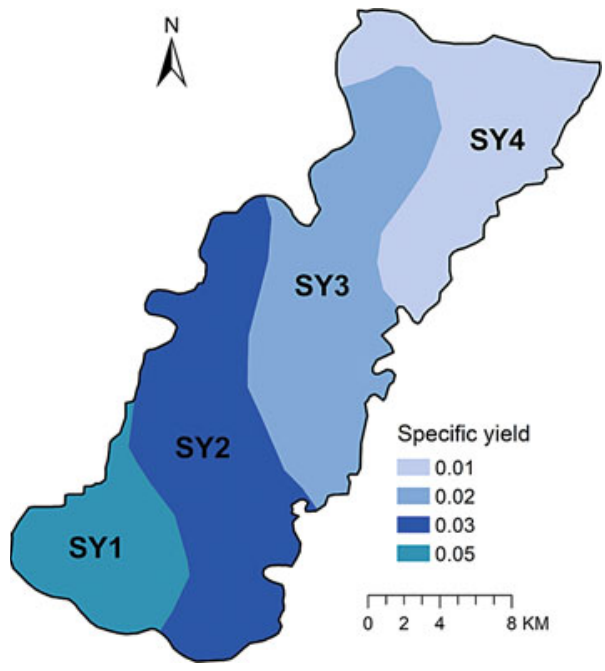

simultaneously increased SY1 will lead to a similar model result. The smaller correlation coefficients show that all other hydraulic conductivities and specific yields are relatively independent, and their relative values can be uniquely determined by calibration.

The groundwater balance of the transient model is presented in Fig. 4.36. The total groundwater recharge is about $0.22 \mathrm{Mio} . \mathrm{m}^{3} /$ day, which contains an average recharge from irrigation backflow and precipitation of around $0.16 \mathrm{Mio} . \mathrm{m}^{3} / \mathrm{day}$ (73\% of the total groundwater recharge). The infiltration from precipitation and irrigation fluctuates gently due to the delay and damping effect of the unsaturated 
Fig. 4.35 Distribution of recharge ratio

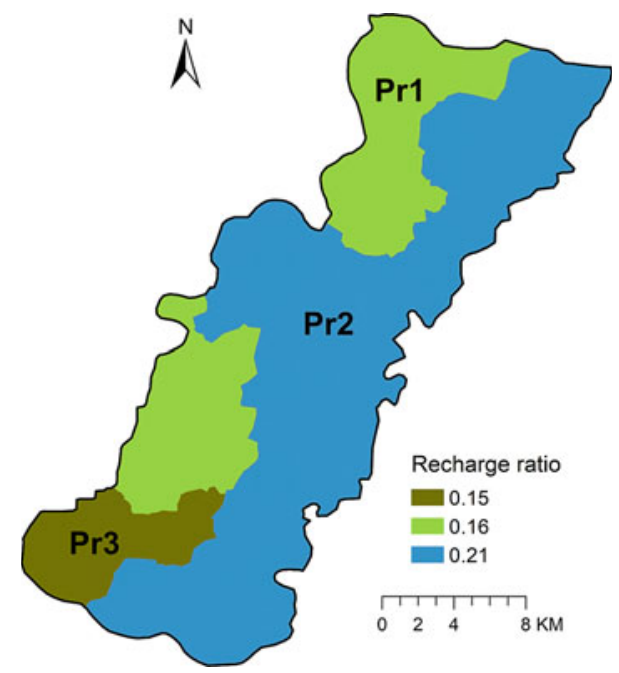

Table 4.2 The correlation coefficients among different calibrated parameters

\begin{tabular}{l|l|l|l|l|l|l|r|c}
\hline & HK1 & HK2 & HK3 & HK4 & SY1 & SY2 & \multicolumn{1}{l}{ SY3 } & SY4 \\
\hline HK1 & 1.00 & 0.03 & 0.00 & 0.00 & 0.60 & -0.04 & 0.00 & 0.00 \\
\hline HK2 & & 1.00 & 0.03 & 0.01 & 0.03 & -0.15 & -0.02 & 0.02 \\
\hline HK3 & & & 1.00 & 0.00 & 0.00 & -0.02 & 0.01 & 0.16 \\
\hline HK4 & & & & 1.00 & 0.00 & -0.01 & -0.06 & -0.39 \\
\hline SY1 & & & & & 1.00 & -0.11 & 0.00 & 0.00 \\
\hline SY2 & & & & & & 1.00 & -0.02 & 0.00 \\
\hline SY3 & & & & & & & 1.00 & -0.39 \\
\hline SY4 & & & & & & & & 1.00 \\
\hline
\end{tabular}

zone. The boundary inflow and the main canals' infiltration are not shown in the figure because they account for a small part of the total groundwater recharge (only $11 \%$ and $16 \%$ respectively). The pumping rate fluctuates strongly. It follows the temporal behavior of precipitation, which directly (and without delay) influences the amount of groundwater pumping used for irrigation. The average pumping rate is about 0.2 Mio. $\mathrm{m}^{3} /$ day.

The aquifer storage increases when groundwater recharge exceeds groundwater withdrawals and is depleted when the groundwater withdrawals exceed groundwater recharge. The groundwater storage starts to deplete in March and recovers after August. The average storage depletion is about $0.025 \mathrm{Mio} . \mathrm{m}^{3} / \mathrm{day}$ or $9 \mathrm{Mio} . \mathrm{m}^{3} /$ year. The depletion in 2019 is large as 2019 was a very dry year. Over-pumping is defined as the longer-term average depletion, which is clearly smaller. To a certain degree groundwater levels inside Guantao are influenced by the larger surroundings via the boundary heads. This influence from the outside can be separated from the influence 


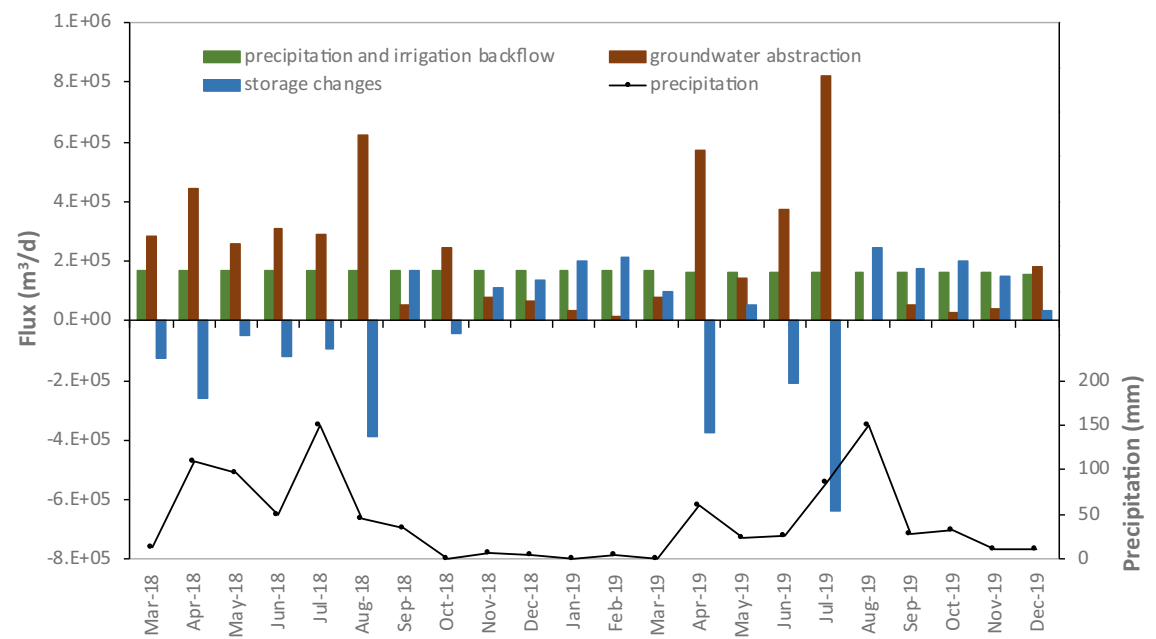

Fig. 4.36 Water budget of 2D groundwater model (in $\mathrm{m}^{3} /$ day)

by pumping in Guantao itself. Li et al. (2019) show that on average inside and outside contribute about equally to groundwater level changes.

The comparison of modelled and observed groundwater heads over time is shown in Fig. 4.37. Some piezometers underestimate and others overestimate observations. The seasonal pattern of groundwater level dynamics, however, is reproduced in most observation wells. The groundwater levels start to decrease from March due to irrigation and reach their lowest values in July/August. From July/August on, groundwater levels start to recover and increase as pumping ceases and recharge from precipitation and irrigation backflow dominate. Some observation wells (wells 901s, 907sd, o801) close to the boundary fail to capture the dynamics of groundwater levels because they are controlled by the specified values of observations on the boundary, which did not show any strong dynamics. As recharge from precipitation and irrigation backflow varies gently in time, the intra-annual groundwater level dynamics are mainly caused by pumping of groundwater from the shallow aquifer. Since the shape of the irrigation area of each village is not known exactly, it is defined by constructing Thiessen polygons around the village centers. It is quite possible that in this process, an observation well falls into the wrong village in the model, and thus captures different groundwater level dynamics. Besides, some observation wells are not strictly used for observation only. They are pumping wells which are monitored only once or twice per month when the pump is switched off. Therefore, it is inevitable that data monitored just before or right after an irrigation event show larger dynamics than they should. 

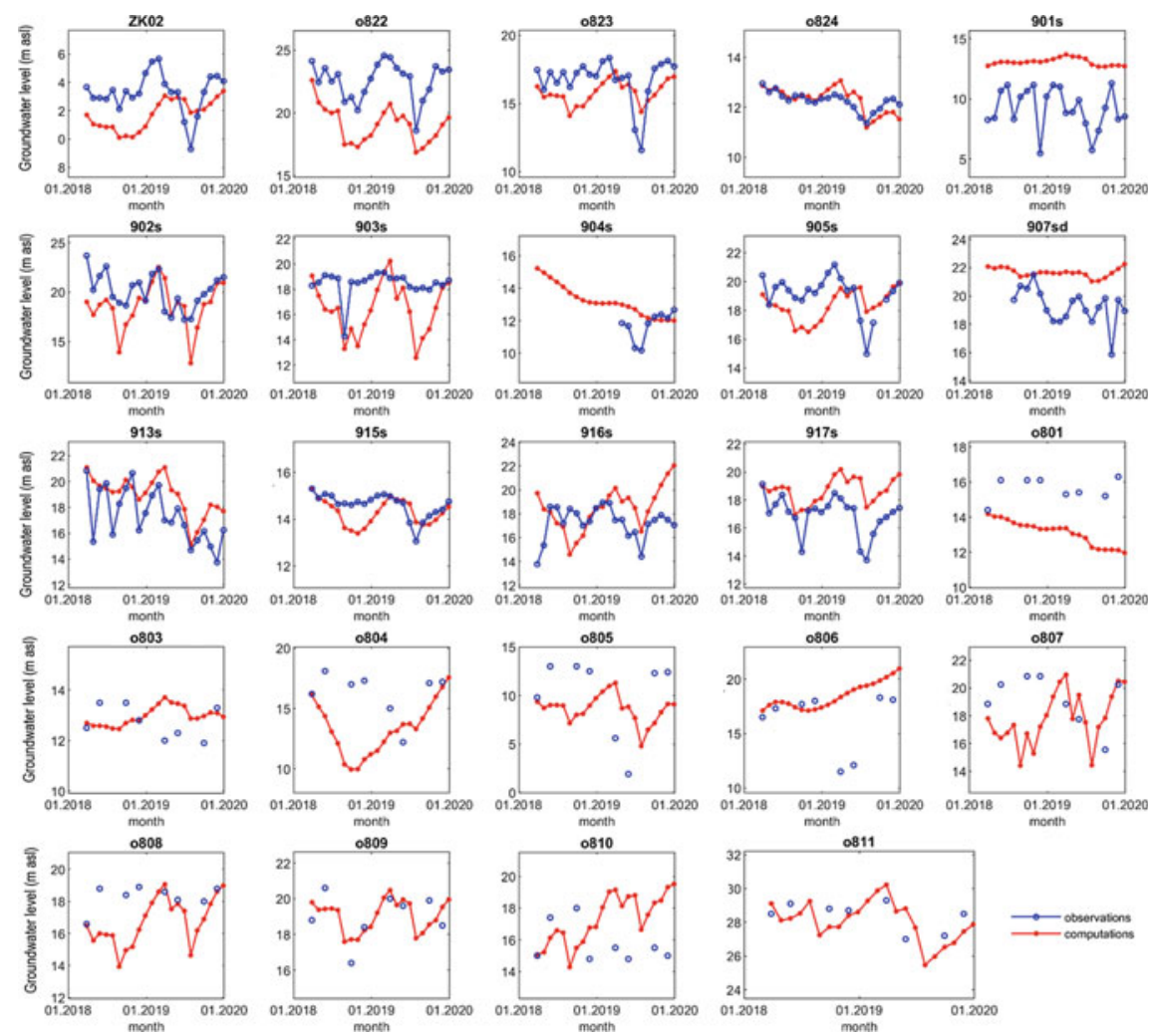

Fig. 4.37 Comparison of calculated and observed monthly time series of groundwater heads at different observation wells

\subsubsection{Real-Time Groundwater Model}

Real-time groundwater modelling, also known as data assimilation, is a dynamic model updating procedure incorporating all data monitored in real time such as groundwater levels, surface water diversions, groundwater pumping, etc. as they become available. It uses an ensemble technique (Ensemble Kalman Filter or EnKF) to update model parameters and states considering the uncertainties in parameters/states/inputs. The model also allows to make a forecast, which is continuously improved on the basis of new observations.

\section{Uncertainty quantification}

The model parameters updated in the real time model include the 4 zonal hydraulic conductivities, 4 zonal specific yields and 3 zonal recharge infiltration ratios shown previously. The parameters are assumed to follow log-normal distributions with a standard deviation of 0.5 . The measurement error is assumed to follow a standard normal distribution with a standard deviation of $1 \mathrm{~m}$. The pumping rate is assumed 
to have a normal error distribution with a standard deviation of $20 \%$ of the mean value.

\section{Procedure}

The principle of the updating process includes: (1) generating fifty replicates for each model parameter/state/input from the assumed distributions; (2) running the numerical model 50 times with different combinations of parameters and inputs; (3) updating model parameters and states by assimilating observations available at this time step using EnKF; (4) inserting the updated parameters/inputs into the numerical model for a model forward run in the next time step; (5) repeating steps $2-4$ until the end of the assimilation period. The procedure is applied to the $2 \mathrm{D}$ model of the shallow aquifer of Guantao. There are 22 monthly assimilation time steps. A damping factor (Hendricks Franssen and Kinzelbach 2008) is introduced in the EnKF to correct spurious model updates and forecasts of the error covariance. Without damping, the procedure converges before having collected enough experience regarding uncertainty and cannot follow larger head changes (Li et al. 2021a). More details concerning the real-time model are provided in Appendix A-5.

\section{Results}

Figures 4.38 and 4.39 represent the results from applying the EnKF method to update parameters and states. The uncertainty of parameters and states decreases with time due to the assimilation of observation data. The dynamics of the ensembles follow the observed groundwater level change very well. However, the ensemble in the northern well cannot completely capture the real observation values during the winter months. This indicates that there is still some bias between the numerical outputs and real observations, which cannot be explained by the presently assumed model uncertainties. The spatial distributions of groundwater level means and standard deviations are shown in Fig. 4.40. Groundwater depression cones have formed in Guantao, which have a dominant influence on the groundwater flow direction. The
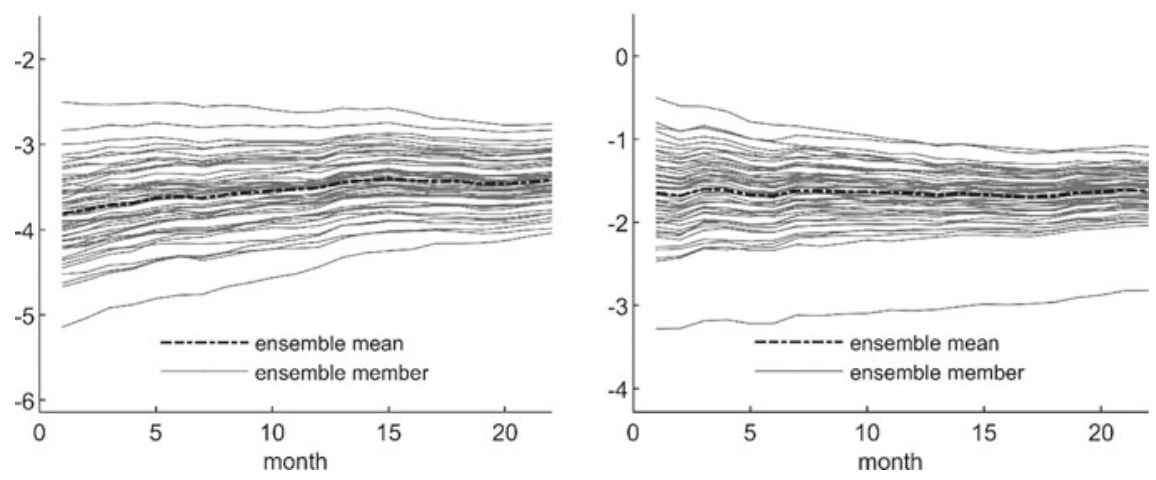

Fig. 4.38 Evolution of typical parameters' probability distribution (log value) (Left: $\log (\mathrm{SY} 3)$, right: $\log (\operatorname{Pr} 2))$ 

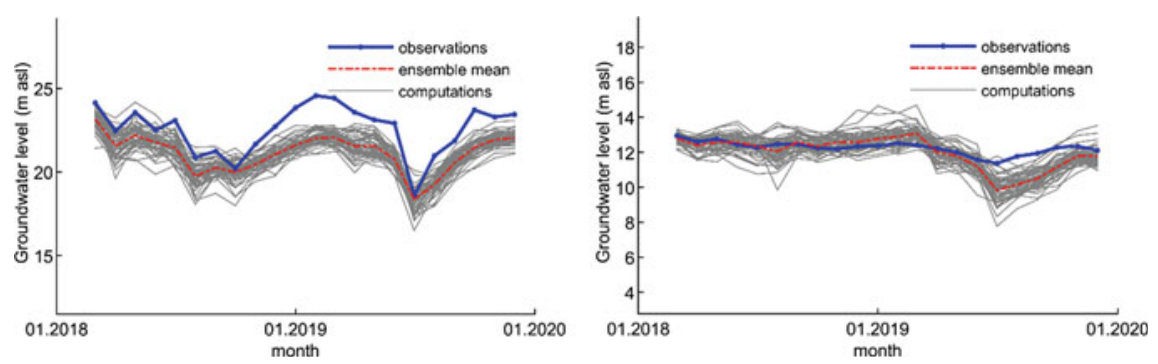

Fig. 4.39 Typical ensemble trajectory (Left: observation well in the north; right: observation well in the south)
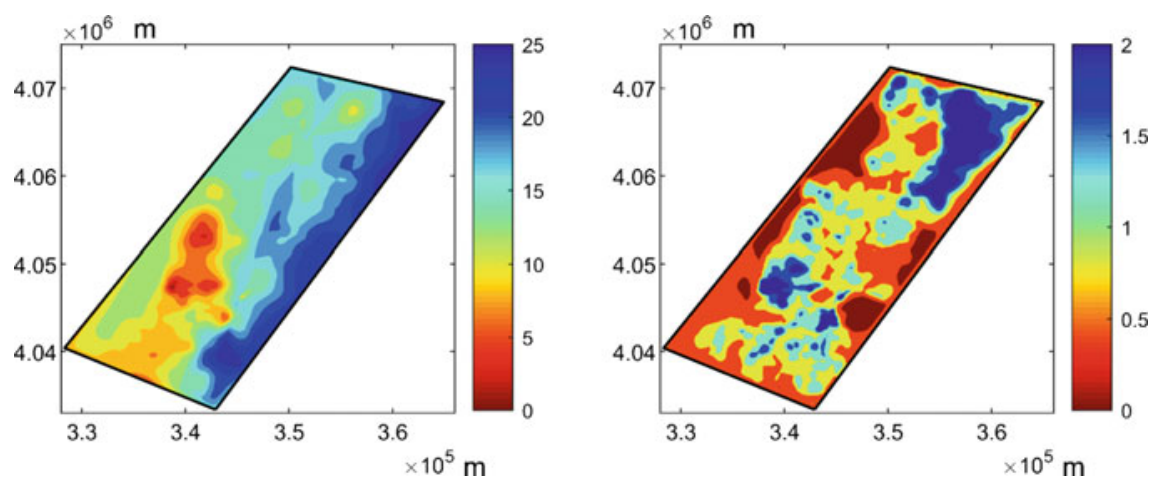

Fig. 4.40 Groundwater contour maps of July, 2019, for ensemble mean (left) and standard deviation (right)

areas with relatively larger standard deviation indicate larger uncertainty. This is due to fewer or no observations in these areas (see observation location map Fig. 4.4 in Sect. 4.2.1). It is obvious that new observation wells have to be installed to reduce uncertainty, especially in the Northeast corner of Guantao.

\section{Conclusions}

The model results show that the assimilation of data in a model has two advantages over traditional modeling: First, it allows a sequential improvement of model parameters with incoming data. Second, it gives results for states and parameters together with a quantitative estimate of their error. The estimate of the error of groundwater heads shows how good the model is in predicting states in the following time step. The real time model has been developed and tested with past observations. In the application, the prediction for the next month is of major interest. The prediction interval can be increased, however at the cost of accuracy. In a predictive mode, the model can be used in operational decision-making, e.g. management decisions before determining winter crop planting in autumn. Irrespective of all parameter uncertainty and prediction uncertainty, the real time model with data assimilation presents the 
best possible use of all information. The map of the ensemble average heads after assimilation is the best head contour map one can obtain. This map is imported into the decision support system as basis for planning. It serves as initial conditions for scenario calculations and in its form of map of distance to groundwater (which is obtained by subtracting the head map from the digital terrain map) one can see where corrections in pumping in Guantao County are needed most urgently.

\subsubsection{Data Driven Groundwater Model}

Traditionally groundwater level forecasts are computed with either box models or numerical models. They require various types of data concerning model structure, model parameters and other model inputs as explained before. Recently, with the development of automatic monitoring, head data sets of higher frequency and greater length are available in real time. Therefore, instead of using complex, physically based models with a large number of model inputs and model parameters, more and more researchers explore the use of data driven models in predicting groundwater levels using a more limited number of data items but with much longer time series of each. Besides the predictions, a quantification of their uncertainty is provided. For more details refer to Appendix A-6.

\section{Data}

Data driven modelling builds a functional relationship between given pairs of input and target output datasets (i.e., samples). Based on the derived relationship, forecasts can then be made for new input data. In this study, the Support Vector Regression (SVR) (Basak et al. 2007) method is used for the prediction of groundwater levels in Guantao County. The data used in Guantao for groundwater level forecasts include monthly groundwater level data, monthly rainfall data, monthly surface water diversion data and monthly agricultural electricity consumption data without correction for non-pumping electricity.

\section{Model development}

We develop data driven models for each of 3 observation wells and their average, which represents the whole of Guantao. The time series data sets are divided into three subsets: training data set from 2007 to 2015, validation data set in 2016 and test data set from 2017 to 2018. The input variables are wavelet decomposed into sub series (Fig. 4.41). The time lags regarding the relevant input variables are preliminarily determined according to a hydrological analysis. The groundwater levels were time lagged by 12 months and the time lag of other input variables varied from 1 to 12 months. Thus, there are 37 input variables in total before wavelet-decomposition.

In the study we use both non-wavelet decomposed input variables and their wavelet decomposed components as potential model inputs to select the best features (Quilty et al. 2019). During input feature selection, only the top features, providing more 

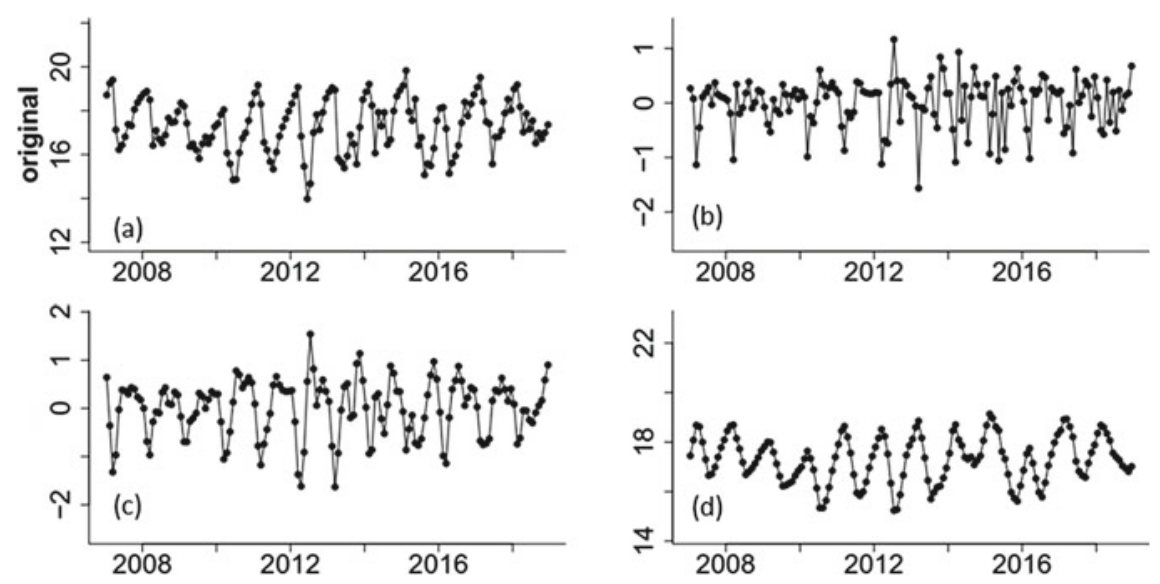

Fig. 4.41 Original groundwater level time series and the corresponding decomposed sub-time series ( (a) is the original time serieis, (b) is the high-frequency sub-time series at the first decomposition level; (c) is the high-frequency sub-time series at the second decomposition level; (d) is the low frequency sub-time series at the second decomposition level)

information to the forecasts than the rest of the features, are retained for the development of the models. We use 100 bootstrap resamples to quantify the uncertainty in the input variable selection and in the model parameters. The groundwater levels are predicted for lead times of 1 month, 3 months and 6 months, respectively.

Results

- Groundwater level prediction of the whole of Guantao

After training SVR models, the groundwater levels are forecasted for 1, 3 and 6 months ahead using the test data. The quality of forecasts at the different lead times is quantified for different SVR models for the three lead times 1, 3 and 6 months. Note that the optimized numbers of input features for the three lead times are 4, 5 and 5 respectively. The groundwater level predictions for the average groundwater level over the whole county are provided in Fig. 4.42.

The root mean square error (RMSE) and the Nash-Sutcliffe efficiency coefficient (NSE) are applied to quantify the model error. The results show that the ensemble mean fits observations well even though some forecasts over- or underestimate the observations. The 1-month lead time predictions have the lowest prediction error and provide the best fit. It is not surprising that the model performance degrades for predictions with larger lead times. Going from lead time of 1 month to lead time of 6 months, the RMSE of the groundwater head predictions averaged over Guantao County increases from $0.6 \mathrm{~m}$ to $0.78 \mathrm{~m}$. The NSE decreases from 0.6 to 0.32 .

- Groundwater level predictions for each single well

Table 4.3 shows the model evaluation metrics of groundwater forecasts for the average of the 3 wells (representing the whole of Guantao) and for each observation 


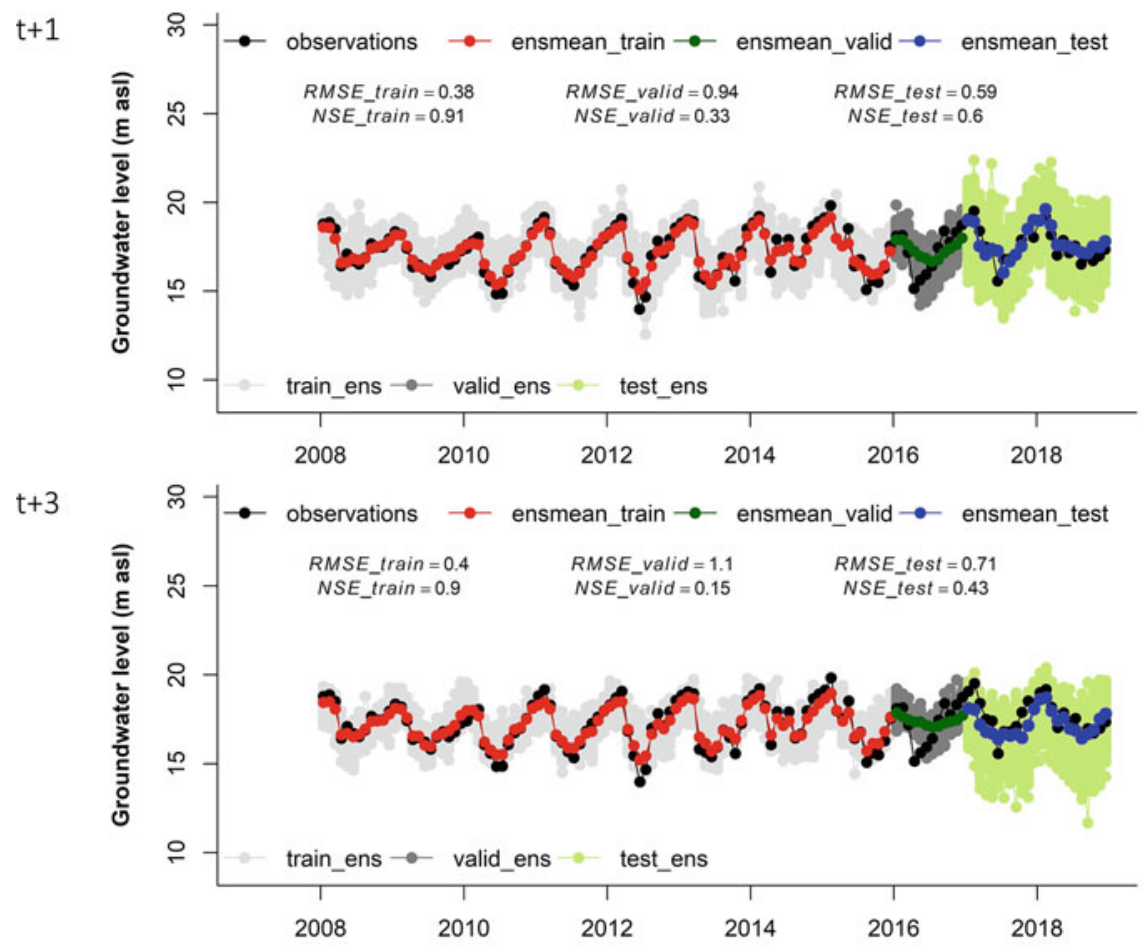

$t+6$

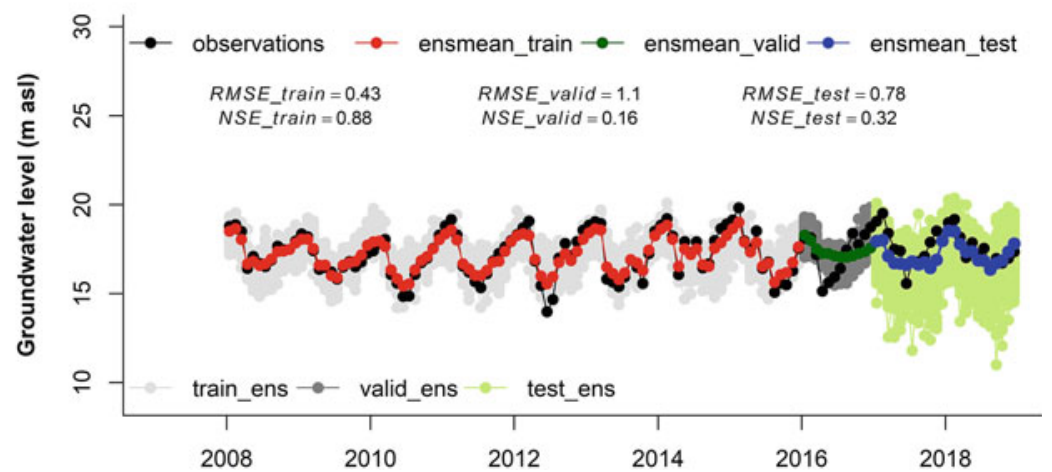

Fig. 4.42 Groundwater level prediction at different lead times $(t+1, t+3$ and $t+6)$. The gray, black and green shadows show the ensembles of groundwater levels calculated for the training period, the validation period and the test period, respectively

well separately (well $\mathrm{N}$ in the north, well $\mathrm{M}$ in the middle and well $\mathrm{S}$ in the south of the county) at 1, 3 and 6 months lead times, respectively. The stochastic groundwater level predictions for each single observation well lead to similar conclusions. As in the case of the county average, the 1-month lead time predictions at each single well yield a lower prediction error and better fit than the predictions for larger lead 
Table 4.3 Model performance for groundwater level predictions at lead times of 1,3, and 6 months in the test period

\begin{tabular}{l|l|c|c|c}
\hline Locations & Index & $\mathrm{t}+1$ & $\mathrm{t}+3$ & $\mathrm{t}+6$ \\
\hline Whole of Guantao & RMSE $(\mathrm{m})$ & 0.59 & 0.71 & 0.78 \\
\hline well N & NSE & 0.60 & 0.43 & 0.32 \\
\hline & RMSE (m) & 2.14 & 3.48 & 3.75 \\
\hline well M & NSE & -0.95 & -1.75 & -4.99 \\
\hline & RMSE (m) & 0.74 & 0.97 & 1.09 \\
\hline well S & NSE & 0.63 & 0.37 & 0.2 \\
\hline & RMSE (m) & 0.62 & 0.83 & 0.89 \\
\hline & NSE & 0.07 & -0.76 & -1.04 \\
\hline
\end{tabular}

times. The prediction for each single observation well underperforms compared to the results for the whole of Guantao (having higher RMSE and lower NSE).

The prediction error decreases from north to south at all lead times. The RMSE decreases from $2.14 \mathrm{~m}$ in well $\mathrm{N}$ to $0.62 \mathrm{~m}$ in well $\mathrm{S}$ at 1 month lead time, from $3.48 \mathrm{~m}$ to $0.83 \mathrm{~m}$ at 3 months lead time and from $3.75 \mathrm{~m}$ to $0.89 \mathrm{~m}$ for 6 months lead time. The model at well $\mathrm{M}$ has the highest NSE of all three wells, implying that the forecast's mean fits observations quite well at well $\mathrm{M}$. The lower accuracy of model predictions for each single well may arise from the fact that the groundwater level in the single well may not be representative for the local area where the other, area-averaged inputs are collected (e.g. precipitation). Besides, the groundwater level in the single well may also be influenced by lateral fluxes over county boundaries, which are not considered as inputs here.

\section{Discussions and conclusions}

A data driven model using a machine learning algorithm is a general way to forecast groundwater levels. Practically, there are also other conventional alternatives to forecast groundwater levels, such as long-term average (S1), long term average plus the average dynamics in a year (S2), simply using the data of the previous month as predictor (S3), and the ensemble mean from the data driven model (S4). Here we take the forecasts at 1 month lead time as an example. The results are shown in Fig. 4.43. The long-term average scenario cannot reproduce annual dynamics (or patterns). S2 considers the annual patterns averaged over the past, and therefore can make a better forecast when the real pattern fits the historical dynamics (e.g. in 2017 but not in 2018). S3 produces better results than $S 1$ and $S 2$ due to the inertia of groundwater level change. But S4 still performs slightly better than S3. The scenario S4 produces the smallest root mean square error (RMSE) of groundwater levels with a value of $0.6 \mathrm{~m}$. The RMSEs for $\mathrm{S} 1, \mathrm{~S} 2$ and $\mathrm{S} 3$ are $1 \mathrm{~m}, 0.88 \mathrm{~m}$, and $0.8 \mathrm{~m}$ respectively.

In conclusion, the data driven model using a machine learning algorithm is recommended in practical applications. Future improvements include the use of longer time series and the use of agricultural electricity consumption data corrected for nonpumping use. This section demonstrates that one can easily implement data driven 


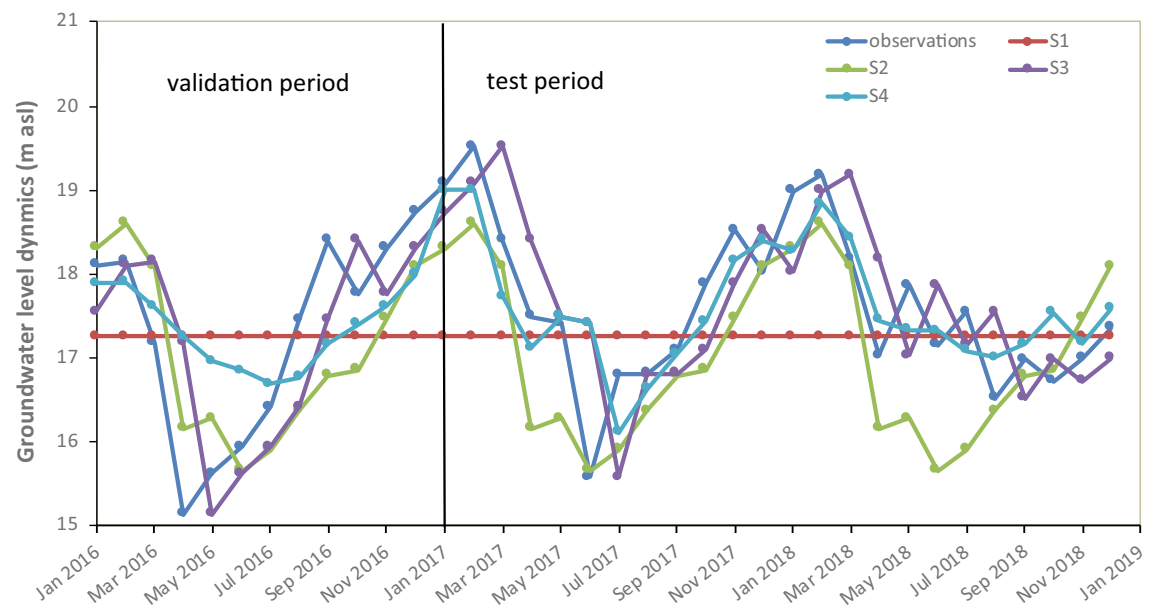

Fig. 4.43 Groundwater level predictions of different scenarios

models to forecast groundwater levels. The method can be applied to any area in the NCP, provided sufficiently long data sets are available. It should however be noted that a model trained with data from the past cannot predict behavior due to events, which never happened within the available time series such as an extreme rainfall, the sudden allocation of large amounts of surface water, or a severe change of the pumping regime due to policy change.

\subsection{An Integrated Decision Support System (DSS)}

\subsubsection{Motivation}

During the project implementation, a number of technical products were developed, including various groundwater models, a crop water demand model, algorithms for land use identification and, most importantly, a database for storing all information collected so far. Those tools have shown to be very useful in the analysis of the overpumping issue in Guantao, and in exploring various mitigation strategies. However, each tool was developed as a separate software resulting from each team member's own research task. But soon it became clear that the lack of coupling between the modules did not correspond to their interconnectedness in real life and thus limited the efficiency of their use. Therefore, in the second phase of the project, one main task was the seamless integration of those tools into a unified framework to assist groundwater management in Guantao. This naturally led to the idea of implementing a decision support system (DSS). 
Decision support systems (DSSs) refer to computer aided programs that help decision makers to solve unstructured or semi-structured problems using data and models (Morton 1971). They are widely used in different fields nowadays. Among them, environmental decision support systems (EDSS) specialize in tackling environmental problems and have attracted a growing attention from researchers, e.g. (Matthies et al. 2005; Hadded et al. 2013; McDonald et al. 2019; Whateley et al. 2015; Shao et al. 2017). The popularity of EDSS, on one hand, is due to the increasing difficulties in solving environmental problems, which are often entangled with human society, turning them into complex coupled human-nature systems (Liu et al. 2007). The complexity is further amplified by global change which imposes extra uncertainties concerning the future state of the world (Pachauri et al. 2014; Walker et al. 2013; Milly et al. 2008). On the other hand, the improvement of computer and monitoring technologies have enabled researchers to produce/access vast amounts of information and to develop more advanced analytic tools. However, those trends not only increase the potential of EDSS, but also demand modern EDSS implementation to be more democratic, user-friendly, and flexible (Mir and Quadri 2009; Hewitt and Macleod 2017; Loucks 1995; Zulkafli et al. 2017). The democratisation implies the participation of stakeholders in data collection, development of EDSS as well as their final operation. The user-friendliness aims at lowering of technical barriers so that policy makers lacking specific knowledge can still themselves apply those analytic tools for their decision making. The flexibility requires EDSS to be able to include new information/functionalities with ease but also to allow integration with legacy models, which were built with state-of-the-art science but not designed for the Internet context (Kumar et al. 2015). Web-based applications have become a popular solution that overcomes many of the challenges such as accessibility: Users can easily visit applications on their computers or smart devices (Swain et al. 2015). The benefit can be further leveraged via cloud computing to remove computation limits, and to provide on-demand load balancing in the face of high numbers of simultaneous users.

In this project, we implement such a web based DSS, named Guantao Decision Support System (GTDSS), using modern information and communication technology (ICT). The GTDSS aims to achieve two goals in particular, as shown below:

(1) Monitoring: Informing decision makers about states of the system based on observation data and model estimates, where the states include groundwater level, cropping area, water use and hydro-climatic conditions, etc.

(2) Planning: Designing management strategies according to sustainability criteria and the target performance specified by decision makers.

The target users are officers from Guantao local water bureau, which is a small department. In addition, they have limited experience in using professional modelling tools, and poor access to ICT technical support-usually outsourced to 3rd party companies. To reduce the technical burden in using our system, the GTDSS is codesigned with stakeholders, implementing a user-friendly operability by adopting interactive visualization and adapting the model configuration to their needs. In 
addition, the GTDSS is based on open-source software and is launched as a web site hosted on a Chinese cloud provider, namely the AliCloud. Users can access the system via the links: https://www.ifu-gwm.com or http://www.giwp-gtdss.cn. The webpage serves as a graphical user-interface (i.e. front-end), which can be opened with any modern browser (Safari browser is currently not supported). On the web site, users can perform various operations, such as running models or query monitoring data. All operations initiated by end-users are handled by the server (i.e. back-end), on which the models and the database are installed. The tools and development workflow can also be applied to other cases for implementing environmental decision support systems (Li 2020).

\subsubsection{Key components}

GTDSS is composed of five key modules:

- Water quota planning

- Scenario analysis

- Irrigation Calculator

- Crop mapping, and

- Data portal

Each module is implemented as individual web page, which can be accessed from the navigation panel on the top (Fig. 4.44). In addition to that, the Home page

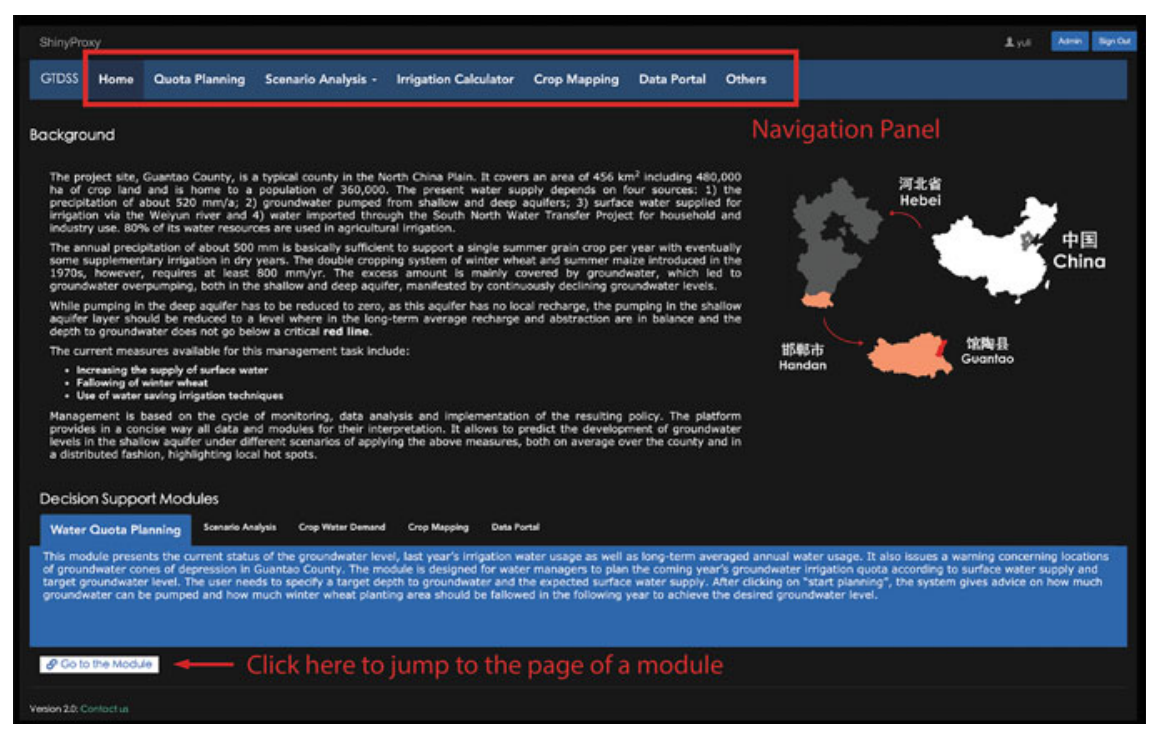

Fig. 4.44 Home page of Guantao Decision Support System (GTDSS) 
provides brief descriptions of the project as well as the functionalities of each module, while the Others page introduces miscellaneous resources such as the groundwater game, the project's and partners' websites, etc. The following sections will give a quick glance at each module and explain its duty. Readers can refer to the Technical Guidebook in Appendix A-8 for more information regarding the instructions of use and technical details.

\section{Quota planning}

This module allows users to plan shallow groundwater pumping and winter wheat fallowing for the next year according to a target depth to groundwater table and expected surface water supply, as input by users. The target depth can only be set within a feasible range defined by two "red lines", namely an upper and a lower bound, respectively. The upper bound mandates the groundwater level to be no higher than the extinction depth ( $5 \mathrm{~m}$ below ground level) to prevent soil salinization from phreatic evaporation. The lower threshold accounts for a minimal level to ensure that the reduced pump yield from a lowered groundwater level is not less than $70 \%$ of the originally designed pump yield, to which a reserve groundwater storage is added, sufficient for mitigating irrigation water shortage over a design drought of 4 years duration. In Guantao, these requirements lead to a lower red line at $30 \mathrm{~m}$ below ground surface. The user interface (UI) is shown in Fig. 4.45.

As output, the module informs the user about the amount of reduction in pumping volume eventually required. This implies a comparison of the calculated sustainable pumping volume with last year's pumping volume. If less shallow groundwater can be used, the quota planning module further suggests the area of winter wheat fallowing needed in order to achieve the required water saving.

The suitable time for quota planning is September, because: (1) the winter wheat planting hasn't started yet; (2) $90 \%$ of annual precipitation has fallen; and (3) the

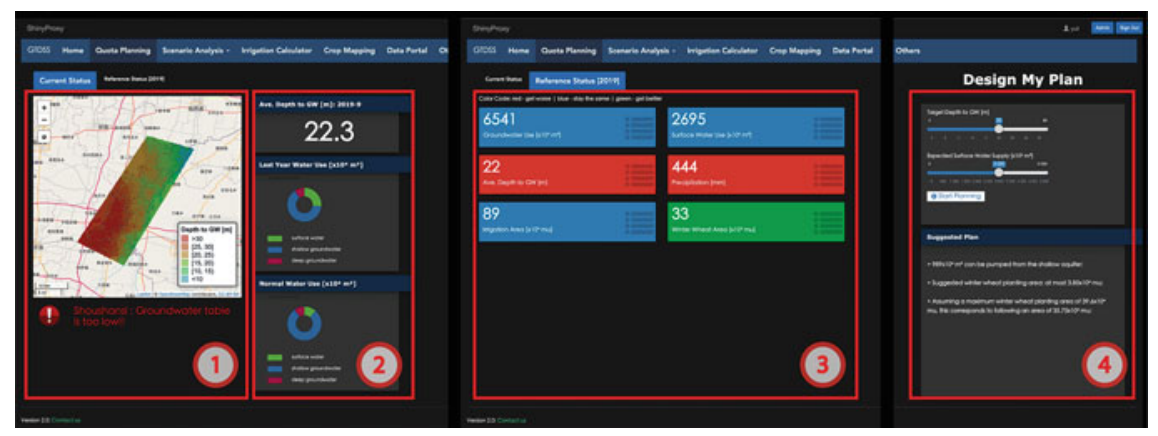

Fig. 4.45 The interface of Quota Planning module. Panels 1-3 inform users about key information on groundwater management drawn from observations. Specifically, panel 1 shows the estimated spatial distribution of depth to groundwater table, panel 2 the observed recent average depth to groundwater table over Guantao and the county's water use, and panel 3 measurements of other key variables. Panel 4 implements input options for quota planning and the output window for displaying results 
surface water supply is known. Under these conditions the uncertainty of model inputs is reduced, and decision makers have sufficient time to prepare the budget for the seasonal fallowing program.

\section{Scenario analysis}

This module implements two groundwater models, namely the box model (or 0$\mathrm{D}$ groundwater model) and the distributed numerical model (or 2-D groundwater model), which were described in Sects. 4.3.1 and 4.3.2.

The inputs for the 0-D groundwater model are the expected surface water supply and the expected pumping electricity use. The output is the predicted (county) average depth to groundwater for the next year. The box model UI is shown in Fig. 4.46.

The 2-D groundwater module allows more comprehensive input options, as shown in Fig. 4.47. For example, users can specify driving forces such as precipitation and surface water supply, "build" ponds for artificial aquifer recharge, and, most importantly, specify inputs for water allocation. In addition, users can define crop water demand and irrigation area for different crops, based on which the model automatically estimates total water use. To take advantage of the spatially distributed nature of the model, the total water use, land use settings and surface to groundwater irrigation ratio can be defined at township level. The output of this module is the prediction of head development over the next 10 years under the given scenario, assuming that conditions remain the same on average over the simulation horizon.

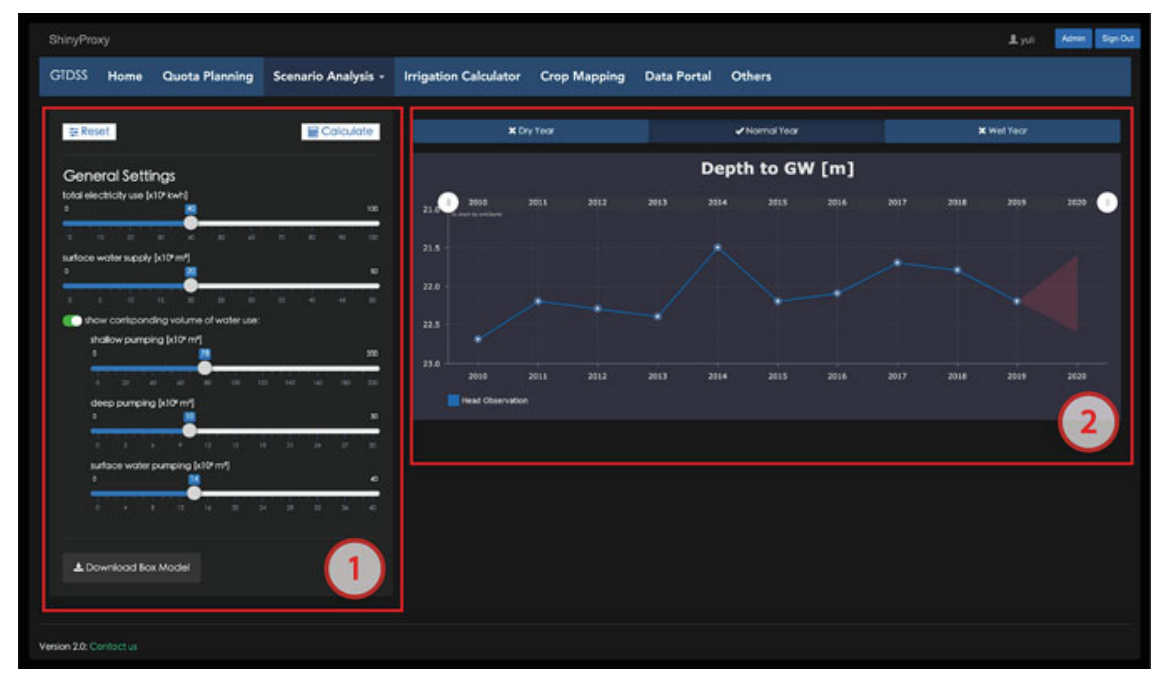

Fig. 4.46 UI of box modeling tool. Panel 1 is the input panel to define simulation scenarios, and panel 2 is the output of depth to groundwater table time-series, with uncertainty bounds for the forecast given in red 


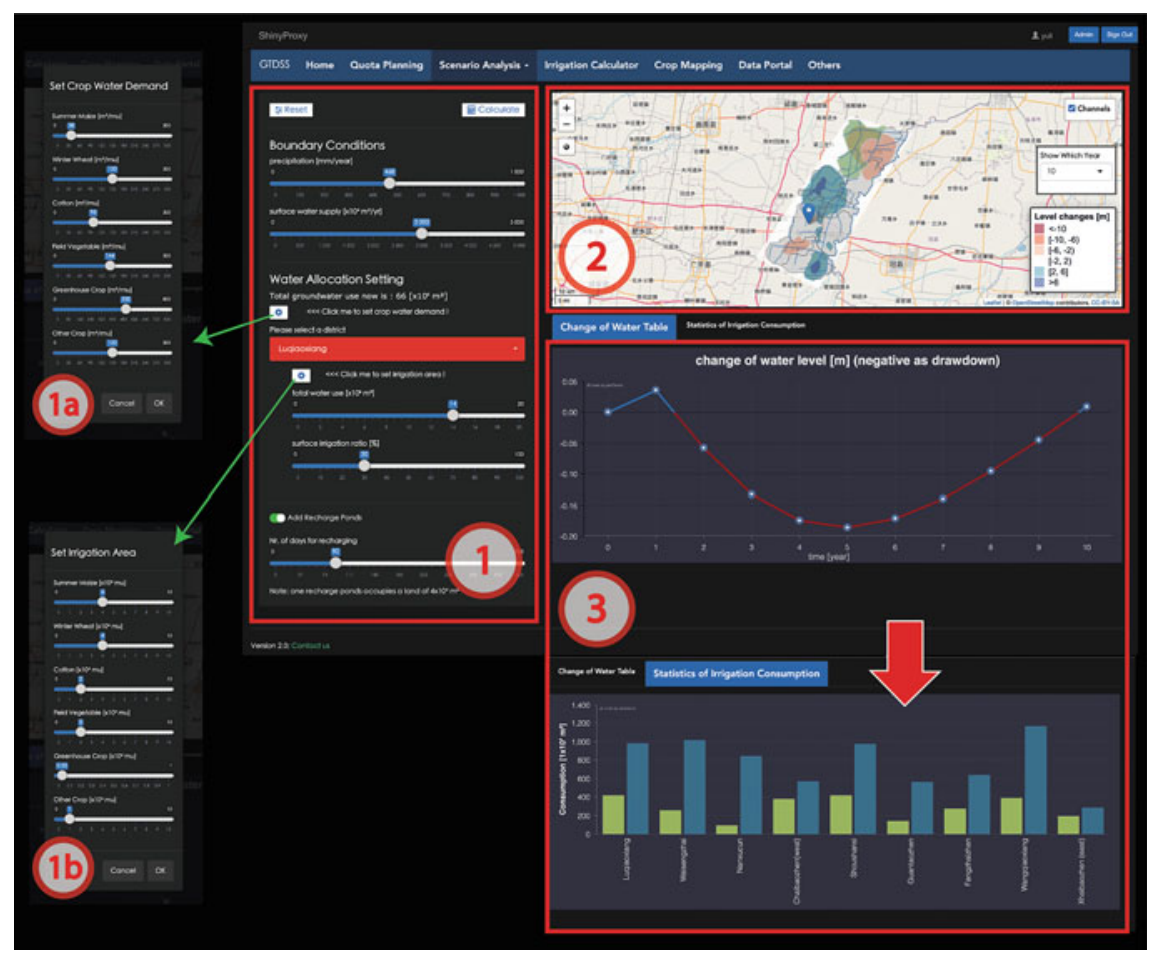

Fig. 4.47 Interface of the 2-D groundwater modelling tool. Panel 1 provides comprehensive input options to specify boundary conditions and the allocation settings on a township basis. For each township, users can also define landuse and crop water demand via panels $1 \mathrm{a}$ and $1 \mathrm{~b}$, respectively. Panel 2 is the output window for the spatial map of simulated groundwater level change. Panel 3 displays the time-series of level change at a selected location, as well as the water allocation results per township

\section{Irrigation calculator}

This module implements the core routine of the Irrigation Calculator App, which is an on-line software that simulates crop water demand under different climate and land conditions. Its capabilities are shown in Box 4.2 and Box 4.3 and described in detail in Appendix A-7. It can be accessed via the links https://app.hydrosolutions.ch/ IrrigationCalc-Guantao2/ or http://www.giwp-gtdss.cn/. As shown in the top panel of Fig. 4.48, the main inputs to the Irrigation Calculator are soil type, crop type and planting date, while the output is crop water demand, either at a monthly time step or aggregated into the annual total. The same model is also used in the 2-D groundwater model introduced in the previous section for providing reference crop water demand. 


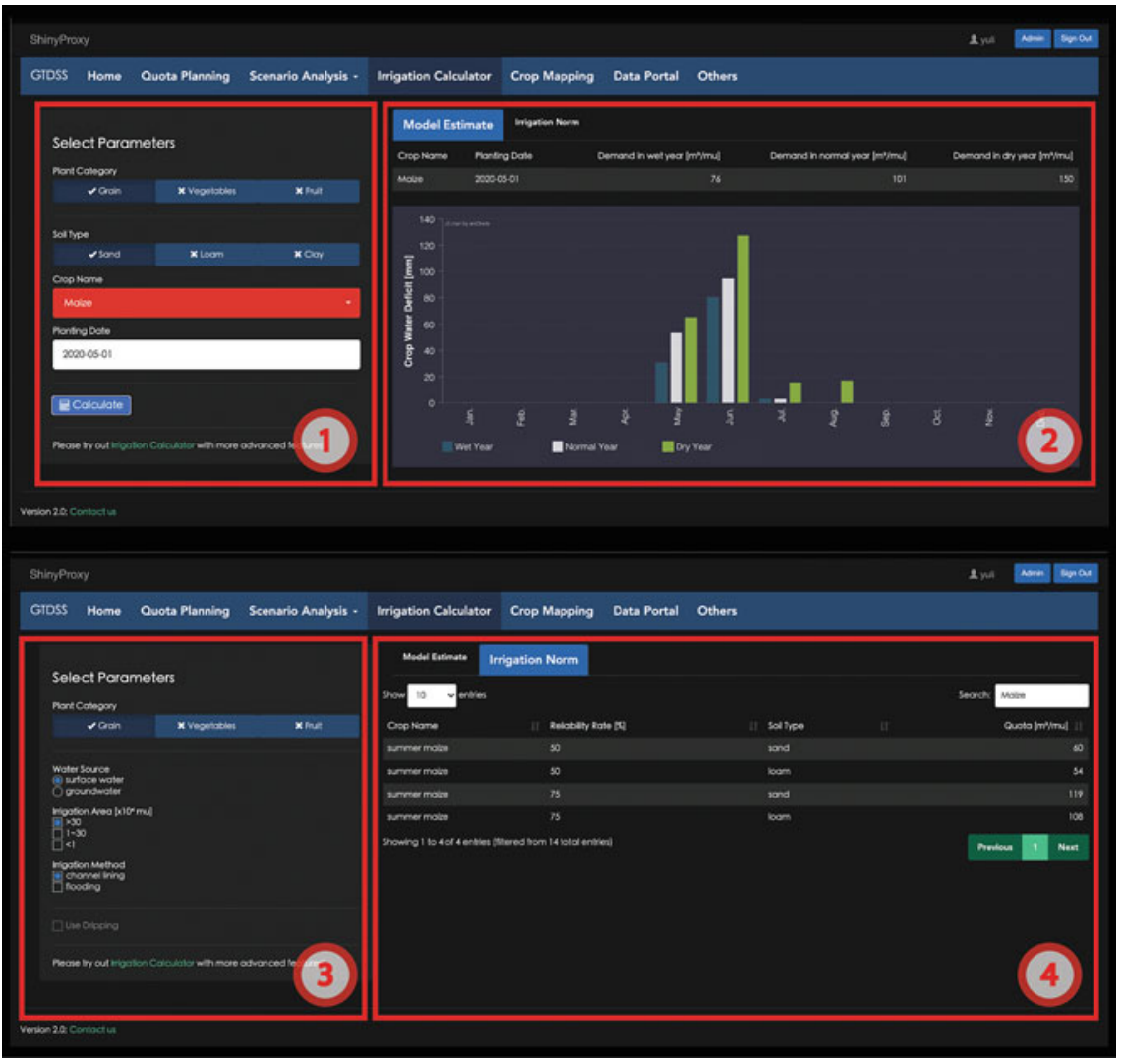

Fig. 4.48 Interface of the Irrigation Calculator module. The top panels are the UIs for estimating crop water demand based on the crop model, where panel 1 is the input window and panel 2 shows outputs. The bottom panels are the UIs for looking up official values defined in the irrigation norm issued by Hebei government. Users' query parameters are specified via panel 3, and the query results are shown in panel 4 


\section{Guantao Irrigation Calculator}

A tool for monthly irrigation water demand in Guantao County, Hebei, China

An important task of water managers around the world is

to deliver water for irrigation when it is needed.

Traditionally this is done by consulting irrigation norms that provide annual estimates of irrigation water demand depending on crop and soil types and on irrigation method and farm size. However, the distribution of the irrigation water throughout the growth season of the plant is often not included in the irrigation norms which makes the planning for timely water deliveries to the farms difficult. Within the frame of this project, a web application was developed, which allows the monthly planning of irrigation water demand: Guantao Irrigation Calculator.

\section{Procedure}

- Choose local average climate or define user specified climate

- Choose local crop types and enter planting dates

- Choose among local predominant soil types

- Choose typical local conveyances and application losses

Output

- Monthly irrigation demand

- Comparison with local irrigation norms

- Saving \& loading of irrigation planning tables

- Available in Chinese \& English

Monitoring of crop activity

- Archive of weekly enhanced vegetation index (EVI)

- Real-time computation of average EVI

- Real-time computation of time series of average EVI

- Comparison to time series of regional average EVI
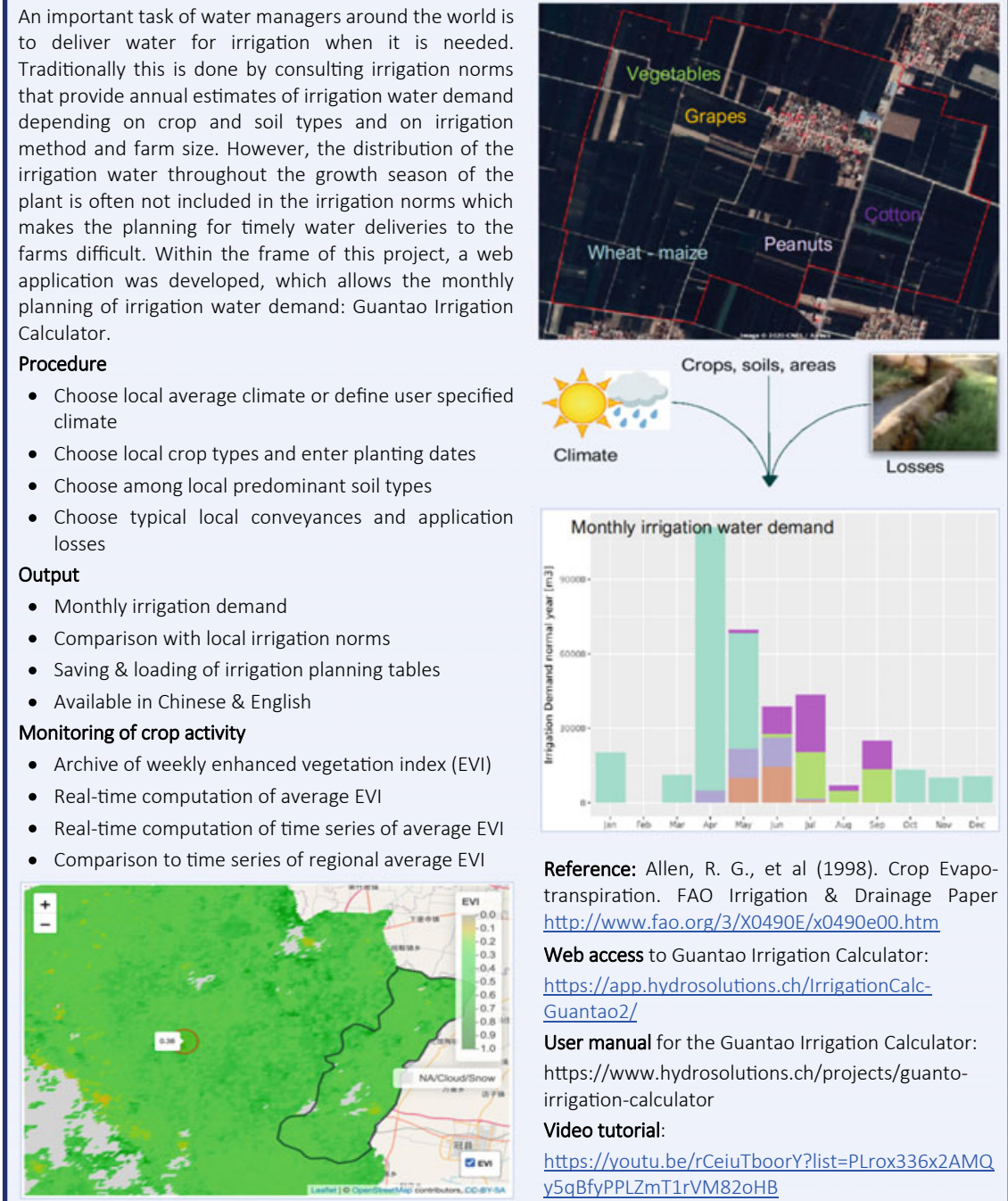

Reference: Allen, R. G., et al (1998). Crop Evapotranspiration. FAO Irrigation \& Drainage Paper http://www.fao.org/3/X0490E/x0490e00.htm

Web access to Guantao Irrigation Calculator: https://app.hydrosolutions.ch/IrrigationCalc-

\section{Guantao2/}

User manual for the Guantao Irrigation Calculator: https://www.hydrosolutions.ch/projects/guantoirrigation-calculator

Video tutorial:

https://youtu.be/rCeiuTboorY?list=PLrox336x2AMQ y5qBfyPPLZmT1rVM820HB

Box 4.2: The Guantao Irrigation Calculator (contributed by Beatrice Marti) 


\section{Heilonggang Irrigation Calculator}

An online tool of calculating monthly irrigation water demand in the Heilonggang low plains

The Guantao irrigation calculator has been modified for application in regions with similar characteristics concerning surface runoff and hydrogeology. These conditions are satisfied in the whole of Heilonggang low plains, which cover a sizable part of the over-pumped region in Hebei Province. Crop water demand is calculated on county level. Changes had to be made regarding the input of weather data, which show a clear South-North trend. 8 weather stations are available from which data can be interpolated for the respective county. Crop activity maps from remote sensing had to be extended to the larger region.

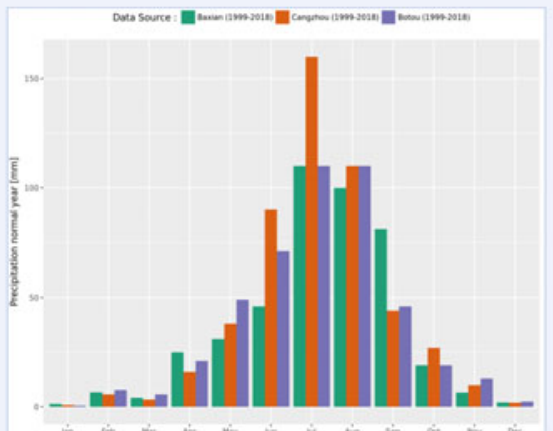

Monitoring crop activity in the entire North China Plain

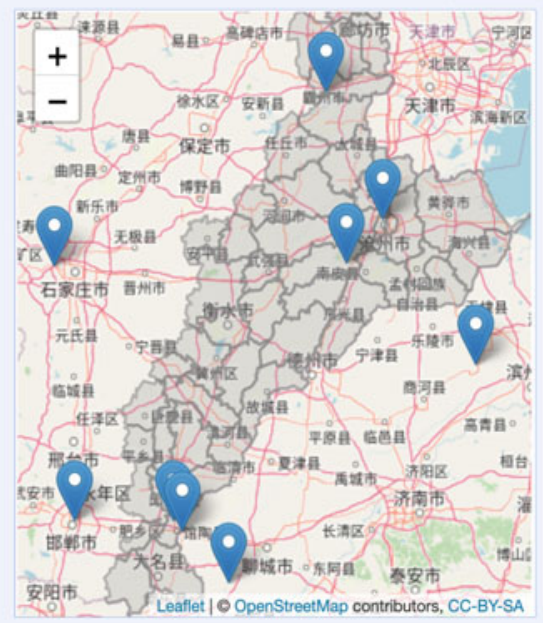

Resources

Access:

https://app.hydrosolutions.ch/irrigationCalc-NCP

Video tutorial:

https://youtu.be/rCeiuTboory?list=PLrox336x2AMQy 5qBfyPPLZmT1rVM82oHB

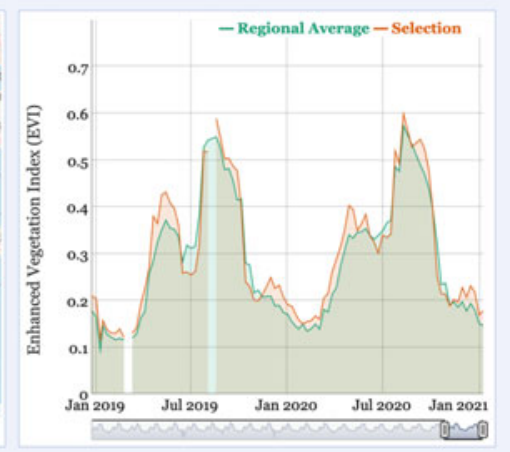

Box 4.3: The Heilonggang Irrigation Calculator (contributed by Beatrice Marti)

In addition, the module also includes an option for looking up the irrigation norm of a crop from the database, which digitizes the official document (DB13/T 1161.12009). It specifies the reference water quota for main crops in different regions of Hebei Province, and gives adjustment factors taking into account the type of water source, the size of irrigation area and the irrigation method. The interface is shown in the bottom panel of Fig. 4.48. 


\section{Crop mapper}

The original CropMapper is an online application that allows users to generate high resolution crop maps by running a state-of-the-art machine learning algorithm on the Google Earth Engine platform (https://hydrosolutions.users.earthengine.app/ view/cropmapper-ncp). For details see Appendix A-2. It utilizes publicly available remote sensing images as inputs. This module periodically retrieves the irrigation map outputs from the full-fledged CropMapper app and stores them into the database of GTDSS, which can then be used for monitoring the irrigation area for a specified crop type and year (see Fig. 4.49). The crop types include summer crop, winter crop, maize, winter wheat and greenhouse vegetables.

\section{Data portal}

This module allows users to download/visualize various data related to Guantao groundwater management, as shown in Fig. 4.50. Table 4.4 lists the variables included in this module and accessible features. All data are extracted from the database.

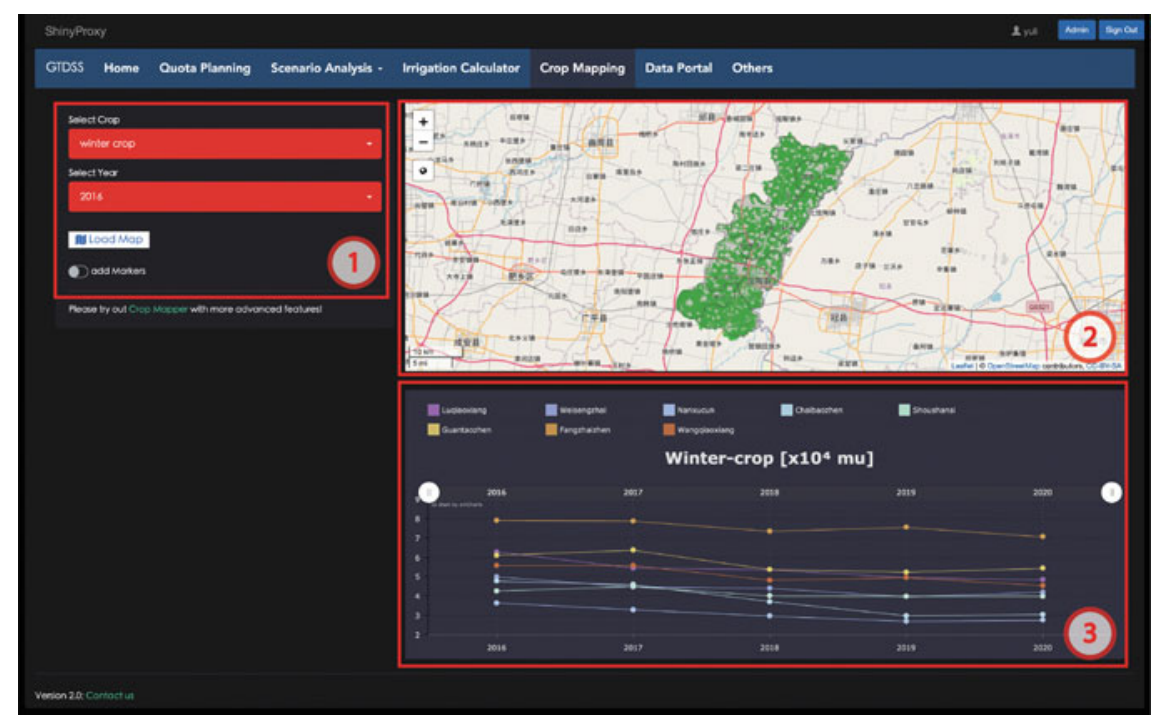

Fig. 4.49 Interface of the CropMapper module. Panel 1 provides input options to query different crop maps for different years. Panel 2 is the output window where the extracted crop map will be rendered on the base layer of Guantao region. Panel 3 displays the time-series of crop areas at township level 


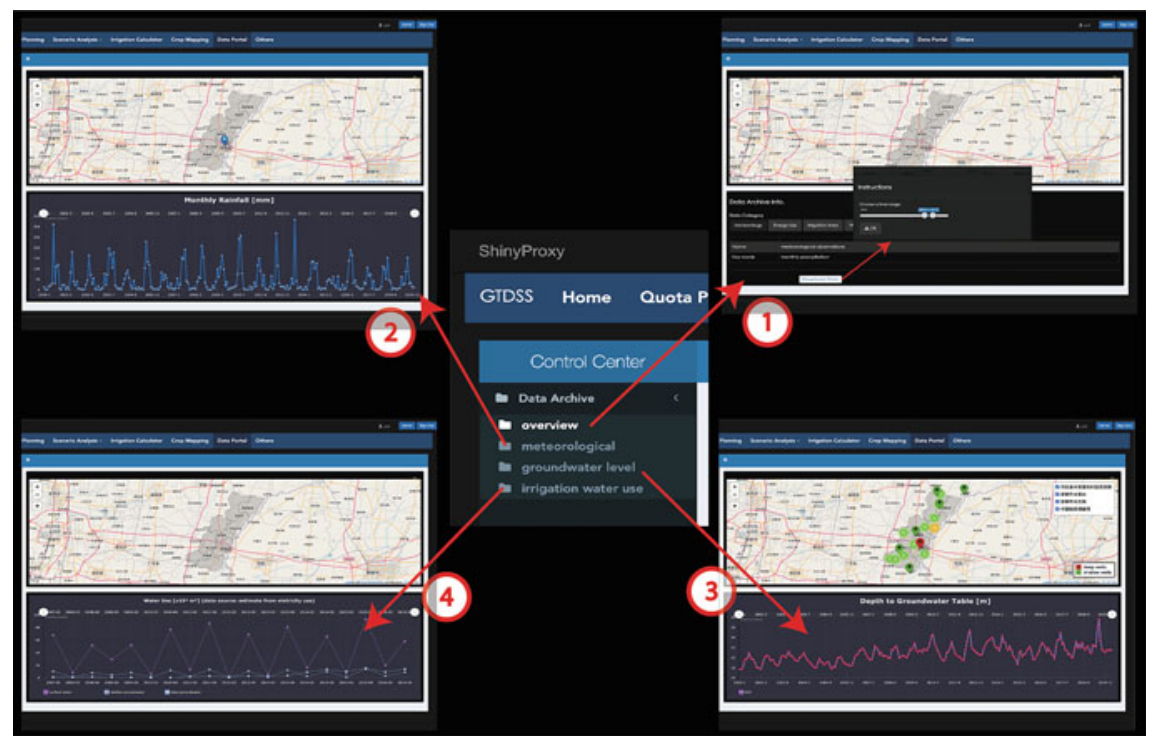

Fig. 4.50 Interface of the data portal module. Panel 1 shows the data inventory and options for downloading data items individually. Panel 2 shows the plot of monthly precipitation time-series. Panel 3 allows users to visualize time-series of depth to groundwater table at different monitoring wells shown on the map. Panel 4 plots water use time-series estimated from electricity consumption.

Table 4.4 List of variables accessible in Data Portal module

\begin{tabular}{l|l|l}
\hline Variable name & $\begin{array}{l}\text { Support for } \\
\text { download }\end{array}$ & $\begin{array}{l}\text { Support for } \\
\text { visualization }\end{array}$ \\
\hline $\begin{array}{l}\text { Monthly } \\
\text { precipitation }\end{array}$ & Yes & Yes \\
\hline $\begin{array}{l}\text { Annual electricity } \\
\text { use }\end{array}$ & Yes & No \\
\hline Annual crop area & Yes & Yes \\
\hline $\begin{array}{l}\text { Monthly irrigation } \\
\text { water use }\end{array}$ & Yes & Yes \\
\hline $\begin{array}{l}\text { Monthly } \\
\text { groundwater } \\
\text { level/depth }\end{array}$ & Yes & Yes \\
\hline
\end{tabular}

\subsubsection{Architecture of the GTDSS}

Figure 4.51 shows the scheme of the Guantao DSS and the data flow between different modules. Specifically, the database holds various types of information ranging from observation data to model parameters used by individual modules. The Irrigation Calculator, the 0-D groundwater model (box model) and the 2-D groundwater 


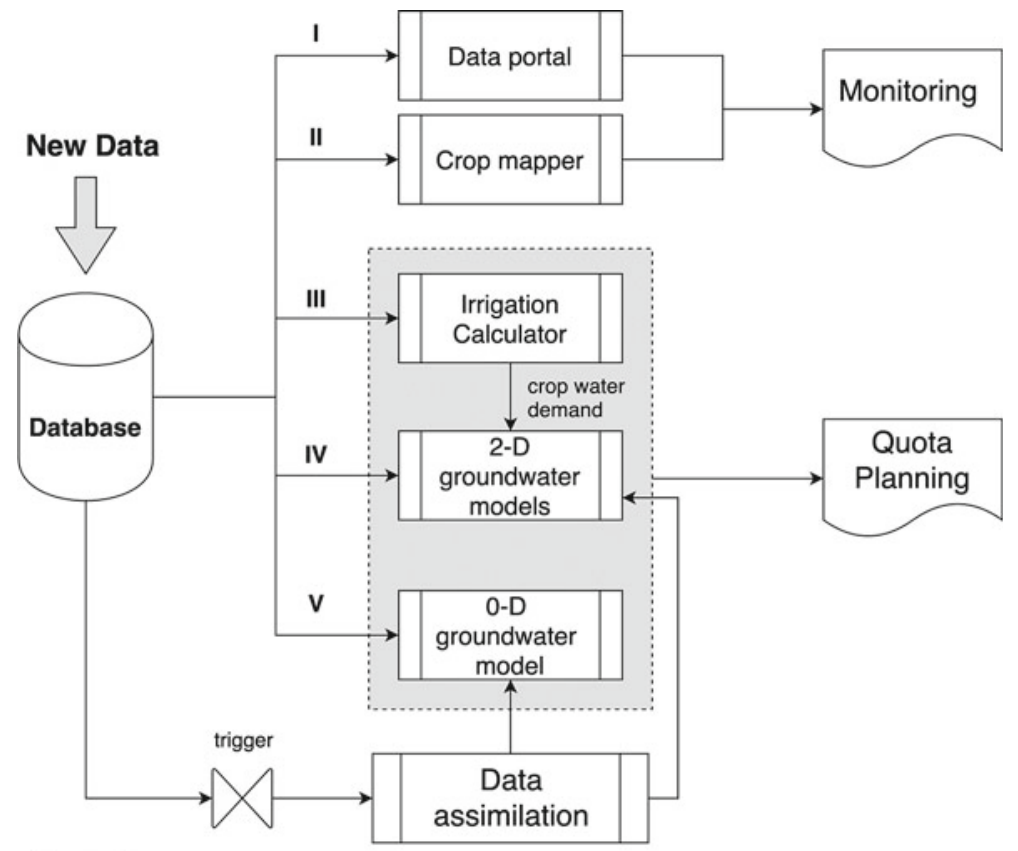

\section{Data-flow}

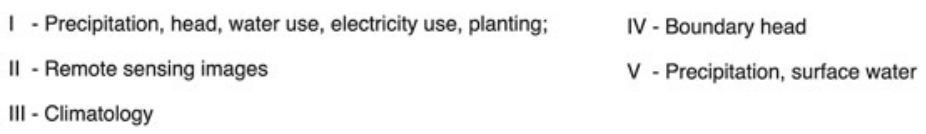

Fig. 4.51 Scheme of the Guantao DSS and data flow between different modules

model are the main modelling components, with which one can run model simulations for given scenarios and assess outcomes (i.e., scenario analysis), or, inversely, specify the desired outcome and explore best strategies to get there (i.e., planning). In addition, the groundwater model parameters and initial conditions of the 2-D groundwater model are updated periodically with the Ensemble Kalman-Filter, which is a modern data assimilation technique to keep a model up to date without manual intervention. The monitoring components consist of the CropMapper module for preparing spatial maps of the main irrigated crops in Guantao, and the data portal module for visualizing essential observation data, such as groundwater heads. 


\section{References}

ADB (2013). Climate Change Adaptation through Groundwater Management of Shanxi Province, People's Republic of China. Asian Development Bank, Loan Project 'Shanxi integrated Agricultural Development Project'. Final Report 0188. PRC ADB Grant Project

Allen RG, Pereira LS, Raes D, Smith M (1998). Crop Evapotranspiration (guidelines for computing crop water requirements). FAO Irrigation and Drainage Paper. http://www.fao.org/3/x0490e/x04 90e00.htm

Basak D, Pal S, Patranabis DC (2007) Support vector regression. Neural Inf Process Lett Rev 11:203-224

Chiang WH, Kinzelbach W (2000) 3D-Groundwater modeling with PMWIN—a simulation system for modeling groundwater flow and pollution. Springer, Berlin Heidelberg New York, p 346p

Hadded R, Nouiri I, Alshihabi O, Maßmann J, Huber M, Laghouane A, Yahiaoui H, Tarhouni J (2013) A decision support system to manage the groundwater of the Zeuss Koutine aquifer using the WEAP-MODFLOW framework. Water Resour Manage 27(7):1981-2000. https://doi.org/10. 1007/s11269-013-0266-7

Harbaugh AW, Banta ER, Hill MC, McDonald MG (2000) MODFLOW-2000, the U. S. Geological Survey modular groundwater model-user guide to modularization concepts and the groundwater flow process, Open-File Rep. 00-92, U.S. Geol. Survey, Reston, Va

Hendricks Franssen HJ, Kinzelbach W (2008) Real-time groundwater flow modeling with the Ensemble Kalman Filter: Joint estimation of states and parameters and the filter inbreeding problem. Water Resour Res 44:W09408. https://doi.org/10.1029/2007WR006505

Hewitt RJ, Macleod CJA (2017) What do users really need? Participatory development of decision support tools for environmental management based on outcomes. Environments 4(4):88. https:// doi.org/10.3390/environments4040088

Kumar S, Godrej AN, Grizzard TJ (2015) A web-based environmental decision support system for legacy models. J Hydroinf 17(6):874-890. https://doi.org/10.2166/hydro.2018.088

Li Y (2020). Towards fast prototyping of cloud-based environmental decision support systems for environmental scientists using R Shiny and Docker. Environ Model Softw 132:0-9https://doi. org/10.1016/j.envsoft.2020.104797

Li N, Kinzelbach W, Li HT, Li WP, Chen F (2019) Decomposition technique for contributions to groundwater heads from inside and outside of an arbitrary boundary: application to Guantao County, North China Plain. Hydrol Earth Syst Sci 23:2823-2840. https://doi.org/10.5194/hess23-2823-2019

Li N, Kinzelbach W, Li HT, Li WP, Chen F (2021) Improving parameter and state estimation of a hydrological model with the ensemble square root filter. Adv Water Resour 147:103813.https:// doi.org/10.1016/j.advwatres.2020.103813

Li Y, Kinzelbach W, Wang H, Ragettli S, Lei ZX, Li WP, Pan H (2021) Management of groundwater overpumping in arid regions: Lessons from Luotuocheng irrigation district, China. (Submitted for publication)

Liu J, Dietz T, Carpenter SR, Alberti M, Folke C, Moran E, Pell AN, Deadman P, Kratz T, Lubchenco J, Ostrom E, Ouyang Z, Provencher W, Redman CL, Schneider SH, Taylor WW (2007) Complexity of coupled human and natural systems. Science 317(5844):1513-1516. https://doi. org/10.1126/science. 1144004

Liu Z (2016) Analysis on the reform of water resources management in Minqin county. Gansu Sci Technol 32:10-13 (in Chinese)

Loucks DP (1995) Developing and implementing decision support systems: a critique and a challenge. J Am Water Resour Assoc 31(4):571-582. https://doi.org/10.1111/j.1752-1688.1995.tb0 3384.x 
Matthies M, Giupponi C, Ostendorf B (2005) Environmental decision support systems: current issues, methods and tools. Environ Model Softw 22(2):123-127. https://doi.org/10.1016/j.env soft.2005.09.005

McDonald S, Mohammed IN, Bolten JD, Pulla S, Meechaiya C, Markert A, Nelson EJ, Srinivasan R, Lakshmi V (2019). Web-based decision support system tools: the Soil and Water Assessment Tool Online visualization and analyses (SWATOnline) and NASA earth observation data downloading and reformatting tool (NASAaccess). Environ Model Softw 120:104499. https://doi.org/10.1016/ j.envsoft.2019.104499

Milly PCD, Betancourt J, Falkenmark M, Hirsch RM, Kundzewicz ZW, Lettenmaier DP, Stouffer RJ (2008) Stationarity is dead: whither water management? Science 319(5863):573-574. https:// doi.org/10.1126/science.1151915

Mir SA, Quadri SMK (2009) Decision support systems: concepts, progress and issues a review. In: Lichtfouse E (ed) Climate change, intercropping, pest control and beneficial microorganisms. Springer, Netherlands, Dordrecht, pp 373-399

Morton MSS (1971) Management decision systems: computer-based support for decision making. Graduate School of Business Administration, Harvard University, Division of Research

Pachauri RK, Allen MR, Barros VR Broome J, Cramer W, Christ R, Church JA, Clarke L, Dahe Q, Dasgupta P, et al. (2014). Climate Change 2014: Synthesis Report. Contribution of Working Groups I, II and III to the Fifth Assessment Report of the Intergovernmental Panel on Climate Change

Quilty J, Adamowski J, Boucher MA (2019) A stochastic data-driven ensemble forecasting framework for water resources: a case study using ensemble members derived from a database of deterministic wavelet-based models. Water Resour Res 55(1):175-202. https://doi.org/10.1029/ 2018WR023205

Ragettli S, Herberz T, Siegfried T (2018) An unsupervised classification algorithm for multitemporal irrigated area mapping in Central Asia. Remote Sens 10(11):1823. https://doi.org/10. 3390/rs 10111823

Sanz D, Calera A, Castano S, Gomez-Alday JJ (2016) Knowledge, participation and transparency in groundwater management. Water Policy 18:111-125. https://doi.org/10.2166/wp.2015.024

Shao H, Yang W, Lindsay J, Liu Y, Yu Z, Oginskyy A (2017) An open source gis-based decision support system for watershed evaluation of best management practices. J Am Water Resour Assoc 53(3):521-531. https://doi.org/10.1111/1752-1688.12521

Swain NR, Latu K, Christensen SD, Jones NL. Nelson EJ, Ame, DP, Williams GP (2015) A review of open source software solutions for developing water resources web applications. Environ Model Softw 67:108-117. https://doi.org/10.1016/j.envsoft.2015.01.014

Walker WE, Lempert RJ, Kwakkel JH (2013) Deep uncertainty. In: Gass SI, Fu MC (eds) Encyclopedia of operations research and management science. Springer, US, pp 395-402

Wang XW, Shao JL, Van Steenbergen F, Zhang QL (2017) Implementing the prepaid smart meter system for irrigated groundwater production in northern china: status and problems. Water 9(6):379. https://doi.org/10.3390/w9060379

Wang L, Kinzelbach W, Yao HX, Steiner J, Wang H (2020) How to meter agricultural pumping at numerous small-scale wells? An indirect monitoring method using electric energy as proxy. Water 12(9):2477. https://doi.org/10.3390/w12092477

Whateley S, Walker JD, Brown C (2015) A web-based screening model for climate risk to water supply systems in the north-eastern United States. Environ Model Softw 73:64-75. https://doi. org/10.1016/j.envsoft.2015.08.001

Yang GY, Gu JF (2008) Handan water resources assessment. Xueyuan Press, Handan (In Chinese) Yang D, Chen J, Zhou Y, Chen X, Chen X, Cao X (2017) Mapping plastic greenhouse with medium spatial resolution satellite data: Development of a new spectral index. J Photogramm. Remote Sens 128:47-60. https://doi.org/10.1016/j.isprsjprs.2017.03.002

Zoha A, Gluhak A, Imran MA, Rajasegarar S (2012) Non-intrusive load monitoring approaches for disaggregated energy sensing: a survey. Sensors 12:16838-16866. https://doi.org/10.3390/ s121216838 
Zulkafli Z, Perez K, Vitolo C, Buytaert W, Karpouzoglou T, Dewulf A, De Bièvre B, Clark J, Hannah DM, Shaheed S (2017) User-driven design of decision support systems for polycentric environmental resources management. Environ Model Softw 88:58-73. https://doi.org/10.1016/ j.envsoft.2016.10.012

Open Access This chapter is licensed under the terms of the Creative Commons Attribution 4.0 International License (http://creativecommons.org/licenses/by/4.0/), which permits use, sharing, adaptation, distribution and reproduction in any medium or format, as long as you give appropriate credit to the original author(s) and the source, provide a link to the Creative Commons license and indicate if changes were made.

The images or other third party material in this chapter are included in the chapter's Creative Commons license, unless indicated otherwise in a credit line to the material. If material is not included in the chapter's Creative Commons license and your intended use is not permitted by statutory regulation or exceeds the permitted use, you will need to obtain permission directly from the copyright holder.

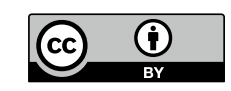

